\title{
Age and growth of Appalachian brook trout in relation to life- history and habitat features
}

Jason Thomas Stolarski

West Virginia University

Follow this and additional works at: https://researchrepository.wvu.edu/etd

\section{Recommended Citation}

Stolarski, Jason Thomas, "Age and growth of Appalachian brook trout in relation to life-history and habitat features" (2007). Graduate Theses, Dissertations, and Problem Reports. 4340.

https://researchrepository.wvu.edu/etd/4340

This Thesis is protected by copyright and/or related rights. It has been brought to you by the The Research Repository @ WVU with permission from the rights-holder(s). You are free to use this Thesis in any way that is permitted by the copyright and related rights legislation that applies to your use. For other uses you must obtain permission from the rights-holder(s) directly, unless additional rights are indicated by a Creative Commons license in the record and/ or on the work itself. This Thesis has been accepted for inclusion in WVU Graduate Theses, Dissertations, and Problem Reports collection by an authorized administrator of The Research Repository @ WVU. For more information, please contact researchrepository@mail.wvu.edu. 
Age and growth of Appalachian brook trout in relation to life-history and habitat features

\title{
Jason Thomas Stolarski
}

\author{
A Thesis \\ Submitted to \\ The Davis College of Agriculture, Forestry, and Consumer Sciences \\ at West Virginia University \\ in partial fulfillment of the requirements \\ for the degree of \\ Master of Science \\ in \\ Wildlife and Fisheries Resources \\ Kyle J. Hartman, Ph.D., chair \\ Michael P. Strager, Ph.D. \\ Stuart A. Welsh, Ph. D. \\ Department of Wildlife and Fisheries
}

Morgantown, West Virginia

2007

Key words: brook trout, age, growth, life-history, geology 


\section{Abstract \\ Age and growth of Appalachian brook trout in relation to life-history and habitat features}

\section{Jason Thomas Stolarski}

Currently, it is perceived that brook trout (Salvelinus fontinalis) are experiencing reductions in both range and abundance across their east coast distribution. Data identifying key habitat features influencing growth rates of these fish will be valuable to managers conducting remediation efforts as growth at age has important consequences to survival and fecundity. Of particular importance within Appalachia may be the influence of surficial geology as the mid Appalachian region receives some of the most acidic rain in the nation. Furthermore, endogenous characteristics such as variation in life-history strategy may also influence growth rates of Appalachian brook trout. However, as the quality of growth rate estimates are directly related to the accuracy and precision of aging techniques we first sought to evaluate various aging methodologies (scale, otolith, and fin ray) to determine the technique optimal for brook trout within Appalachia.

Scale and otolith aging techniques produces age estimates of similar accuracy and precision while estimates garnered from fin ray techniques were of reduced accuracy and precision. Scale techniques tended to underestimate fish age within older (age $>2$ ) cohorts while otoliths provided the most consistent age estimates across cohorts. Due to the rarity of older individuals within natural populations, scale techniques may be used as a non-lethal alternative to otolith techniques without sacrificing accuracy of age estimates.

Investigations regarding the influence of various habitat characteristic including surficial geologic type indicate $\mathrm{pH}$, brook trout density, elevation, and macroinvertebrate density to influence brook trout growth rates within cohorts $0-2$. While geologic type was not found to be significantly influencing brook trout growth, trends in $\mathrm{pH}$ among geologic types and the inclusion of $\mathrm{pH}$ in stepwise models predicting brook trout growth as a function of habitat features suggest that geology may influence growth rates of these fish. Within an area which receives high amounts of acid precipitation such as the midAppalachian region, geologic derived $\mathrm{pH}$ may play an important role in determining the upper limit of growth within headwater lotic environments. Actual growth rates may then be a function of secondary mechanisms such as density and elevation.

Within partially migratory fluvial populations of Appalachian brook trout, fluvial individuals tended to maintain significant length and weight advantages within cohorts 1 and 2 over resident individuals. Among older cohorts (3 and 4) the convergence of length measures may indicate the presence of substantial fishing pressure. Growth and condition advantages exhibited among fluvial individuals are most likely a result of increased energy consumption within downstream positions. However, fluvial maturation schedules may also play a role. 


\section{Acknowledgements}

I would first like to thank Kyle Hartman for giving me the opportunity to conduct this work through which I have grown immensely both as a researcher and an individual. I would also like to thank my committee members: Michael Strager and Stuart Welsh for their advice and help throughout this process. Of course I could not forget the many individuals who helped me in the field including Ken, Garrett, Jon, Ryan, and Jared. Much gratitude needs to be paid to Patrick Palumbo, who was my field technician during the data collection phase of this research. Patrick worked through adverse weather condition and long hours while always maintaining a positive attitude. Funding for this project was provided by MeadWestvaco, the United Stated Department of Agriculture, and the West Virginia Department of Natural Resources. Finally, I would like to thank my parents who first took me fishing. I would have never thought that evenings on the Connecticut River could ever turn into so much or bring me so far. Thank you all. 


\section{Table of Contents}

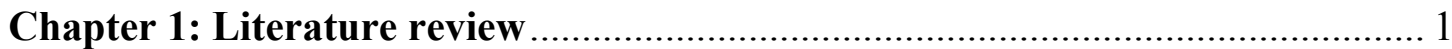

Geology and the ionic content of waters .................................................... 2

Temperature and food...................................................................... 2

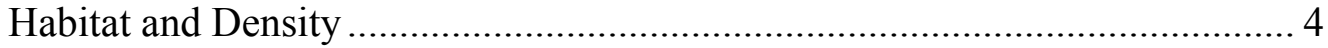

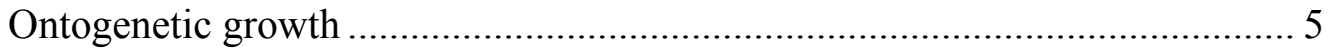

Exotic species interactions .................................................................. 5

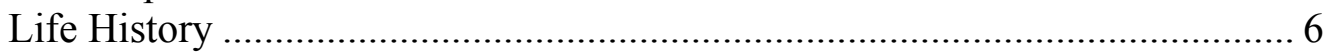

Fish aging and its relevance to growth ............................................... 6

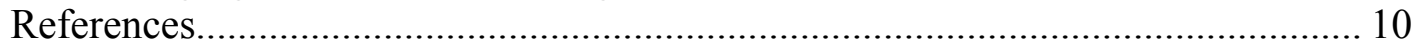

Chapter 2: Age and annulus verification in Appalachian brook trout................. 18

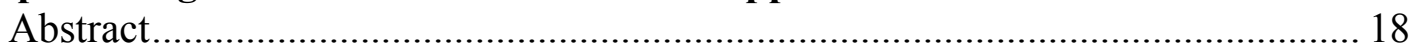

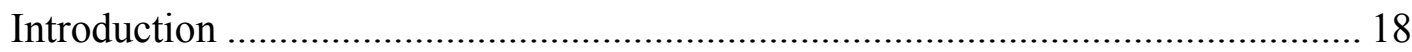

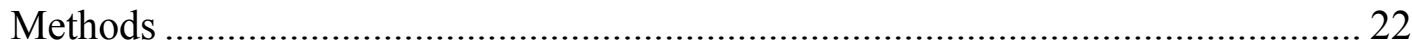

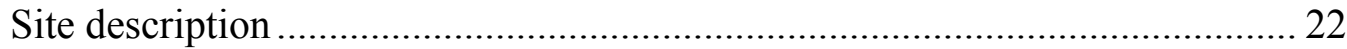

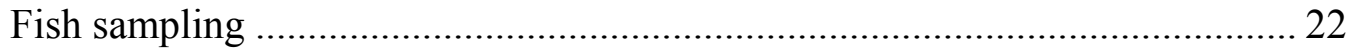

Hard part preparation......................................................................... 23

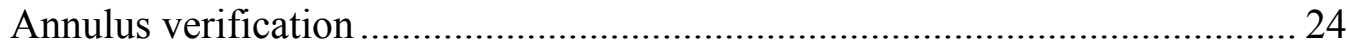

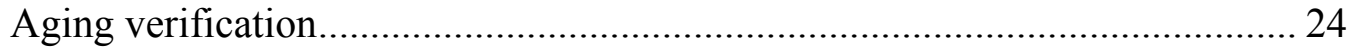

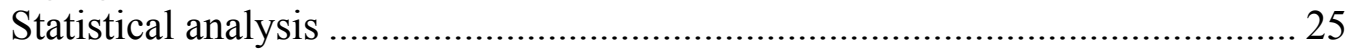

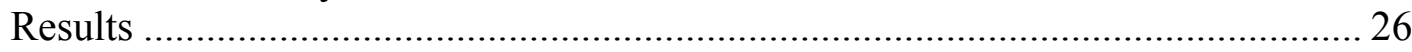

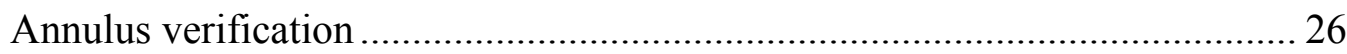

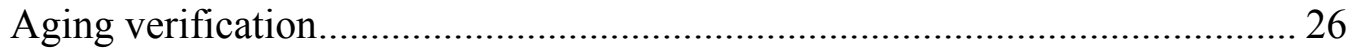

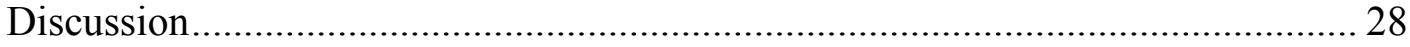

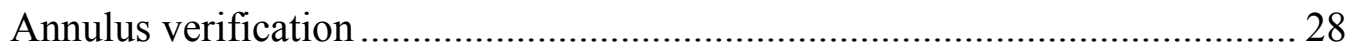

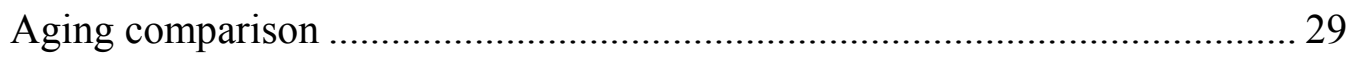

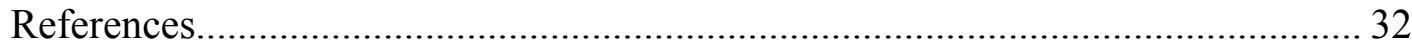

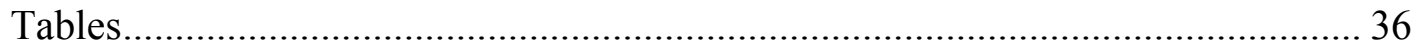

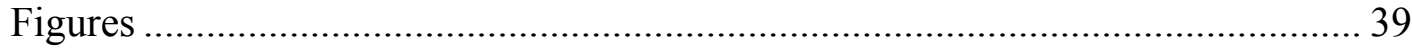

Chapter 3: The influence of geology and habitat features on growth rates of

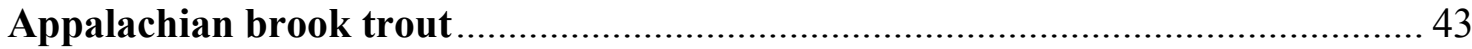

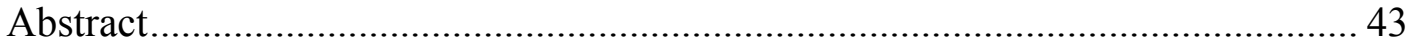

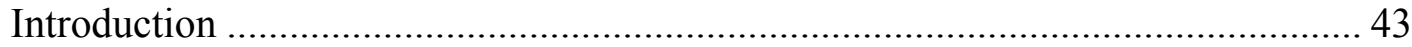

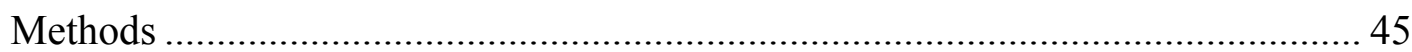

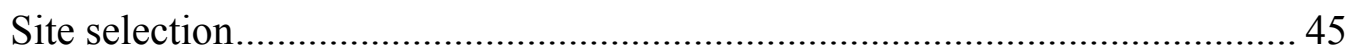

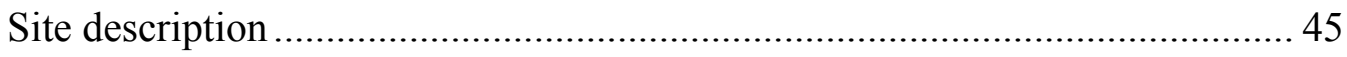

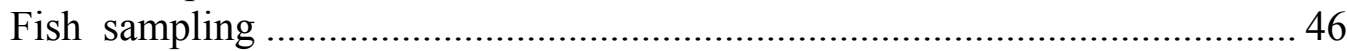

Macroinvertebrate sampling .......................................................... 47

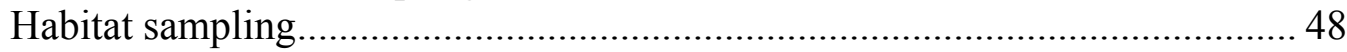

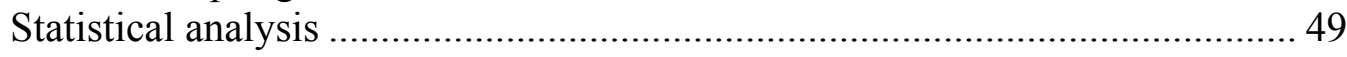

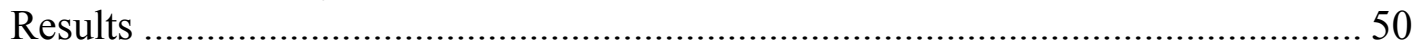

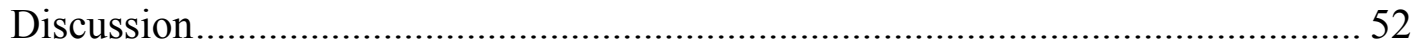

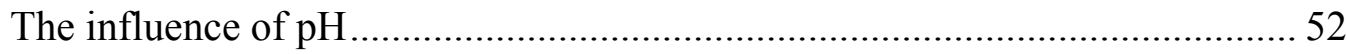




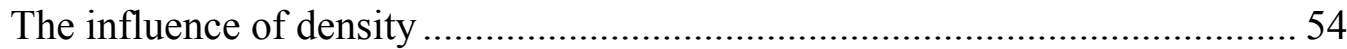

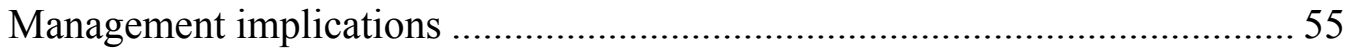

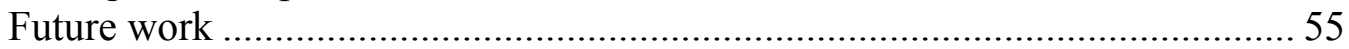

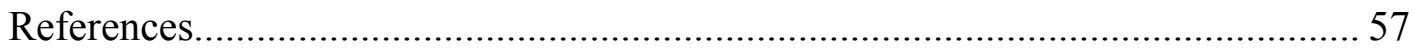

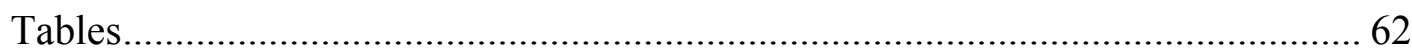

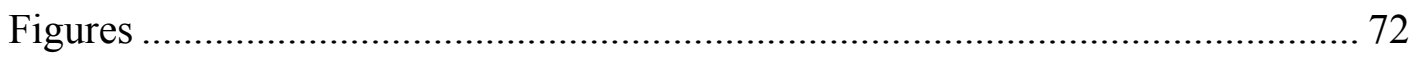

Chapter 4: Growth and condition of fluvial and resident individuals within partially

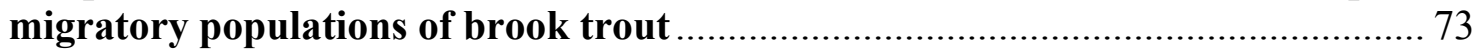

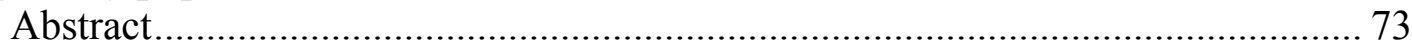

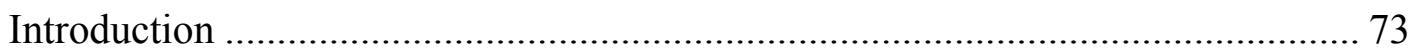

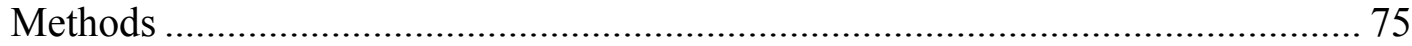

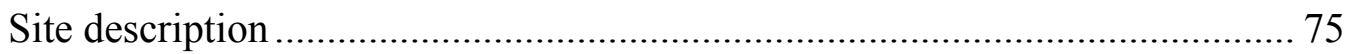

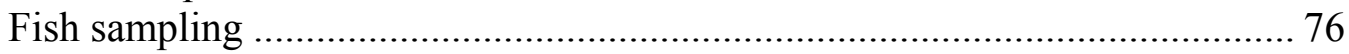

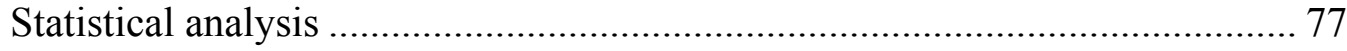

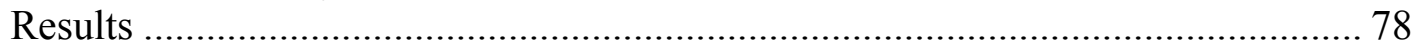

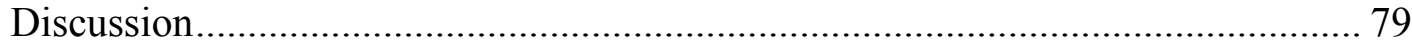

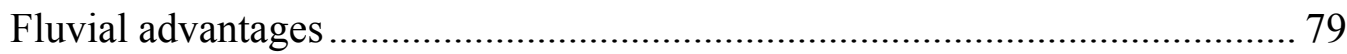

Fishing pressure and other sources of mortality ....................................... 81

Management implications ................................................................... 81

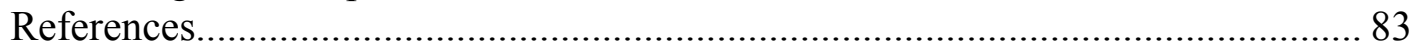

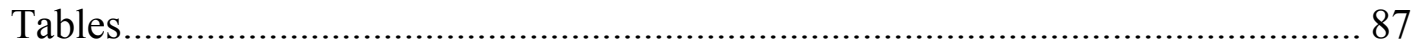

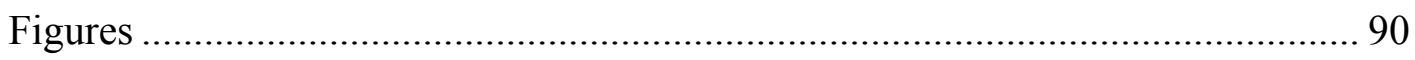

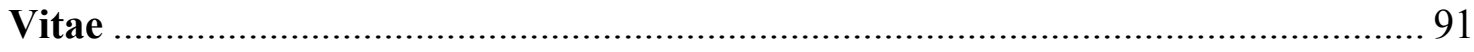




\section{Chapter 1: Literature review}

A stream is inherently linked to the valley it occupies (Hynes 1975, Isaak and Hubert 2001). Core watershed characteristics influence stream hydrology and biology through complex biotic and abiotic interactions operating at multiple scales (Isaak and Hubert 2001). Watershed characteristics such as geology and basin relief have been used to describe patterns in stream habitat (Lanka et al. 1987, Nelson et al. 1992), hydrology (Zecharias and Brutsaert 1988), and water chemistry (Likens and Buso 2006). In the presence of a fishery however, basin characteristics are often used to describe patterns in the production and growth of fish (O’Conner and Power 1976, Clarke and Scruton 1999).

Fish growth, measured in units of length, weight, or energy and defined as a change in size or amount of bodily material, is an important ecological characteristic of fish populations. Elevated growth rate and associated improved condition may increase over-winter survival (Quinn and Peterson 1996), egg quantity and quality (Wooton 1998), and disease resistance (Barton et al. 2002), ultimately influencing abundance. Furthermore, in the presence of a sport fishery, increased growth rate and production, facilitates elevated harvest and the likelihood of larger, more desirable individuals.

Accurate estimation of fish growth rate in natural systems is reliant on the ability to maintain constant time intervals over which growth is evaluated. In lieu of tagging or lab studies where the growth period is known, many growth rate estimates are dependant on fish aging techniques. Hard parts such as scales, otoliths, and fin rays are used to infer age, and growth rate is thus estimated annually (Hubert et al. 1987). Therefore, accurate growth rate estimates are inherently linked to the accuracy of aging techniques.

Appalachian brook trout (Salvelinus fontinalis) typically inhabit headwater, low nutrient, high elevation streams that are inherently unproductive (Boiling et al. 1975). Individuals tend to be small $(<200 \mathrm{~mm})$ and are presumably slow growing. Growth at age within these small lotic systems is often viewed as the culmination of basin wide influences and used as a population descriptor. Compared to similar communities, growth can be used to identify environmental or ecological conditions which influence it (Neves and Pardue 1983, Scarnecchia and Bergersen 1987). This information is of 
particular importance in light of anthropogenic stressors such as logging, the introduction of exotic species, acidic inputs, and over fishing within Appalachia that have resulted in reductions in brook trout abundance and range (Larson and Moore 1985, Marschall and Crowder 1996). Therefore, it is prudent to understand environmental factors that influence growth in these systems to maximize production, mitigate for these natural and anthropogenic stressors, and aid in population recovery.

The content of this literature review will be to provide a synthesis of relevant literature discussing significant endogenous and exogenous factors affecting Appalachian brook trout growth. Furthermore, the importance of fish aging techniques in growth rate estimation will also be discussed.

Geology and the ionic content of waters -- The ionic content of waters generally measured as acid neutralizing capacity or alkalinity influences biotic interactions in lotic environments (Egglishaw 1968, Krueger and Waters 1983). Ionic concentration is a function of basin hydrology and geology (Allen 1995, Likens and Buso 2006). Waters flowing over geologies which weather readily (karst) impart greater amounts of carbonate and bicarbonate species than geologies tolerant to weathering (sandstone) resulting in an elevated ability to resist reductions in $\mathrm{pH}$ (Johnson et al. 1981, Sharpe et al. 1987, Isaac and Hubert 2001). Waters exhibiting higher alkalinity (and thus greater $\mathrm{pH}$ ) have greater rates of decomposition (Egglishaw 1968) and additionally allow autotrophic organisms to uptake nutrients more efficiently at lower concentrations. These processes facilitate increased autotrophic and primary consumer production resulting in increased production (Cooper and Scherer 1967, O’Conner and Power 1976) and growth (Beyerle and Cooper 1960, Oconner and Power 1976) of secondary consumers, i.e. brook trout, within these systems. Alternatively, reduced alkalinity and $\mathrm{pH}$ have been shown to reduce brook trout growth (Mount et al. 1988). Growth reductions are thought to be a result of acid induced metabolic stress (Mount et al. 1988) caused by the mobilization of toxic metals (Driscoll et al. 1980), and reduced invertebrate forage at low pH (Kobuszewski and Perry 1993).

Temperature and food -- Brook trout are ectothermic and metabolic processes are governed by the temperature of the surrounding environment. Increases in temperature 
are accompanied by increases in metabolism and food conversion efficiency resulting in increased growth potential (Elliot 1994, Wooton 1998). However, at temperatures close to thermal maximum, metabolic costs of respiration and the elimination of wastes exceed the metabolic advantages of increased temperature resulting in decreases in growth potential (Wooton 1998, Hartman and Sweka 2001). Peak metabolism and growth potential for brook trout occurs near $20^{\circ} \mathrm{C}$ with incipient lethal temperature occurring between 23 and $24^{\circ} \mathrm{C}$ (Hartman and Cox, in press). In the presence of sufficient forage and in the absence of extended periods of thermal stress (temperature $>20^{\circ} \mathrm{C}$ ) brook trout may be able to grow across the range of temperatures they inhabit (Hartman and Sweka 2001). In the event that stream temperatures do exceed thresholds, salmonids may occupy thermal refuge habitat in attempt to avoid detrimental conditions and increase survival (Nielson et al. 1994, Elliot 2000). Refuge habitat consists of deep pools or spring seeps where temperatures are reduced compared to surrounding environments.

While growth is attainable for brook trout throughout a range of stream temperatures it is only in the presence of forage in sufficient quantity (Elliot 1994, Filbert and Hawkins 1995) and quality (Nakano et al. 1999) that it may occur. Individuals must consume a minimal amount of energy (maintenance ration) in order to fulfill daily metabolic requirements thus achieving zero net growth. Individuals feeding at levels below this for extended periods of time will experience reductions in mass and ultimately death. Growth is achieved when feeding in excess of maintenance ration.

Lotic salmonids have been most frequently cited to obtain energy from aquatic macroinvertebrate communities (Bruce 1979, Allan 1981). However, as early as 1951, research on the Horokiwi Stream in New Zealand indicated that the amount of energy provided by the local aquatic macroinvertebrate community was insufficient to fulfill the energetic requirements of observed standing stocks (Allen 1951). It was hypothesized that energy subsidies were being provided by the ingestion of terrestrial invertebrates (Allan 1951, Edwards and Huryn 1995). Recent research in Japan (Nakano et al. 1999, Kawaguchi et al. 2001), and Appalachia (Utz and Hartman 2007, Sweka and Hartman, in press), has documented the importance of terrestrial invertebrates in brook trout diets and is in support of this hypothesis. Furthermore, the importance of terrestrial invertebrates to salmonid diets may vary throughout the year (Kawaguchi et al. 2003, Utz and Hartman 
2007). Kawaguchi et al. (2003) found terrestrial consumption to be the greatest during summer. Within Appalachia, consumption of terrestrial macroinvertebrates was found to be greater than aquatic macroinvertebrate consumption in every season, but winter (Utz and Hartman 2007). Terrestrial invertebrate energy subsidies may become critical during periods when aquatic macroinvertebrate abundance is limited, such as summer, or within unproductive systems with reduced aquatic macroinvertebrate communities such as in Appalachian soft-water streams.

Habitat and density -- Riparian vegetation, through its influence on allochthonous nutrient and terrestrial invertebrate inputs affects energy sources available for salmonid growth and production within lotic environments (Vannote et al. 1980, Polis et al. 1997, Allan et al. 2003). The amount and type of riparian vegetation has been found to influence terrestrial invertebrate input and in-stream nutrient biomass (Hynes 1975, Edwards and Huryn 1995, Allan et al. 2003). Edwards and Huryn (1995) noted 10 to $30 \%$ reductions in terrestrial inputs in pasture streams compared to native forest and grassland streams. Furthermore, decay rates of in-stream leaf litter vary by tree species, potentially altering aquatic macroinvertebrate communities (Nelson et al. 1969, Petersen and Cummins 1974, Golden 2000). Riparian induced energetic differences may translate to growth and production differences in secondary consumers (Kawaguchi and Nakano 2001).

Growth is further altered by in-stream habitat type. Salmonids require multiple complementary habitats in order to grow, survive, and reproduce. Foraging salmonids in headwater streams will utilize habitat that maximizes net energy gain (Fausch and White 1981, Fausch 1984). Habitat preference is modified however by intraspecific hierarchies which constrain energy consumption of juvenile and subdominant individuals, often relegating them to suboptimal (riffle) habitats (Fausch 1984). Juvenile growth is still achieved in riffle habitats (Huges and Reynolds 1994, Rosenfeld and Boss 2001) due to reduced energetic requirements of body size however it may be a fraction of potential growth that is experienced in optimal habitat (Vøllestad et al. 2002, Lobon-Cervia 2005). Inverse relationships found between salmonid growth and consumption and density may indicate density dependence (Vøllestad et al. 2002, Utz 2005, Utz and Hartman 2006) 
Larger adults tend to occupy more energetically profitable positions in pool habitat due to elevated energy demands associated with body size (Rosenfeld and Boss 2001). In the absence of piscivory (where large adults are able to indirectly benefit from riffle habitat by ingesting juvenile fish) a balance of forage producing riffle and pool habitat is needed to maximize growth across cohorts. Habitat preference and growth may also be modified due to increased intraspecific competition for preferred habitats by abiotic conditions such as turbidity (Sweka and Hartman 2001), cover (Wilzbach and Cummings 1986) and the presence of large woody debris (Harvey 1998). Additionally, pool habitat serves as critical summer foraging and refuge habitat during periods of thermal stress and low flows (Hakala and Hartman 2004).

Ontogenetic growth -- Salmonid growth rates are modified endogenously through the influence of ontogeny (Wooton 1998). Immature individuals experience greater rates of growth due to allocation of energy strictly to growth and survival. Once mature, energy budgets facilitate the production of sperm and eggs diverting energy once used for growth often resulting in growth rate reductions (Wooton 1998, Vøllestad et al. 2002). Depending on juvenile rates of growth, brook trout mature at age-1 or-2 (Jonsson and Jonsson 1993), and have been observed to live up to 4 years of age within Appalachian systems (Whitworth and Strange 1983, Hining et al. 2000).

Exotic species interactions -- Introductions of exotic brown (Salmo trutta) and rainbow trout (Oncorhynchus mykiss) have been hypothesized as a one of the causal mechanisms of native brook trout range reductions (Larson and Moore 1985, Clarke and Rose 1997). Several hypotheses have attempted to describe the means by which this phenomenon occurs including latitudinal differences in water temperatures, year-class failures, lower fecundity of brook trout, and competition (Clarke and Rose 1997). The later hypothesis has received attention in the literature due to the size at age advantage of exotic trout (Whitworth and Strange 1983, Larson and Moore 1985, Fausch 1988). One would expect a niche shift to occur in the presence of a superior competitor. Lohr and West (1992) found that after reducing rainbow trout density, sympatric brook trout shifted from the periphery to deeper main channel positions. Additionally, Moore et al. (1983) found 
increases in brook trout abundance and biomass following the removal of sympatric rainbow trout. Both studies indicate the possibility of exotic trout exhibiting a competitive advantage. In this case, subordinate brook trout will experience reduced growth and survival in the presence of a superior exotic trout species.

Life History -- Fluvial salmonids, by adopting a mobile life history strategy seek to maximize lifetime fitness by moving into larger mainstem systems. These individuals take advantage of seasonally or spatially patchy food resources and reduced competition to maximize their growth potential (Hilderbrand and Kershner 2004). Recent research has documented that brook trout are highly mobile (Gowan et al. 1994, Gowan and Fausch 1995, Petty et al. 2005), however, few studies have investigated growth differences between migratory and resident forms. Mogen and Kaeding (2005) found no differences in the size of migratory and resident bull trout (Salvelinus confluenyus) while Hilderbrand and Kershner (2004) found similar results in the growth rate of migratory and resident cutthroat trout (Oncorhynchus clarki). In Appalachia, Thorne (2004) found only marginal differences in growth between brook trout found in mainstem vs. headwater habitats with mainstem abundance being low. These data indicate potential costs to migration including energetic requirements of migration, increased risk of predation, angling mortality, and temperature extremes, possibly restricting the expression of a migratory life history. Data regarding growth rates of migratory salmonids, especially in Appalachia are limited and highlight the need for further research so to better understand the ecology of migratory individuals.

Fish aging and its relevance to growth -- Accurate estimations of growth depend on accurate measurements of change in body material and the ability to measure this change over a constant time interval. Assuming individuals within a population remain under similar environmental conditions throughout their lifetime, growth then becomes a function of the amount of time that an individual has had to grow. In the absence of laboratory studies where the period over which growth is evaluated is known, field studies often rely on fish aging techniques to maintain a constant time interval. The 
primary need for age determinations is then to provide the means to identify cohorts and distinguish them from others within a population (Carlander 1974).

Salmonids are typically aged using otoliths, scales, and fin rays (Kruse et al. 1997, Williamson and Macdonald 1997). While increments are formed differently by each hard part, they are interpreted similarly, and work under the assumption that periodic increments are formed at constant intervals and are related to growth.

It is generally accepted that the hyalodentine (bony) layer of a scale only grows at its edge presumably at a rate that is proportional to the growth rate of the fish (Simkiss 1974). By this process, mineral rings are formed on the surface of a scale. In temperate climates, growth varies seasonally with increases in the spring and early summer indicated by increased spacing between mineral rings and decreases during late fall and winter marked by decreased ring spacing. Age is inferred by counting zones of similarly spaced rings. However, intraseasonal variations in growth and condition caused by reproduction and periods of food limitation may result in scale reabsorption (Bilton 1974). Scale reabsorption interrupts patterns in ring formation and ultimately creates false annuli (Simkiss 1974). False annuli and ontogenetic reductions in growth over time are the main contributors to inaccuracies in scale based age estimations (Carlander 1974, Devries and Frie 1996). While inconsistent, scale-based techniques are still used in current research due to the ease of sampling, and because they are a non-lethal means of age estimation.

Bone-based hard parts such as otoliths are metabolically inert (Simkiss 1974). Formation of annual increment occurs in isolation of physiological changes which occur throughout the lifetime of a fish (Pannella 1971, Simkiss 1974). In addition, salmonid skeletal tissue lacks osteocyte cells resulting in a skeletal system made up of acellular bone which prevents the reabsorption of calcium back into the body (Pannella 1971). For these reasons, otoliths have gained favor in the literature and are believed to produce age estimations with increased accuracy and precision (Chilton and Bilton 1986, Graynoth 1996, Hining et al. 2000). Age is estimated by counting opaque bands representing spring periods of fast growth and clear sections representing winter periods of slow growth. The causes of annual increment formation are unclear but may be influenced by 
seasonal variation in environmental conditions, specifically water temperature (Pannella 1971, Graynoth 1996).

Otolith removal and preparation techniques are potential drawbacks to their use as aging structures. Otolith removal is a lethal procedure and may not be acceptable in some age and growth studies. Additionally, considerable amounts of time are required to prepare otoliths for viewing (Secor et al. 1992). In order to view annuli, otoliths are usually embedded in epoxy and sectioned with a variable speed precision saw (Secor et al. 1992).

Fin rays offer a non-lethal, bone based method of age estimation. The physiology behind the formation of fin ray annular increments is unclear, however, as with otoliths, reabsorbtion does not occur (Simkiss 1974). Despite this advantage, fin ray techniques are used infrequently (Beamish 1981). Preparation of samples is technical and requires mounting and sectioning (Beamish 1981). Because otoliths are prepared in a similar fashion it may be that if mounting is required researchers would prefer to use the proven structure rather than an un-researched one. Studies aging salmonids using fin rays have produced mixed results. Williamson and Macdonald (1997) found fin ray ages to be more precise than scale ages, Chilton and Bilton (1986) and Hubert et al. (1987) found that fin ray ages generally corroborated scale ages while Graynoth (1996) found fin rays only produced reliable estimates for some juvenile cohorts. Errors in fin ray aging are generally attributed to the poor identification of the first annuli (Beamish 1973).

Aging errors resulting from the above mentioned morphological inconsistencies in various hard parts bias cohort specific growth rate estimates. The introduction of systematic inaccuracies can further modify growth rate estimations of multiple cohorts. Scales have been shown to systematically underestimate older salmonids (Graynoth 1996, Hining et al. 2000). Such bias will inflate growth estimates for younger age classes and can lead to errors in mortality, production, and survival estimates. The former effect is of the most concern in headwater lotic systems where the goal is often to use cohort specific growth rates to identify environmental conditions which influence growth. Errors in aging will reduce the predictive capacity of growth to describe these relationships (Carlander 1974). 
Identification of aging errors and bias has prompted the necessity of validation studies. Validation procedures in natural environments typically take the form of mark recapture studies where individuals of known age (usually age 0) are marked externally and internally, then recaptured in successive years (Beamish and McFarlane 1983). Annual recaptures within a cohort allows an observer to identify and track annulus formation resulting in hard parts of known age. Through comparison with known age hard parts, one then is able to determine the accuracy of age estimations from a given hard part. Validation becomes more important in older individuals or within populations exhibiting slow growth due to the increased probability of false checks and the inhibition of annulus formation (Carlander 1974).

Comprehensive validation studies in natural environments require considerable time to complete, especially if the species of interest is long lived. Validation is further complicated by species which exhibit high mortality (Whitworth and Strange 1983) and migration rates (Petty et al. 2005) such as Appalachian brook trout. To avoid these pitfalls, researchers have marked individuals of multiple cohorts at one time, and upon recapture, examine annulus formation across cohorts (Hining et al. 2000). This approach allows for only two cohorts ( 0 and 1$)$ to be validated. However, annual increment formation can be verified for all cohorts. Verification of annual increment formation in older cohorts combined with aging unvalidated cohorts by multiple methods may act to reduce aging errors (Beamish and McFarlane 1983) and represent the best means available in attempts to validate Appalachian brook trout aging structures.

The objectives of this research are to: (1) Verify annular increment formation in scales, otoliths, and fin rays and investigate the utility of using these hard parts to estimate Appalachian brook trout age; (2) Evaluate the role of several environmental variables on Appalachian brook trout growth and production rates; and (3) Compare growth of resident and migratory individuals. 


\section{Reference List}

Allan, J.D. 1981. Determinants of diet of brook trout (Salvelinus fontinalis) in a mountain stream. Canadian Journal of Fisheries and Aquatic Sciences. 38:184-192.

Allan, J.D. 1995. Stream Ecology: structure and function of running waters. Kluwer Academic Publishers, Dordrecht, The Netherlands.

Allan, J.D., M. S. Wipfli, J. P. Caouette, A. Prussian, and J. Rodgers. 2003. Influence of streamside vegetation on inputs of terrestrial invertebrates to salmonid food webs. Canadian Journal of Fisheries and Aquatic Sciences. 60:309-320.

Allan, R.K. 1951. The Horokiwi stream: a study of a trout population. The New Zealand Marine Department of Fisheries Bulletin. 10:1-231.

Barton, B.A., J. D. Morgan, and M. N. Vijayan. 2002. Physiological and conditionrelated indicators of environmental stress in fish. Pages 111-148 in S.M. Adams, editor. Biological indicators of aquatic ecosystem stress. American Fisheries Society, Bethesda Maryland.

Beamish, R.J. 1973. Determination of age and growth of populations of the white sucker (Catostomus commersoni) exhibiting a wide range in size at maturity. Journal of the Fisheries Research Board of Canada. 30:607-616.

Beamish, R.J. and G. A. McFarlane. 1983. The forgotten requirement for age validation in fisheries biology. Transactions of the American Fisheries Society. 112:735743.

Beamish, R.J. 1981. Use of fin ray sections to age walleye pollok, pacific cod, and albacore, and the importance of this method. Transactions of the American Fisheries Society. 11:287-299.

Bilton, H.T. 1974. Effects of starvation and feeding on circulus formation on scales of young sockeye salmon of four racial origins, and of one race of young kokanee, coho and chinook salmon. The Proceedings of an International Symposium on the Aging of Fish.

Boling, R.H., E. D. Goodman, J. A. Van Sickle, J. O. Zimmer, K. W. Cummings, R. C. Peterson, and S. R. Reice. 1975. Toward a model of detritus processing in a woodland stream. Ecology. 56:141-151.

Bruce, W.J. 1979. Age and growth of brook trout (Salvelinus frontinalis) in the Churchill River Watershed. Canadian Fisheries and Marine Service. Technical Report 907. 907:1-18.

Carlander, K.D. 1974. Difficulties in aging fish in relation to inland fishery management. 
Pages 200-205 in T.B Bagenal, editor. Proceedings of an International Symposium on the Aging of Fish. Unwin Brothers, Surrey, England

Chilton, D.E. and H. T. Bilton. 1986. New method for ageing chinook salmon (Oncorhynchus tshawytscha) using dorsal fin rays, and evidence of its validity. Canadian Journal of Fisheries and Aquatic Sciences. 43:1588-1594.

Clarke, K.D. and D. A. Scruton. 1999. Brook trout production dynamics in the streams of a low fertility Newfoundland watershed. Transactions of the American Fisheries Society. 128:1222-1229.

Clarke, M.E. and K. A. Rose. 1997. Factors affecting competitive dominance of rainbow trout over brook trout in southern Appalachian streams: implications of an individual-based model. Transaction of the American Fisheries Society. 126:1-20.

Cooper, E.L. and R. C. Scherer. 1967. Annual production of brook trout (Salvelinus fontinalis) in fertile and infertile streams of Pennsylvania. Proceedings of the Pennsylvania Academy of Science. 41:65-70.

Devries, D.R. and R. V. Frie. 1996. Determination of age and growth. Pages 483 -508 in B.R. Murphy and D.W. Willis, editors. Fisheries techniques, $2^{\text {nd }}$ edition. American Fisheries Society, Bethesda Maryland.

Driscoll, C.T., J. P. Baker, J. J. Bisogni, and C. L. Schofield. 1980. Effects of aluminum speciation on fish in dilute acidified waters. Nature. 284:161-164.

Edwards, E.D. and A. D. Huryn. 1995. Annual contribution of terrestrial invertebrates to a New Zealand stream. New Zealand Journal of Marine and Freshwater Research. 29:467-477.

Egglishaw, H.J. 1968. The quantitative relationship between bottom fauna and plant detritus in streams of different calcium concentrations. Journal of Applied Ecology. 5:731-740.

Elliot, J.M. 2000. Pools as refugia for brown trout during two summer droughts: trout responses to thermal and oxygen stress. Journal of Fish Biology. 20:10-18.

Elliot, J.M. 1994. Quantitative ecology and the brown trout. Oxford University Press, New York, NY.

Fausch, K.D. and R. J. White. 1981. Competition between brook trout (Salvelinus fontinalis) and brown trout (Salmo trutta) for positions in a Michigan stream. Canadian Journal of Fisheries and Aquatic Sciences. 38:1220-1227.

Fausch, K.D. 1984. Profitable stream positions for salmonids: relating specific growth rate to net energy gain. Canadian Journal of Zoology. 62:441-451. 
Fausch, K.D. 1988. Tests of competition between native and introduced salmonids in streams: what have we learned? Canadian Journal of Fisheries and Aquatic Sciences. 45:2238-2246.

Filbert, R.B. and C. P. Hawkins. 1995. Variation in condition of rainbow trout in relation to food, temperature, and individual length in the Green River, Utah. Transactions of the American Fisheries Society. 124:824-835.

Golden, M.E. 2000. The influences of multiple leaf species and flood disturbance on leaf pack processing in Appalachian mountain headwater streams. Masters Thesis, West Virginia University, Morgantown.

Gowan, C. and K. D. Fausch. 1995. Mobile brook trout in two high elevation Colorado streams: re-evaluating the concept of restricted movement. Canadian Journal of Fisheries and Aquatic Sciences. 53:1370-1381.

Gowan, C., M. K. Young, K. D. Fausch, and S. C. Riley. 1994. Restricted movement in resident stream salmonids: a paradigm lost? Canadian Journal of Fisheries and Aquatic Sciences. 51:2626-2637.

Graynoth, E. 1996. Determination of the age of brown and rainbow trout in a range of New Zealand lakes. Marine \& Freshwater Research. 47:749-756.

Hakala, J.P. and K. J. Hartman. 2004. Drought effect on stream morphology and brook trout (Salvelinus fontinalis) populations in forested headwater streams. Hydrobiologia. 515:202-213.

Hartman, K.J. and K. M. Cox. in press. Refinement and testing of a brook trout bioenergetics model. Transactions of the American Fisheries Society. 00:00000000 .

Hartman, K.J. and J. A. Sweka. 2001. Development of a bioenergetics model for Appalachian brook trout. Proceedings of the Southeastern Association of Fish and Wildlife Agencies. 55:38-51.

Harvey, B. 1998. Influence of large woody debris on retention, immigration, and growth of coastal cutthroat trout (Oncorhynchus clarki clarki) in stream pools. Canadian Journal of Fisheries and Aquatic Sciences. 55:1902-1908.

Hilderbrand, R.H. and J. L. Kershner. 2004. Are there differences in growth and condition between mobile and resident cutthroat trout? Transactions of the American Fisheries Society. 133:1042-1046.

Hining, K.J., J. L. West, M. A. Kulp, and A. D. Neubauer. 2000. Validation of scales and otoliths for estimating age of rainbow trout from southern Appalachian streams. 
North American Journal of Fisheries Management. 20:978-985.

Hubert, W.A., G. T. Baxter, and M. Harrington. 1987. Comparison of age determinations based on scales, otoliths and fin rays for cutthroat trout from Yellowstone Lake. Northwest Science. 61:32-36.

Hughes, N.F. and J. B. Reynolds. 1994. Why do Arctic grayling (Thymallus arcticus) get bigger as you go upstream? Canadian Journal of Fisheries and Aquatic Sciences. 51:2154-2163.

Hynes, H.B.N. 1975. The stream and its valley. Internationale Vereinigung für theoretische und angewandte Limnologie Verhandlungen. 19:1-15.

Isaak, D.J. and W. A. Hubert. 2001. Production of stream habitat gradients by montane watersheds: hypothesis tested based on spatially explicit path analyses. Canadian Journal of Fisheries and Aquatic Sciences. 58:1089-1103.

Johnson, N.M., C. T. Driscoll, J. S. Eaton, G. E. Likens, and W. H. McDowell. 1981. Acid rain, dissolved aluminum and chemical weathering at the Hubbard Brook Experimental Forest, New Hampshire. Geochimica et Cosmochimica Acta. 45:1421-1437.

Jonsson, B. and N. Jonsson. 1993. Partial migration: niche shift versus sexual maturation in fishes. Reviews in Fish Biology and Fisheries. 3:348-365.

Kawaguchi, C., Y. Taniguchi, and S. Nakano. 2003. Terrestrial invertebrate inputs determine the local abundance of stream fishes in a forested stream. Ecology. 84:701-708.

Kawaguchi, Y. and S. Nakano. 2001. Contribution of terrestrial invertebrates to the annual resources budget for salmonids in forest and grassland reaches of a headwater stream. Freshwater Biology. 46:303-316.

Kobuszewski, D.M. and S. A. Perry. 1993. Aquatic insect community structure in an acidic and a circumneutral stream in the Appalachian mountains of West Virginia. Journal of Freshwater Ecology. 8:37-45.

Krueger, C.C. and T. F. Waters. 1983. Annual production of macroinvertebrates in three streams of different water quality. Ecology. 64:840-850.

Kruse, C.G., W. A. Hubert, and F. J. Rahel. 1997. Using otoliths and scales to describe age and growth of Yellowstone cutthroat trout in a high-elevation stream system, Wyoming. Northwest Science. 71:30-38.

Lanka, R.P. and W. A. Hubert. 1987. Relations of geomorphology to stream habitat and trout standing stock in small Rocky Mountain streams. Transactions of the 
American Fisheries Society. 116:21-28.

Larson, G.L. and S. E. Moore. 1985. Encroachment of exotic rainbow trout into stream populations of native brook trout in the southern Appalachian mountains. Transactions of the American Fisheries Society. 114:195-203.

Likens, G.E. and D. C. Buso. 2006. Variation in stream water chemistry throughout the Hubbard Brook Valley. Biogeochemistry. 78: 1-30.

Lobon-Cervia, J. 2005. Spatial and temporal variation in the influence of density dependence on growth of stream-living brown trout (Salmo trutta). Canadian Journal of Fisheries and Aquatic Sciences. 62:1231-1242.

Lohr, S.C. and J. L. West. 1992. Microhabitat selection by brook trout and rainbow trout in a southern Appalachian stream. Transaction of the American Fisheries Society. 121:729-736.

Marschall, E.A. and L. B. Crowder. 1996. Assessing population responses to multiple anthropogenic effects: a case study with brook trout. Ecological Applications. 6:152-167.

Mogen, J.T. and L. R. Kaeding. 2005. Identification and characterization of migratory and nonmigratory bull trout populations in the St. Mary River drainage, Montana. Transactions of the American Fisheries Society. 134:841-852.

Moore, S.E., B. Ridley, and G. L. Larson. 1983. Standing crops of brook trout concurrent with removal of rainbow trout from selected streams in Great Smoky Mountains National Park. North American Journal of Fisheries Management. 3:72-80.

Mount, D.R., C. G. Ingersoll, D. D. Gulley, J. D. Fernandez, T. W. LaPoint, and H. L. Bergman. 1988. Effect of long-term exposure to acid, aluminum, and low calcium on adult brook trout (Salvelinus fontinalis) survival, growth, fecundity, and progeny survival. Canadian Journal of Fisheries and Aquatic Sciences. 45:16231632.

Nakano, S., Y. Kawaguchi, Y. Taniguchi, H. Miyasaka, Y. Shibata, H. Urabe, and N. Kuhara. 1999. Selective foraging on terrestrial invertebrates by rainbow trout in a forested headwater stream in northern Japan. Ecological Research. 14:351-360.

Nelson, D.J., N. R. Kevern, J. L. Wilhm, and N. A. Griffith. 1969. Estimates of periphyton mass and stream bottom area using phosphorus-32. Water Research. 3:367-373.

Nelson, R.L., W. S. Platts, D. P. Larsen, and S. E. Jenson. 1992. Trout distribution and habitat in relation to geology and geomorphology in the North Fork Humboldt River drainage, northeastern Nevada. Transactions of the American Fisheries 
Society. 121:405-426.

Neves, R.J. and G. B. Pardue. 1983. Abundance and production of fishes in a small Appalachian stream. Transactions of the American Fisheries Society. 112:21-26.

Nielson, J.L., T. E. Lisle, and V. Ozarki. 1994. Thermally stratified pools and their use by steelhead in northern California streams. Transactions of the American Fisheries Society. 123:613-626.

O'Connor, J.F. and G. Power. 1975. Production by brook trout (Salvelinus fontinalis) in four streams in the Matamek Watershed, Quebec. Journal of the Fisheries Research Board of Canada. 33:6-18.

Pannella, G. 1971. Fish otoliths: daily growth layers and periodical patterns. Science (New York, NY). 173:1124-1126.

Petersen, R.C. and K. W. Cummins. 1974. Leaf pack processing in a woodland stream. Freshwater biology. 4:343-368.

Petty, T.J., P. J. Lamothe, and P. M. Mazik. 2005. Spatial and Seasonal Dynamics of Brook Trout Populations Inhabiting a Central Appalachian Watershed. Transactions of the American Fisheries Society. 134:572-587.

Polis, G.A., W. B. Anderson, and R. D. Holt. 1997. Toward an integration of landscape and food web ecology: the dynamics of spatially subsidized food webs. Annual Review of Ecological Systems. 28:289-316.

Quinn, T.P. and P. N. Peterson. 1996. The influence of habitat complexity and fish size on over-winter survival and growth of individually marked juvenile coho salmon (Oncorhynchus kisutch) in Big Creek, Washington. Canadian Journal of Fisheries and Aquatic Sciences. 53:1555-1564.

Rosenfeld, J.S. and S. Boss. 2001. Fitness consequences of habitat use for juvenile cutthroat trout: energetic costs and benefits in pools and riffles . Canadian Journal of Fisheries and Aquatic Sciences. 58: 585-593.

Scarnecchia, D.L. and E. P. Bergersen. 1987. Trout production and standing crop in Colorado's small streams, as related to environmental features. North American Journal of Fisheries Management. 7:315-330.

Secor, D.H., J. M. Dean, and E. H. Laban. 1992. Otolith removal and preparation for microstructural examination. Special Publication of the Canadian Journal of Fisheries and Aquatic Sciences. 117:19-57.

Sharpe, W.E., V. G. Leibfried, W. G. Kimmel, and D. R. DeWalle. 1987. The relationship of water quality and fish occurrence to soils and geology in an area of 
high hydrogen and sulfate ion deposition. Water Resources Bulletin. 23:37-46.

Simkiss, K. 1974. Calcium metabolism of fish in relation to aging. Pages 1-12 in T.B. Bagenal, editor. Ageing of fish. The Grensham Press, Old Working, England.

Sweka, J.A. and K. J. Hartman. in press. Contribution of terrestrial invertebrates to yearly brook trout prey consumption and growth. Transactions of the American Fisheries Society. 0:0000-0000.

Sweka, J.A. and K. J. Hartman. 2001. Influence of turbidity on brook trout reactive distance and foraging success. Transactions of the American Fisheries Society. 130:138-146.

Thorne, D. 2004. Spatial and seasonal variation in brook trout diet, growth, and consumption in a complex Appalachian watershed. Masters thesis, West Virginia University, Morgantown.

Utz, R.M. and K. J. Hartman. 2007. Identification of critical prey items to Appalachian brook trout (salvelinus fontinalis) with emphasis on terrestrial organisms. Hydrobiologia. 575:259-270.

Utz, R.M. 2005. Temporal trends in consumption, growth, and successful feeding traits of a central Appalachian brook trout population at the watershed scale. Masters Thesis, West Virginia University, Morgantown.

Utz, R.M. and K. J. Hartman. 2006. Temporal and spatial variation in the energy intake of a brook trout (Salvelinus fontinalis) population in an Appalachian watershed. Canadian Journal of Fisheries and Aquatic Sciences. 63:2675-2686.

Vannote, R.L., W. G. Minshall, K. W. Cummins, J. R. Sedell, and C. E. Cushing. 1980. The river continuum concept. Canadian Journal of Fisheries and Aquatic Sciences. 37:130-137.

Vøllestad, L.A., E. M. Olsen, and T. Forseth. 2002. Growth-rate variation in brown trout in small neighboring streams: evidence of density dependence? Journal of Fish Biology. 61:1513-1527.

Whitworth, W.E. and R. J. Strange. 1983. Growth and production of sympatric brook and rainbow trout in an Appalachian stream. Transactions of the American Fisheries Society. 112:469-475.

Williamson, C.J. and J. S. Macdonald. 1997. The use of three ageing techniques to estimate the growth rates for rainbow trout (Oncorhynchus mykiss) and bull trout (Salvelinus confluentus) from selected locations near Takla Lake, B.C. Canadian Technical Report of Fisheries and Aquatic Sciences.26pp. 
Wilzbach, M.A., K. W. Cummins, and J. D. Hall. 1986. Influence of habitat manipulations on interactions between cutthroat trout and invertebrate drift. Ecology. 67:898-911.

Wooton, R.J. 1998. Ecology of Teleost Fishes. Kluwer Academic Publishers, Dordrecht, The Netherlands.

Zecharias, Y.B. and W. Brutsaert. 1988. The influence of basin morphology on groundwater outflow. Water Resources Research. 24:1645-1650. 
Chapter 2: Age and annulus verification in Appalachian brook trout

\begin{abstract}
Appalachian brook trout (Salvelinus fontinalis) are typically aged using scales despite a lack of research documenting the effectiveness of this technique. Scales are often preferred as they are believed to require less effort to generate age estimations and are non-lethal compared to alternative methods. To evaluate the relative effectiveness of different aging methodologies for brook trout, we measured the accuracy, precision, and processing time of scale, sagittal otolith, and pectoral fin ray techniques. Three independent readers, age bias plots, coefficient of variation $(\mathrm{CV})$, and percent agreement (PA) were used to measure within-structure, among-reader and within-reader, amongstructure precision. Accuracy was estimated from comparisons to consensus age. Consensus age was determined via a combination of annulus formation verification and multiple aging techniques. Annulus formation was verified using oxytetracycline in otoliths for ages zero through three, but not within scales and fin rays. Per sample processing time in minutes for scales (13.88) was similar to that of otoliths (12.23). Fin ray techniques required the longest per sample processing time (22.68). Scale accuracy $(\mathrm{CV}=3.77, \mathrm{PA}=89.30)$ and precision $(\mathrm{CV}=6.59, \mathrm{PA}=82.30)$ were similar to otolith accuracy $(\mathrm{CV}=3.81, \mathrm{PA}=88.89)$ and precision $(\mathrm{CV}=7.45, \mathrm{PA}=81.48)$, while fin rays exhibited the poorest measures of accuracy $(\mathrm{CV}=8.36, \mathrm{PA}=74.49)$ and precision $(\mathrm{CV}=$ 11.30, $\mathrm{PA}=65.84)$. Scales tended to underestimate fish age in older individuals (age $>2)$ while otoliths provided the most consistent ages across cohorts. Scale deficiencies within older cohorts were not reflected in overall estimates of accuracy and precision due to the prevalence of younger (age $<3$ ) cohorts within the sample. Within systems that contain a similar age distribution, scale techniques will provide age estimations rivaling that of otoliths in terms of accuracy and precision. However, if a larger proportion of older (age $>2$ ) individuals exist, spot checks using otoliths is recommended.
\end{abstract}

\title{
Introduction
}

Scale based aging techniques have been the prevailing methodology utilized by fisheries scientists in the estimation of freshwater fish age since the early part of the $20^{\text {th }}$ century 
(Carlander 1987). Scales have gained favor as they are relatively easy to collect and do not require the fish to be sacrificed. While less common until recently, bony structures such as otoliths, fin rays, vertebrae, and opercle bones have also be used in the estimation of fish age (Silkstrom 1983, Devries and Frie 1996, Kruse et al. 1997). With the exception of fin rays, bone based aging procedures are lethal. As this may be unacceptable within the framework of some studies, bone based aging techniques are sometimes restricted or used to supplement a non-lethal aging procedure (Neves and Pardue 1983). Additionally, the extraction and preparation of bony hard parts may be time and resource intensive compared to scales (Secor et al. 1992). Increased effort may be tolerable however, if the ages produced by a given bony structure are of greater precision and accuracy.

Measures of precision examine the reproducibility of ages produced by different readers of the same structure or different structures by the same reader. Understanding trends in precision are important when choosing a hard part to use in age analysis as greater precision may reduce aging errors (Carlander 1974). This is of increased importance within longer studies and larger data sets as age estimates are often produced by multiple readers who may not have similar abilities. Precision has been measured with metrics such as percent agreement, index of percent error (Beamish and Fournier 1981), and most recently, coefficient of variation (Chang 1982, Campana et al. 1995) along with graphical displays such as age-scatter, -difference, and -bias plots. Highly precise age estimations can still be in err however if the ages produced by a given structure do not accurately reflect the true age of the fish.

Accuracy measures agreement of an age produced by a given hard part to the true age of a fish. The accuracy of a given hard part can be measured through comparison to hard parts of known age. This process is called validation. Validation of a given structure is an important, yet often overlooked part of aging studies (Beamish and McFarlane 1983), possibly due to the difficulty in obtaining fish of known age. Acquisition of known age hard parts typically takes the form of a mark-recapture study where fish of known age (usually age 0 ) are marked and recaptured in successive years (Beamish and McFarlane 1983). Within a natural setting these procedures become increasingly difficult, especially if the species of interest exhibits high mortality and 
migration rates. In lieu of known aged fish, verification of annulus formation and aging via multiple methods may permit accuracy to be estimated. Verification of annular increment formation across cohorts demonstrates that increments accrue regularly over time and are available to be counted. Furthermore, aging individuals by multiple methods may act to reduce errors in age estimation (Beamish and McFarlane 1983). Estimates of accuracy do not permit validation, but may provide valuable insight into the ability of a structure to emulate the true age of a fish.

Within Appalachia, brook trout (Salvelinus fontinalis) are the only native salmonid present. While once abundant, populations have declined in size and range as a result of multiple historic and current anthropogenic impacts such as logging, acid mine drainage, acid precipitation, exotic species introductions, and overfishing (Larson and Moore 1985, Marschall and Crowder 1996). As a result, brook trout are currently the subject of a comprehensive conservation and restoration plan; The Eastern Brook Trout Joint Venture (EBTJV 2005). Researchers conducting conservation efforts in conjunction with this effort benefit from accurate and precise estimates of fish age. Fish age, and size at age allow for the computation of cohort specific growth rates and the examination of population age structure and year class abundance. Changes in age structure or growth rate over time are important in the evaluation of conservation efforts and implementation of management strategies. Misinterpretation of annuli will inhibit the accurate understanding of these metrics and may lead to poor management decisions. As accuracy and precision may vary among aging structures (Carlander 1974, Hubert et al. 1987, Devries and Frie 1996) it is important to understand trends before choosing a hard part for age analysis.

Brook trout have historically been aged using scales (Cooper 1951, Alvord 1953, Hatch 1961, Cooper and Scherer 1967) and more recently, otoliths (Hall 1991, Toetz et al. 1991). Fin ray techniques have not been utilized to age brook tout although they have been employed to age cutthroat trout (Oncorhynchus clarki) (Hubert et al. 1987), rainbow trout (Oncorhynchus mykiss), brown trout (Salmo trutta) (Graynoth 1996) and arctic grayling (Thymallus arcticus) (Silkstrom 1983). Of the two predominant aging methods, otoliths are believed to produce superior age estimates (Hubert et al. 1987, Kruse et al. 1997, Hining et al. 2000). Otoliths are metabolically inert with annulus formation related 
more to external environmental conditions rather than the growth rate of the fish (Pannella 1971). Furthermore, reabsorbtion of calcium from otoliths back into the body does not occur (Pannella 1971, Simkiss 1974). Alternatively, scale annulus formation is directly linked to physiological changes that occur throughout a fish's lifetime (Simkiss 1974, Bilton 1975). While this characteristic allows fish age to be estimated from scales it becomes a detriment to the quality of estimates within older individuals (Hining et al. 2000). Ontogenetic reductions in growth may inhibit annuli formation or cause annuli to form closer together, obscuring annular patterns, often resulting in ages that may be erroneous or of questionable accuracy (Carlander 1974, Bilton 1975). The creation of false annuli caused by scale reabsorbtion during periods of food limitation or stress (Simkiss 1974) further complicates scale age estimation (Carlander 1974, Beamish and McFarlane 1983, Graynoth 1996).

Despite flaws, many researchers continue to use scales for age estimation within Appalachia (Neves and Pardue 1983, Whitworth and Strange 1983, Hakala and Hartman 2004). These methodologies however are not completely unfounded. Scale collection and preparation may be less resource intensive than otolith and fin ray techniques because mounting and sectioning are not required. Additionally, it may be unacceptable for fish to be sacrificed for age estimation. Furthermore, Appalachian brook trout populations are typically dominated by one and two year olds with the oldest individuals reported as being 4 years of age (Cooper and Scherer 1967, Whitworth and Strange 1983). As scale deficiencies generally do not appear until later in life (Simkiss 1974, Bilton 1975), scale techniques may be well suited for age analysis within such populations (Hining et al. 2000).

The objectives of this research are to: (1) Verify annular increment formation in scales, otoliths, and fin rays; (2) Evaluate in terms of accuracy and precision the use of scales otoliths and fin rays in estimating Appalachian brook trout age; and (3) Compare the amount of time required to collect, prepare, and estimate age from the three aging structures.

\section{Methods}


Study site description -- Annulus verification research was conducted on brook trout from Stonecoal Run, a second order tributary of the Middlefork River located within the MeadWestvaco Experimental Research Forest, Pocahontas County, West Virginia. Aging verificati on research was conducted on brook trout within Big Run, Back Run, Sawmill Branch, and Vance Run, located within the Monongahela National Forest, Pendleton County, West Virginia. These streams are all 1 st and $2^{\text {nd }}$ order tributaries of the North Fork of the South Branch of the Potomac River. All streams included within the study are inhabited predominantly by brook trout and mottled sculpin (Cottus bairdii) and were chosen due to the presence of naturally reproducing populations of brook trout. The majority of land cover within the watersheds is that of mixed deciduous hardwood forest.

Fish sampling -- To verify annulus formation, a mark recapture study was conducted. In August 2005, brook trout $(\mathrm{N}=285)$ of various sizes were captured using a pulsed DC backpack electrofishing unit and a one pass removal technique. Brook trout were captured from a $500 \mathrm{~m}$ continuous section, spanning from the mouth of the creek to a substantial waterfall. All individuals were immobilized in a $120 \mathrm{mg} / \mathrm{L}$ solution of clove oil and ethanol (Anderson et al. 1997), weighed to the nearest gram using a spring scale, and measured to the nearest $\mathrm{mm}$ total length. Each fish was also marked externally with a caudal fin visible implant elastomer (VIE) mark (Northwest Marine Technology, Shaw Island, WA) and internally with oxytetracycline (OTC) (Hining et al. 2000). OTC (50 $\mathrm{mg} / \mathrm{kg}$ fish) was diluted at a 1:10 ratio with an $8 \%$ saline solution to reduce viscosity (Hining et al. 2000) then injected with a 26 gauge needle. The needle was inserted ventrally midway between the pectoral and anal fins at a shallow angle to reduce damage to internal organs. Once injected, OTC rapidly binds to free calcium and is incorporated into calciferous structures upon deposition cycles (Harris 1960). When viewed under ultra-violet light, OTC fluoresces providing a biomarker. The OTC mark serves as a mark of capture after which annulus formation can be accessed upon recapture and hard part extraction one year later. Once fully processed, individuals were placed in a live well and allowed to recover before being released close to the point of capture. In August of 2006, 18 brook trout of various sizes exhibiting an external caudal mark were recaptured as well as two young of the year. Young of the year were used to examine annulus 
formation within the age 0 cohort. Fish were collected following the previous collection methods and sacrificed in a $500 \mathrm{mg} / \mathrm{L}$ solution of clove oil and ethanol. Individuals were frozen and transported back to West Virginia University laboratories for hard part removal and analysis.

Brook trout were collected for the aging verification study during the spring (March 11-13) of 2006. Young of the year had likely emerged by this time however were too small to be effectively captured and therefore were not included within this study. Individuals were sampled using a pulsed DC backpack electrofishing unit and a one pass removal technique. Fish were processed following previously described methods, but were not marked. Once collected, inclusion into the study was based upon a specific sampling protocol. Such a protocol is warranted in order to minimize the number of individuals which are required to be sacrificed and to enable the sampling of individuals from the range of lengths exhibited within the population. Obtaining a representative sample assures that: (1) All cohorts within the population are represented, and: (2) The variability in length within these cohorts is accounted for. The latter is especially important as growth at age likely influences scale morphology and thus the accuracy and precision of age estimates (Bilton 1975). A representative sample which spans the range of lengths within each cohort will account for any within cohort differences in aging structure accuracy and precision which may exist as a result of size. To do this, as fish were collected, individual length was continuously fed into a length frequency histogram and an effort was made to collect five fish within each $10 \mathrm{~mm}$ size bin. However, due to the scarcity of very large $(>200 \mathrm{~mm})$ and small $(<70 \mathrm{~mm})$ individuals this was often not fulfilled within these size bins. Individuals who fell within a size bin that required additional sampling were sacrificed, frozen, and transported back to West Virginia University laboratories for hard part removal. To minimize impact, no more than 40 individuals were taken from any one stream.

Hard part preparation - In the laboratory, fish were allowed to thaw and scales were removed posterior to the dorsal fin and above the lateral line (DeVries and Frie 1996). Scales (20 to 30 ) from each fish were wet mounted on a glass slide and viewed at $45 \mathrm{X}$ under a microscope. Both sagittal otoliths were removed following the "open the hatch" 
method (Secor et al. 1992), cleaned, dried, and stored in plastic vials. If necessary, otoliths were sanded gently (800 grit), then polished (1200 grit) with sand paper to clarify annuli. Both sagittae were viewed whole under a dissection scope at 12X. Right pectoral fins were removed, dried, and mounted in Epo-fix Embedding Resin ${ }^{\circledR}$. Mounted fin rays were cross-sectioned $(0.5 \mathrm{~mm})$ via an Isomet variable speed precision saw operating at $300 \mathrm{rpm}$ (Beamish and Chilton 1977). Several consecutive fin ray sections were mounted to a glass slide using crystal bond and viewed under a microscope at $45 \mathrm{X}$. Age estimations were garnered from the first or second fin ray of the most easily read crosssection. Total removal and processing time was recorded for all non-OTC marked hard parts.

Annulus verification -- OTC-marked hard parts were removed and prepared following the previously described methodology as non-OTC hard parts, however they were stored in light proof vials to prevent OTC fading. Annuli were identified and counted following DeVries and Frie (1996) under previously noted magnification. Under ultraviolet light, hard parts were investigated for the presence of a fluorescent mark and annulus formation following it.

Aging verification -- In order for accuracy to be measured, a definitive age for each individual is required. This has been done previously using comparison to individuals of known age. Known age hard parts are typically acquired with a mark-recapture study where fish of known age (usually age 0 ) are marked and recaptured in successive years (Beamish and McFarlane 1983). Acquisition of known age hard parts in a natural setting may become increasingly difficult within species exhibiting high mortality and migration rates such as Appalachian brook trout (Whitworth and Strange 1983, Petty et al. 2006). Accuracy may still be estimated however, through a combination of annular increment formation verification and aging by multiple techniques. While not producing individuals of known age, this methodology proves annual increment formation occurs and minimizes the possibility of aging errors. This latter approach to accuracy was used within this study. 
To permit accuracy estimates, a consensus age was determined for each individual in lieu of a true age. Consensus age was estimated for each individual via scales and sagittal otoliths following the previously described methods, as well as by length frequency analysis (Peterson 1892, Isaac 1990) by one experienced reader. When two out of the three estimations agreed it was accepted as the definitive, or consensus age for that fish. If no two ages agreed the sample was removed from the data set. Further age estimates were provided by three independent readers trained in annulus identification. Each reader estimated fish age from scales, otoliths, and fin rays without knowledge of fish length. To maintain independence, samples were randomized before each reading and no reader made multiple readings of the dataset within the same day. Total dataset reading time for each structure was recorded.

Statistical analysis -- Age bias plots (Campana et al. 1995), percent agreement (PA), and coefficient of variation (CV) (Chang 1982) were used to investigate within-reader, among-structure bias and among-reader, within-structure precision. Bias must first be addressed before precision can be measured due to possible systematic over- or underestimation of ages. If one structure consistently produces different ages than another, estimates of precision will be biased and may lead to misinterpretation. To detect bias, age bias plots were created for each within-reader, among-structure comparison. Compared to previous visual methods used to evaluate bias such as scatter and age difference plots, age bias plots are more sensitive to non-linear bias across age classes (Campana et al. 1995). Age bias plots depict the mean age assigned by one reader for all fish assigned a given age by a second reader. For example, if reader A assigns 5 fish as age 1 but reader $\mathrm{B}$ assigns ages 1,2,2,3, and 3 for those individuals then the mean age assigned by reader B is 2.2. The selection of reader for the abscissa is arbitrary. Each age class contains $95 \%$ confidence intervals which enable interpretation of deviance from the 1:1 equivalence line. Either parallel or separated lines of increasing divergence indicate bias between the two age estimations. As errors may be non-linear, visual examination is the most effective method to explore potential bias (Campana et al. 1995). Upon unbiased results, precision was estimated for each structure using $\mathrm{CV}$ as 


$$
C V_{j}=100 \bullet \frac{\sqrt{\sum_{i=1}^{R} \frac{\left(X_{i j}-X_{j}\right)^{2}}{R-1}}}{X_{j}}
$$

Where $X_{i j}$ is the $i^{\text {th }}$ age determination for the $j^{\text {th }}$ fish, $X_{j}$ is the mean age of the $j^{\text {th }}$ fish and $\mathrm{R}$ is the number of times each fish is aged. $\mathrm{CV}$ is averaged across samples for each structure to produce a mean $\mathrm{CV}$.

Accuracy was measured with PA and mean $\mathrm{CV}$ with consensus age.

Relationships were displayed graphically by plotting age estimates pooled by structure with $95 \%$ confidence intervals against consensus age. Due to the prevalence of younger cohorts (age $<3$ ) within natural populations, additional analysis was performed on data pooled into young (age 1 and 2) and old (age 3 and 4) age groups. Age group accuracy was measured with PA and mean $\mathrm{CV}$ with consensus age. Age group precision was measured with PA and mean CV for among-reader, within-structure comparisons.

To investigate the amount of effort required by each structure to generate ages, the total removal, preparation, and reading time in minutes was summed for each structure. Per sample processing time for each structure was computed as the quotient of the total number of samples within the data set and total processing time. Multiple readings of each structure facilitated testing for differences in mean reading time. Differences were investigated using analysis of variance (ANOVA) with a post hoc Tukey test completed in SAS ${ }^{\circledR}$ version 8.3 statistical software package (SAS Institute 1999) at an alpha of 0.05 .

\section{Results}

Annulus verification - OTC marks were visible and annulus formation was confirmed in otoliths for all $(\mathrm{N}=18)$ recaptured individuals spanning ages zero through three (Table 1) (Figure 1). However, OTC marks were unable to be identified on scales and fin rays, thus annulus formation could not be directly verified for these structures. Young of the year $(\mathrm{N}=2)$ exhibited annulus formation on scales, otoliths and fin rays. Unfortunately, no recaptured fish was older than age 3 , thus annulus formation within all structures was not verified beyond this cohort. 
Aging verification -- A total of 83 fish were collected and sacrificed from the four sample streams. Two samples were removed from analysis, one during consensus age determination due to hard part inconsistencies and the other following the three independent readings. The later individual possessed hard parts of unique shape and large size, resulting in readings which were not independent. A final total of 81 individuals ranging from 61 to $239 \mathrm{~mm}$ and encompassing ages one through four were included in analysis (Figure 2).

Mean PA and mean CV with consensus age showed accuracy to be highest for scales and otoliths and lowest for fin rays (Table 2). Pooled analysis by age group revealed greater mean PA and lower mean $\mathrm{CV}$ with consensus age across structures within the young age group. When viewed graphically, scales and fin rays tended to underestimate consensus age within older individuals (age $>2$ ) (Figure 3). Scale underaging occurred in cohorts greater than two years of age and fin rays within the age 4 cohort. Otoliths showed minimal disagreement with consensus age and provided the most consistent estimations among cohorts (Figure 3).

Age bias plots of within-reader, among-structure comparisons show minimal bias (Figure 4). That is, equivalence and empirical lines did not exhibit extensive paralleled or increasing divergence. Fin rays tended to underestimate ages assigned by otoliths and scales for the oldest (age 4) cohort and overestimate within the youngest cohort (age 1). Scales also tended to underestimate ages assigned by otoliths, but for fish greater than two years of age. While age bias plots identify inconsistencies, none persist in more than two consecutive cohorts or represent a difference greater than one year and can effectively be ignored for precision estimates. Otolith/scale comparisons ( $\mathrm{PA}=81.48$, $\mathrm{CV}=6.77)$ exhibited the best mean estimates of precision with scale/fin ray $(\mathrm{PA}=69.96$, $\mathrm{CV}=10.81)$ and otolith/fin ray $(\mathrm{PA}=67.90, \mathrm{CV}=10.98)$ comparisons being similar.

Among-reader within-structure measures of precision indicate that scale based estimations were only slightly more precise than otolith estimations as evidenced by mean PA and mean CV (Table 2). Fin rays exhibited the poorest precision (Table 2). Analysis of data pooled by age group again revealed increased precision among all structures within the young age group. 
Removal and preparation time varied substantially with structure (Table 3). Results of ANOVA indicate no significant difference between structure reading times (F $=4.86, \mathrm{p}=0.057)$. However, a post hoc Tukey test indicated that fin ray reading time was significantly greater than scale reading time $(\mathrm{p}<0.05)$.

\section{Discussion}

Annular increment formation in Appalachian brook trout was confirmed in otoliths for ages zero to three. Similar work by Hining et al. (2000) has verified annulus formation for Appalachian rainbow trout populations within cohorts one through four. Additionally, Hall (1990) verified otolith annulus formation of brook trout occupying high altitude alpine lakes between the ages of five and ten. Within this research, Greater otolith accuracy and precision compared to that of scales and fin rays, especially within older cohorts (age $>2$ ) reflects this consistency. Otolith annuli once created are not reabsorbed and formation is believed to be related to environmental factors rather than a result of internal rhythms (Pannella 1971). Therefore, unlike scales, and possibly fin rays, alterations in growth rate and condition do not restrict annulus formation (Simkiss 1974) and is likely the reason why otoliths are believed to produce superior age estimates (Hubert et al. 1987, Kruse et al. 1997, Hining et al. 2000).

Unfortunately, it is still unknown as to whether Appalachian brook trout within this study form scale and fin ray annular marks at regular intervals as OTC marks were not identified within these structures. However, trends in the accuracy and precision of scales and fin rays may offer insight into the consistency of annulus formation within each structure. Within younger (age $<3$ ) cohorts, scale techniques produced estimates rivaling that of otoliths (verified structure) in terms of accuracy and precision possibly indicating consistent scale annulus formation within these cohorts. Hining et al. (2000) found similar trends in scale and otolith techniques within Appalachian populations of rainbow trout. Trends were attributed to the finding that $76 \%$ of age 1 individuals formed a second annulus within 12-15 months of initial capture while only $32 \%$ of age 2 fish formed a third. This resulted in the underestimation of fish age and reduced the accuracy and precision of scale based age estimates within older (age $>2$ ) cohorts. While it is uncertain as to the cause of scale underestimation within this research, failure to form 
identifiable annuli at advanced age is likely involved. This research contributes to a growing body of literature which suggests that scales tend to underestimate fish age within older cohorts (Silkstrom 1983, Hubet et al. 1987, Graynoth 1996, Hining et al.2000).

Decreased accuracy and precision of fin ray age estimates in comparison with otolith and scale ages suggests that annulus formation within fin rays is less consistent. Factors influencing fin ray annular formation are relatively unknown, but as with otoliths it is believed that annuli are not able to be reabsorbed (Simkiss 1974). For this reason, fin ray techniques have the potential to produce more reliable estimates than scales and offer a non-lethal alternative to otolith techniques. Salmonid fin rays have been shown to produce estimates similar to that of otoliths (Silkstrom 1983, Williamson and Macdonald 1997), and scales (Chilton and Bilton 1986), but they may also produce estimates poorer than scales (Hubert et al. 1987). Errors in fin ray aging have been attributed to the difficulty in identifying the first annuli (Beamish 1981). Some under-aging occurred within the age 4 cohort, but overall increased errors (both over-and under-estimations) among all cohorts suggests that consistent misidentification of the first annuli did not occur in brook trout fin rays. Decreased accuracy and precision among all cohorts in comparison to scales and otoliths may be a result of faulty preparation, or reflect the true incapacity of fin rays to estimate Appalachian brook trout age. As this may be the first investigation of the use of fin rays to age Appalachian brook trout further research may be warranted to refine fin ray aging techniques.

Despite cohort specific trends in scale estimations, overall accuracy and precision of scale and otolith techniques remained similar. This result is contrary to many salmonid aging studies (Silkstrom 1983, Graynoth 1996, Williamson and Macdonald 1997, Hining et al.2000) and is likely an artifact of greater proportions of younger cohorts within natural Appalachian brook trout populations (Cooper and Scherer 1967, Whitworth and Strange 1983) and individual growth characteristics. Younger individuals have fewer annuli to identify and count, therefore reducing the chances that an error might occur. Furthermore, the accentuation of brook trout growth stanzas may promote coherent annuli interpretation. Appalachian brook trout experience substantial growth within a short time period during the spring and experience very little throughout the rest 
of the year (Utz 2005). Scale morphology reflects this growth with areas of increased ring spacing. False check formation is most likely to occur outside this spring growth period during more energetically stressful summer or winter months (Bilton 1975, Utz and Hartman 2006). Because growth is minimal throughout these times of the year, checks which may form blend in with areas of decreased growth resulting in discrete fast and slow growth/check periods. Increased growth rates throughout the summer, winter, or fall in other, more productive systems may distinguish checks and contribute to aging errors through interpretation of false annuli (Carlander 1974). Within older age classes however, ontogenetic shifts in growth rate may overpower this phenomenon resulting in less discernable annuli.

In our samples, scale techniques did not benefit from decreased processing time in relation to otoliths due to small scale size and the prominence of regenerated scales. Upwards of $80 \%$ regenerated scales were common within samples and required that 20 30 scales were mounted, increasing processing time. Furthermore, otolith annuli were clearly discernable without mounting and sectioning, dramatically reducing processing time. Significantly shorter fin ray reading times is likely a result of the sectioning process. However, overall greater fin ray per sample processing time further reduces their utility within Appalachian systems.

As accuracy is not dealt with in many aging studies it is important to discuss possible drawbacks to techniques used within this research. In light of long-term markrecapture study difficulties within species exhibiting high rates of migration and mortality such as Appalachian brook trout (Whitworth and Strange 1983, Petty et al. 2006), verification of annulus formation and aging via multiple techniques may provide the best technique to estimate accuracy. Annulus formation verification demonstrates cohort specific annular increment formation and aging via multiple methods may reduce errors in consensus age (Beamish and McFarlane 1983). Despite these efforts, errors in consensus age may still exist. Additionally, structure specific trends in accuracy among cohorts may reflect consensus age methodology as well as accuracy. Consensus age was determined from scale, otolith and length frequency analysis. When scale or otolith ages are plotted against consensus age, both axis potentially contain ages generated from scales or otoliths and are thus no longer independent of one-another. For example, 
decreased scale and increased otolith accuracy at advanced age may be a result of consensus age being primarily determined by otolith and length frequency techniques for these individuals. However, precision measures reinforce accuracy estimates and follow previously recorded patterns in salmonid aging research. For these reasons we believe that accuracy methodology used here is sound.

In conclusion, research presented here verifies that brook trout consistently lay down annular marks in otoliths. Our research also suggests that within Appalachian systems scale aging techniques are an acceptable non-lethal aging alternative to otoliths while fin rays are of decreased utility. Scale techniques did tend to underestimate fish age within older (age $>2$ ) cohorts. However, due to low proportions of these cohorts within natural Appalachian populations these trends were not apparent within overall accuracy and precision estimates. Within populations containing greater proportions of older cohorts, spot checks using otoliths is recommended. 


\section{Reference List}

Alvord, W. 1953. Validity of age determinations from scales of brown trout, rainbow trout, and brook trout. Transactions of the American Fisheries Society. 83:91-103.

Anderson, G.W., S. R. Mckinley, and M. Colavecchia. 1997. The use of clove oil as an anesthetic for rainbow trout and its effects on swimming performance. Transactions of the American Fisheries Society. 17:301-307.

Beamish, R.J. and D. Chilton. 1977. Age determination of lingcod (Ophidon elongatus) using dorsal fin rays and scales. Journal of the Fisheries Research Board Canada. 34:1305-1313.

Beamish, R.J. 1981. Use of fin ray sections to age walleye pollok, pacific cod, and albacore, and the importance of this method. Transactions of the American Fisheries Society. 11:287-299.

Beamish, R.J. and D. A. Fournier. 1981. A method for comparing the precision of a set of age determinations. Canadian Journal of Fisheries and Aquatic Sciences. 38:982983.

Beamish, R.J. and G. A. McFarlane. 1983. The forgotten requirement for age validation in fisheries biology. Transactions of the American Fisheries Society. 112:735743.

Bilton, H.T. 1975. Factors influencing the formation of scale characters. International North Pacific Fisheries Commission Bulletin. 32:102-108.

Campana, S.E, M. Christina Annand, and J. McMillan. 1995. Graphical and statistical methods for determining the consistency of age determinations. Transactions of the American Fisheries Society. 124:131-138.

Carlander, K.D. 1987. A history of scale age and growth studies of North American freshwater fish. Pages 3-14 in R.C. Summerfelt and G.E. Hall, editors. Age and Growth of fish. Iowa State University Press, Ames.

Carlander, K.D. 1974. Difficulties in aging fish in relation to inland fishery management. Pages 200-205 in T.B Bagenal, editor. Proceedings of an International Symposium on the Aging of Fish. Unwin Brothers, Surrey, England.

Chang, W.Y.B. 1982. A statistical method for evaluating the reproducibility of age determination. Canadian Journal of Fisheries and Aquatic Sciences. 39:12081210 .

Chilton, D.E. and H. T. Bilton. 1986. New method for aging chinook salmon (Oncorhynchus tshawytscha) using dorsal fin rays, and evidence of its validity. 
Canadian Journal of Fisheries and Aquatic Sciences. 43:1588-1594.

Cooper, E.L. 1951. Validation of the use of scales of brook trout, (Salvelinus fontinalis), for age determination. Copeia. 2:141-148.

Cooper, E.L. and R. C. Scherer. 1967. Annual production of brook trout (Salvelinus fontinalis) in fertile and infertile streams of Pennsylvania. Proceedings of the Pennsylvania Academy of Science. 41:65-70.

Devries, D.R. and R. V. Frie. 1996. Determination of age and growth. Pages 483 -508 in B.R. Murphy and D.W. Willis, editors. Fisheries techniques, $2^{\text {nd }}$ edition. American Fisheries Society, Bethesda Maryland.

Eastern Brook Trout Joint Venture. 2005. Available: http://www.easternbrooktrout.org. (September 2007).

Graynoth, E. 1996. Determination of the age of brown and rainbow trout in a range of New Zealand lakes. Marine \& Freshwater Research. 47:749-756.

Hakala, J.P. and K. J. Hartman. 2004. Drought effect on stream morphology and brook trout (Salvelinus fontinalis) populations in forested headwater streams. Hydrobiologia. 515:202-213.

Hall, D.L. 1991. Age validation and aging methods for stunted brook trout. Transactions of the American Fisheries Society. 120:644-649.

Harris, W.H. 1960. A microscopic method of determining rates of bone growth. Nature. 188:1037-1038.

Hatch, R.W. 1961. Regular occurrence of false annuli in four brook trout populations. Transactions of the American Fisheries Society. 90:6-12.

Hining, K.J., J. L. West, M. A. Kulp, and A. D. Neubauer. 2000. Validation of scales and otoliths for estimating age of rainbow trout from southern Appalachian streams. North American Journal of Fisheries Management. 20:978-985.

Hubert, W.A., G. T. Baxter, and M. Harrington. 1987. Comparison of age determinations based on scales, otoliths and fin rays for cutthroat trout from Yellowstone Lake. Northwest Science. 61:32-36.

Issac, V.J. 1990. The accuracy of some length-based methods for fish population studies. International Center for Living Aquatic Resources Management Technical Report 27, Manila, Philippines.

Kruse, C.G., W. A. Hubert, and F. J. Rahel. 1997. Using otoliths and scales to describe age and growth of Yellowstone cutthroat trout in a high-elevation stream system, 
Wyoming. Northwest Science. 71:30-38.

Larson, G.L. and S. E. Moore. 1985. Encroachment of exotic rainbow trout into stream populations of native brook trout in the southern Appalachian mountains. Transactions of the American Fisheries Society. 114:195-203.

Marschall, E.A. and L. B. Crowder. 1996. Assessing population responses to multiple anthropogenic effects: a case study with brook trout. Ecological Applications. 6:152-167.

Neves, R.J. and G. B. Pardue. 1983. Abundance and production of fishes in a small Appalachian stream. Transactions of the American Fisheries Society. 112:21-26.

Pannella, G. 1971. Fish otoliths: daily growth layers and periodical patterns. Science (New York, NY). 173:1124-1126.

Peterson, C.G.J. 1892. Fiskenes biologiske forhold i Holbaek Fjord, 1890-91. Beretning fra de Danske Biologiske Station for 1890(91). 1:121-183.

Petty, T.J., P. J. Lamothe, and P. M. Mazik. 2005. Spatial and Seasonal Dynamics of Brook Trout Populations Inhabiting a Central Appalachian Watershed. Transactions of the American Fisheries Society. 134:572-587.

Sas Institute. 2003. SAS 9.1 (computer software). SAS Institute Inc., Cary, North Carolina.

Secor, D.H., J. M. Dean, and E. H. Laban. 1992. Otolith removal and preparation for microstructural examination. Special Publication of the Canadian Journal of Fisheries and Aquatic Sciences. 117:19-57.

Silkstrom, C.B. 1983. Otolith, pectoral fin ray, and scale age determinations for arctic grayling. Progressive Fish Culture. 45:220-223.

Simkiss, K. 1974. Calcium metabolism of fish in relation to aging. Pages 1-12 in T.B. Bagenal, editor. Ageing of fish. The Grensham Press, Old Working, England.

Toetz, D., M. Muoneke, and J. Windell. 1991. Age, growth and condition of brook trout (Salvelinus fontinalis) from an unexploited alpine lake. Northwest Science. 65:8992.

Utz, R.M. 2005. Temporal trends in consumption, growth, and successful feeding traits of a central Appalachian brook trout population at the watershed scale. Masters Thesis, West Virginia University, Morgantown.

Utz, R.M. and K. J. Hartman. 2006. Temporal and spatial variation in the energy intake of a brook trout (Salvelinus fontinalis) population in an Appalachian watershed. 
Canadian Journal of Fisheries and Aquatic Sciences. 63:2675-2686.

Whitworth, W.E. and R. J. Strange. 1983. Growth and production of sympatric brook and rainbow trout in an Appalachian stream. Transactions of the American Fisheries Society. 112:469-475.

Williamson, C.J. and J. S. Macdonald. 1997. The use of three ageing techniques to estimate the growth rates for rainbow trout (Oncorhynchus mykiss) and bull trout (Salvelinus confluentus) from selected locations near Takla Lake, B.C. Canadian Technical Report of Fisheries and Aquatic Sciences. 26pp. 
Table 1: Length, weight and age of brook trout recaptured from Stonecoal Run. With the exception of age 0 fish, all individuals exhibited an otolith OTC mark and annulus formation following it.

\begin{tabular}{lcc}
\hline Length $(\mathrm{mm})$ & Weight $(\mathrm{g})$ & Age (years) \\
\hline \hline 121 & 17 & 1 \\
123 & 16 & 1 \\
149 & 35 & 2 \\
136 & 28 & 1 \\
105 & 10 & 1 \\
201 & 78 & 3 \\
187 & 52 & 3 \\
163 & 35 & 2 \\
159 & 38 & 2 \\
211 & 90 & 3 \\
110 & 13 & 1 \\
115 & 15 & 1 \\
120 & 16 & 2 \\
233 & 125 & 3 \\
210 & 78 & 3 \\
174 & 54 & 2 \\
134 & 20 & 2 \\
73 & 5 & 0 \\
69 & 5 & 0 \\
196 & 63 & 3 \\
\hline
\end{tabular}


Table 2: Accuracy and precision of scales, otoliths, and fin rays. Accuracy is measured as mean PA and CV with consensus age and precision as mean PA and CV of amongreader, within-structure comparisons. Both are computed across all samples and within young (age $<3$ ) and old age groups (age $>2$ ).

\begin{tabular}{|c|c|c|c|c|}
\hline Accuracy/Precision & Metric & Scale & Otolith & Fin ray \\
\hline \multirow[t]{6}{*}{ Accuracy } & Overall PA & 89.30 & 88.89 & 74.49 \\
\hline & Young & 92.98 & 90.64 & 77.78 \\
\hline & Old & 80.56 & 84.72 & 66.67 \\
\hline & Overall CV & 3.77 & 3.81 & 8.36 \\
\hline & Young & 2.87 & 3.75 & 8.49 \\
\hline & Old & 6.16 & 4.13 & 8.00 \\
\hline \multirow[t]{6}{*}{ Precision } & Overall PA & 82.30 & 81.48 & 65.84 \\
\hline & Young & 84.57 & 82.76 & 70.73 \\
\hline & Old & 76.39 & 81.75 & 54.62 \\
\hline & Overall CV & 6.59 & 7.45 & 11.30 \\
\hline & Young & 6.21 & 7.28 & 10.92 \\
\hline & Old & 7.57 & 7.99 & 11.86 \\
\hline
\end{tabular}


Table 3: Total removal, processing, and mean reading times for each aging structure in minutes. Average time per sample is garnered by dividing total removal, preparation and mean reading time by the number of samples $(\mathrm{N}=83)$ within the data set.

\begin{tabular}{lcccc}
\hline Structure & Removal & Preparation & Mean Reading & Processing Time Per Sample \\
\hline \hline Scale & 35 & 967 & $122^{\mathrm{A}}$ & 13.88 \\
Otolith & 532 & 359 & $100^{\mathrm{AB}}$ & 12.23 \\
Fin ray & 54 & 1709 & $74^{\mathrm{B}}$ & 22.68 \\
\hline
\end{tabular}

Mean reading times with different letters signify significant differences. 


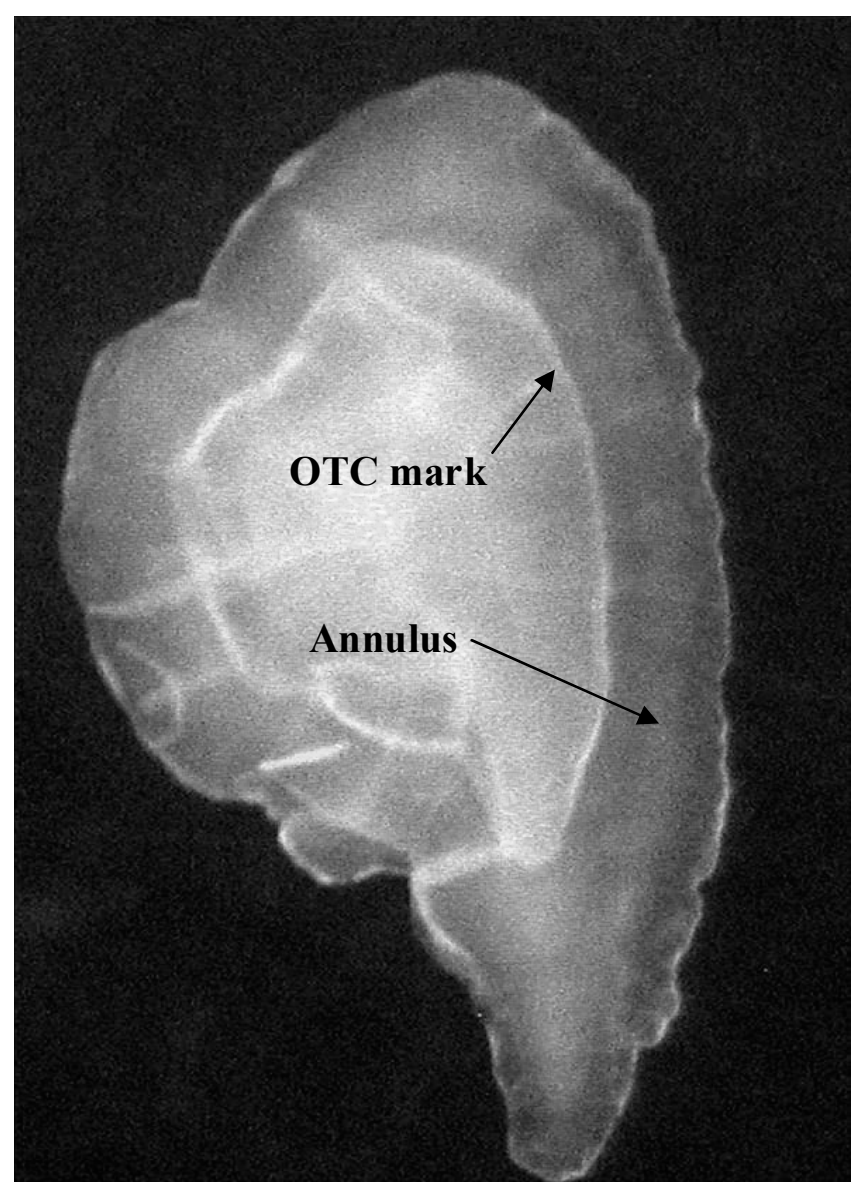

Figure 1: Brook trout otolith exhibiting annulus formation after OTC mark. 


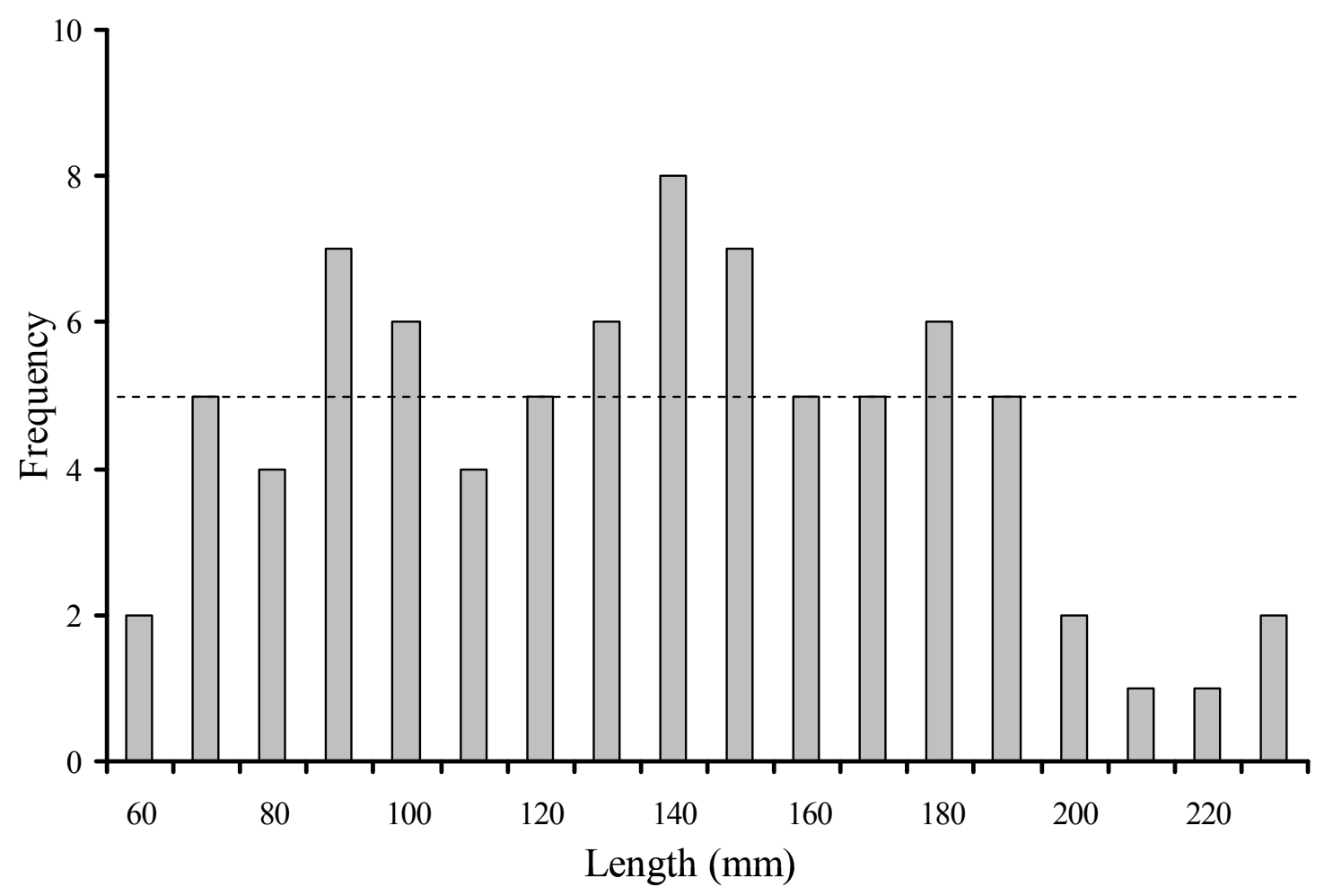

Figure 2: Length frequency histogram of brook trout included within age verification study. The dashed line indicates the number of individuals that are required to be collected within each size bin following sampling protocol. 

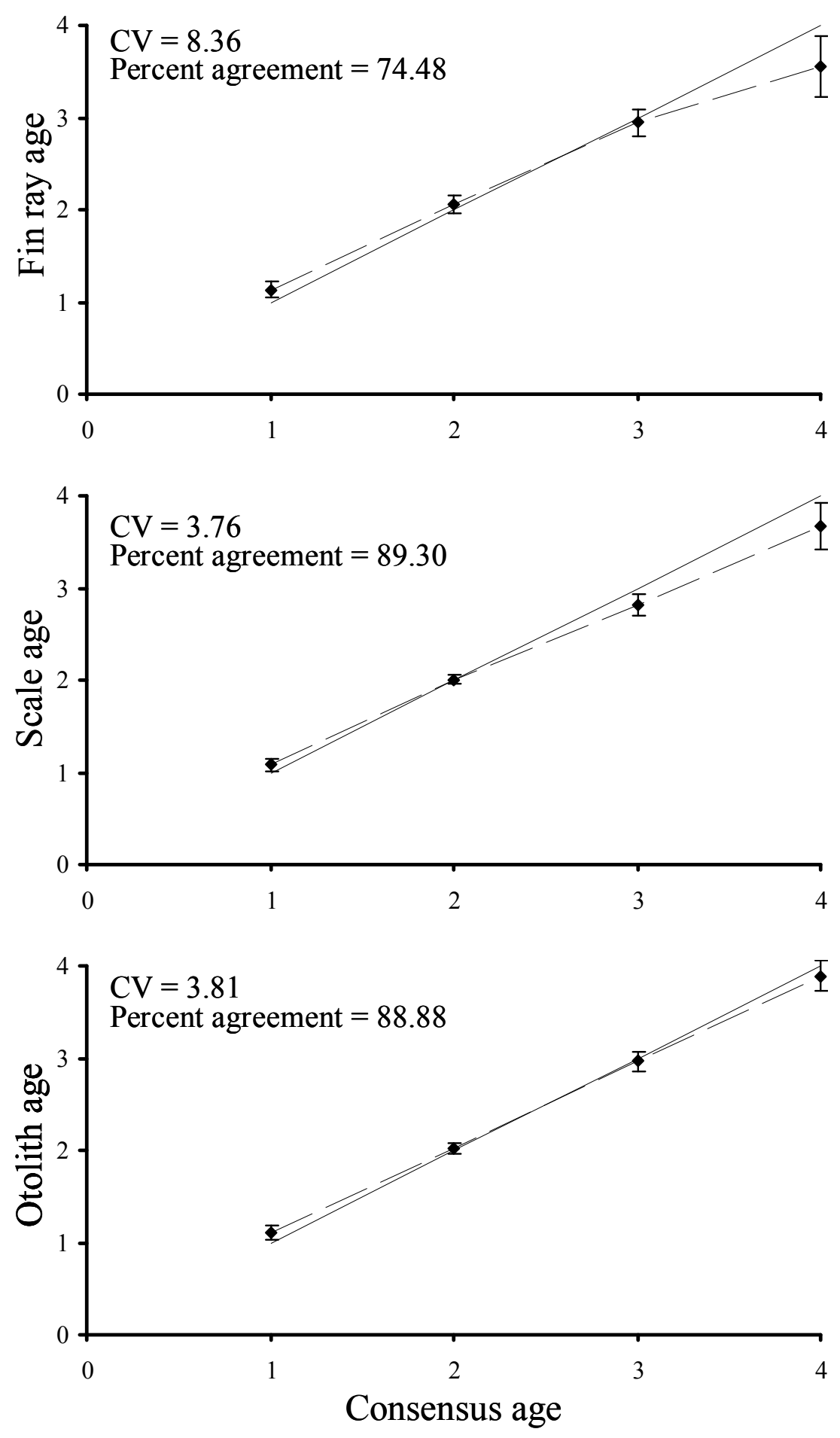

Figure 3: Mean estimated age from three independent readers lumped by structure as a function of consensus age. Deviance of the empirical (broken) line from the 1:1 equivalence line (solid) shows over or underestimation and is significant if outside the bounds of $95 \%$ confidence intervals. 

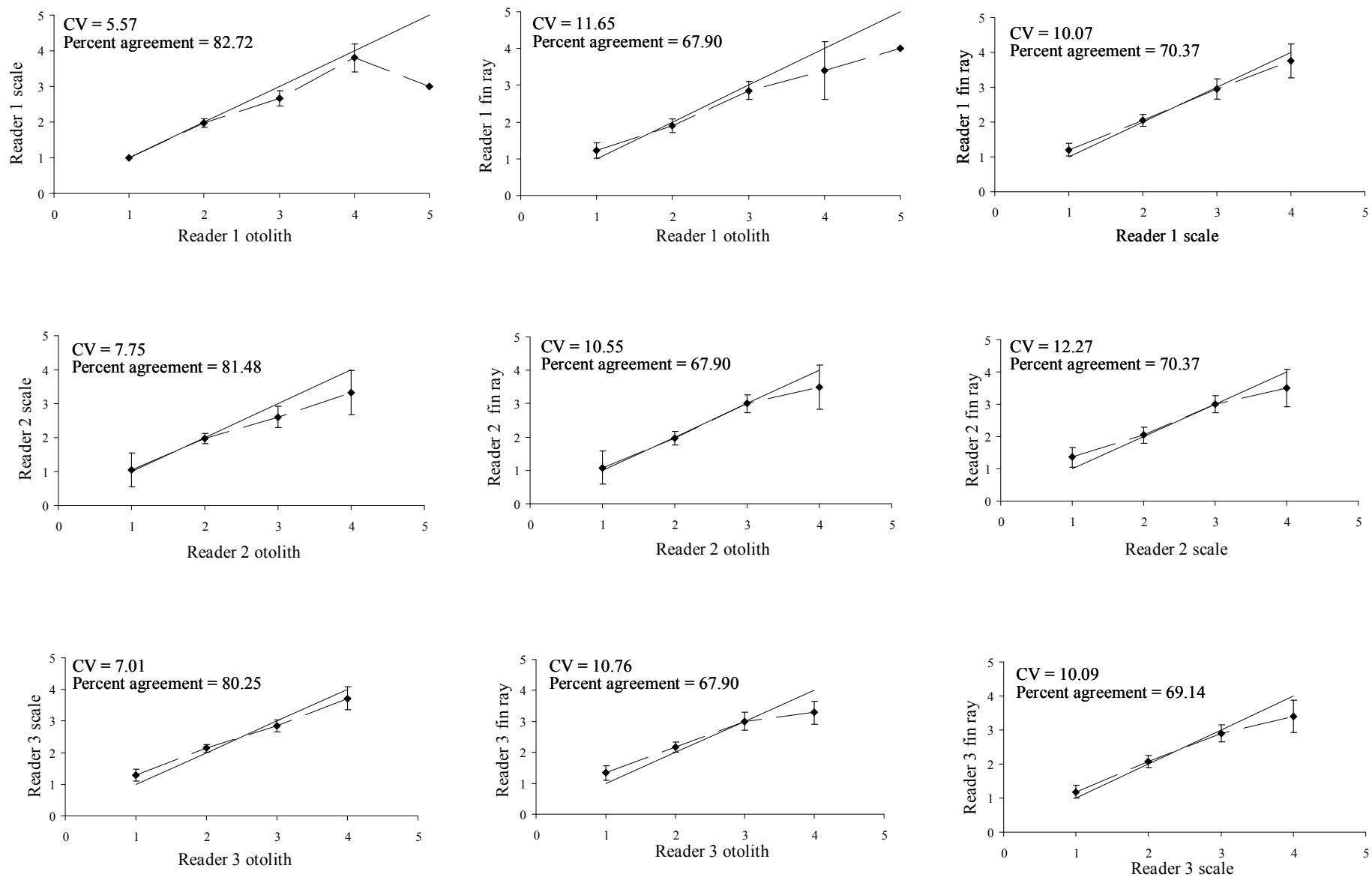

Figure 4: Age bias plots with 95\% confidence intervals (for points with multiple observations) showing within reader among structure comparisons. Bias is interpreted as either paralleled or separated lines of increasing divergence of the empirical (broken) line from the equivalence (solid) line. 


\title{
Chapter 3: The influence of geology and habitat features on growth of Appalachian brook trout.
}

\begin{abstract}
Within headwater lotic environments, evidence suggests that surficial stream geology may influence stream water quality, macroinvertebrate community structure, and salmonid growth rates. To investigate these relationships, physical and biological characteristics were quantified within 25 headwater streams lying within geologic types Hampshire, Chemung, Mauch Chunk, Pottsville-limed, and Pottsville-unlimed. Univariate and multivariate analysis of variance and linear regression techniques were used to investigate potential differences in water quality, macroinvertebrate communities, and brook trout (Salvelinus fontinalis) growth rates among geologic types. Macroinvertebrate richness $(\mathrm{F}=4.38, \mathrm{p}=0.047)$ and density $(\mathrm{F}=7.34, \mathrm{p}=0.013)$ were positively correlated to $\mathrm{pH}$. Streams within Hampshire geologies tended to have denser and richer macroinvertebrate communities than streams within Pottsville sites. Trends in $\mathrm{pH}$ among geologic types suggest $\mathrm{pH}$ is influenced by surficial geologic type. No differences were detected in brook trout growth rates among geologic types, however, trends in $\mathrm{pH}$ among geologic types, and the inclusion of $\mathrm{pH}$ into stepwise multilinear regression models predicting growth as a function of habitat variables suggest that geology may influence brook trout growth. This research suggests that geologic induced water quality may play an important role in determining the upper limit of brook trout growth within Appalachian systems. Actual brook trout growth may then be determined by such secondary mechanisms such as elevation and competition.
\end{abstract}

\section{Introduction}

The average $\mathrm{pH}$ of rain fall within the mid-Appalachian region is among the lowest in the United States (Baker 1990). Within headwater lotic environments acid precipitation may substantially reduce stream $\mathrm{pH}$ and thus alter the ecology and biology of multiple trophic levels (Mulholland et al. 1992, Meegan et al. 1996, Mount 1989). Decreased pH has been shown to reduce the diversity and biomass of benthic macroinvertebrate communities and hinder the growth and reproduction of top predators, brook trout (Salvelinus fontinalis) (Mullholland et al. 1992, Mount et al. 1998). Potentially the most 
detrimental effect of acidic inputs is a reduction of in-stream detrital rates as the decomposition of allochthonous inputs is a primary source of nutrients and energy within headwater streams (Vannote et al. 1980, Burton et al. 1985). Reduced nutrient concentrations may lead to reductions in productivity within adjacent trophic levels potentially reducing entire stream productivity (Burton et al 1985).

Streams retain the ability to resist acid induced reductions in $\mathrm{pH}$ through the influence of surficial geology (Johnson et al. 1981). Through natural weathering processes, bedrock releases base cations into surface waters allowing for the neutralization of acid. Waters flowing over Hampshire (limestone dominated) geologic types will release greater amounts of base cations and thus provide a stronger buffer against acidic inputs (Welsh and Perry 1997). However, as weathering properties vary among geologic types so will the buffering ability provided by each. For instance, streams flowing over Pottsville (sandstone dominated) geologic types may be at greater risk of acidification as this geologic type offers little buffering capacity (Herlihy et al 1993). Within an area which receives high amounts of acid rain such as the midAppalachian region, geology may play an important role in influencing the $\mathrm{pH}$ of running waters and thus the aquatic organisms which are supported within these environments (Sharpe et al. 1987, Welsh and Perry 1997, Eggleton and Morgan 2001).

Previous research in English chalk streams have found that sections of stream flowing over chalk geologies contain more abundant and diverse benthic macroinvertebrate communities (Cannan and Armitage 1999). However research such as this within Appalachia is rare. Within Appalachia, fish occurrence has been attributed to geologic type (Sharpe et al. 1987, Welsh and Perry 1997). Streams flowing over poorly buffered geologic types (Pottsville) tended to contain less diverse fish populations (Welsh and Perry 1997). While brook trout may be more resilient to acidic conditions compared to other species found within these systems, brook trout occurrence is also likely influenced by geology (Sharpe et al 1987).

While studies have investigated the influence of geology on brook trout occurrence, few have attempted to relate geology to growth (Eggleton and Morgan 2001). As benthic macroinvertebrates are an important food source for brook trout (Allan 1981), stream geology may influence brook trout growth through alterations in the benthic 
macroinvertebrate community composition. However, other factors such as habitat complexity and competition may also contribute to determining growth within these systems (Nakano 1995, Rosenfeld and Boss 2001).

The objectives of this research are to: (1) Examine water quality characteristics and aquatic macroinvertebrate communities among Appalachian headwater streams of differing geologic origin; and (2) Determine the influence that geology and other physical and biological characteristics of headwater streams have on Appalachian brook trout growth.

\section{Methods}

Site selection -- Streams were chosen due to accessibility, the presence of naturally reproducing brook trout populations, and uniform subwatershed geology which was discerned from a statewide geologic map. Upon successful fulfillment of criteria, five streams within five geologic types (Chemung, Hampshire, Mauch Chunk, Pottsvillelimed and Pottsville-unlimed) were selected. The addition of limestone sand to poorly buffered streams (Pottsville group) by the West Virginia Division of Natural Resources (WVDNR) and the West Virginia Department of Environmental Protection allowed for the creation of two Pottsville groups (limed and un-limed). The addition of limestone sand is a practice common to the region (WVDNR 2001) and is used to remediate the deleterious effects of acid mine drainage and acid rain. The liming of streams has been found to successfully increase $\mathrm{pH}$, restore fish communities, and increase invertebrate abundance (Clayton et al. 1998). However, invertebrate production and diversity and fish biomass may not reach pre-acidification conditions following treatment (McClurg 2004). As conditions within limed streams may not be similar to un-limed streams, separate groups were warranted.

Site Description -- Research was conducted on $251^{\text {st }}$ and $2^{\text {nd }}$ order headwater streams located within four counties in north central West Virginia (Figure 1) (Table 1). Seventeen sites were located within the Monongahela National Forest (MNF) while the remaining 8 were located within the MeadWestvaco Experimental Research Forest (MWERF). Watersheds of streams located within the Monongahela National forest were 
not actively logged however sites within the MWERF are actively managed for wood fiber. Watersheds tended to be dominated by secondary-growth hardwood deciduous forest. In nearly all sites, fish assemblages were dominated by brook trout and mottled sculpin (Cottus bairdii). Other fish sampled include white sucker (Catostomus commersoni), fantail darter (Etheostoma flabellare), northern hogsucker (Hypentelium nigricans), rainbow trout (Oncorhynchus mykiss), longnose dace (Rhinichthys cataractae), western blacknose dace (Rhinichthys obtusis), brown trout (Salmo trutta), creek chub (Semotilus atromaculatus). Two streams, Little Low and Crooked Fork contain artificial habitat manipulations ( $\mathrm{k}$ dams and $\mathrm{v}$ dams). These structures serve to create larger and deeper pool habitat which are thought to be more stable over time than naturally occurring pools.

Brook trout sampling -- During July of 2006, brook trout were captured from all 25 research streams using a pulsed DC backpack electrofishing unit and a standard three pass removal technique. Brook trout were captured from three $100 \mathrm{~m}$ sampling sections (up, mid, and low) within each stream. Sampling sections were representative of stream habitat and were typically separated from each-other by $500 \mathrm{~m}$. However, within shorter and smaller $1^{\text {st }}$ order streams $500 \mathrm{~m}$ buffers could not be maintained. In these instances, sampling sections were separated by the greatest distance possible while maintaining reaches that were representative of existing stream conditions. Before collection, the upstream and downstream boundaries of the section were blocked by nets to meet the assumption of a closed population. All captured brook trout were immobilized in a 120 $\mathrm{mg} / \mathrm{L}$ solution of clove oil and ethanol (Anderson et al. 1997), weighed to the nearest gram using a spring scale, measured to the nearest $\mathrm{mm}$ total length, and sampled for scales. Scales were removed from an area above the lateral line, posterior to the dorsal fin (DeVries and Frie 1996) and placed in individually labeled scale envelopes for later examination. Scale samples were taken to permit aging as a non-lethal method of age determination was warranted due to the high number of fish being sampled.

Furthermore, scale techniques may yield age estimates of similar accuracy and precision to otolith techniques within younger (age <3) cohorts (Stolarski 2007). Once fully processed, fish were placed in an in-stream live well and allowed to recover before being 
released close to the point of capture. Occasionally a larger adult ( $>180 \mathrm{~mm})$ was sacrificed using an overdose of clove oil $(240 \mathrm{mg} / \mathrm{L})$. Otoliths from these individuals were extracted and used with length frequency data to spot check scale ages of older individuals, as scale aging techniques may deteriorate within older (age $>2$ ) cohorts (Hining et al. 2000, Stolarski 2007). In the laboratory, scales (20 to 30) from each fish were wet mounted on a glass slide and viewed at $45 \mathrm{X}$ under a microscope. Annuli were identified and counted following Devries and Frie (1996) and age was estimated for each individual by an experienced reader.

Cohorts within each stream were separated via scale based age estimations and mean length of each cohort was calculated. Instantaneous growth rate was then calculated for each cohort as:

$$
\mathrm{G}=\log _{\mathrm{e}}\left(\mathrm{Y}_{2}\right)-\log _{\mathrm{e}}\left(\mathrm{Y}_{1}\right) / \mathrm{t}_{2}-\mathrm{t}_{1}
$$

Where $Y_{2}$ is the mean fish length $(\mathrm{mm})$ at time $2\left(\mathrm{t}_{2}\right)$, and $\mathrm{Y}_{1}$ is mean fish length $(\mathrm{mm})$ at time $1\left(\mathrm{t}_{1}\right)$ (Busaker et al. 1990). As age 0 fish have not completed a full year of growth at the time of sampling, length at emergence and the timing of emergence had to be estimated in order to compute growth within this cohort. Previous brook trout research has measured mean length at emergence as $15.24 \mathrm{~mm}$ and the bulk of emergence to occur near March $1^{\text {st }}$ (Curry et al. 1991, Hunt 1966). These measures were used to compute age 0 growth in this research

Population estimates for each brook trout sampling section were computed using the depletion process of Zippin in the program CAPTURE (White et al. 1982). If fewer than 30 fish were captured, then the actual number of fish caught was substituted as an estimate (Riley and Fausch 1992). Section population estimates within each stream were averaged together to obtain a mean population estimate for each stream. Fish density $\left(\mathrm{fish} / \mathrm{m}^{2}\right)$ for each stream was then calculated as the mean population estimate divided by the mean wetted area $\left(\mathrm{m}^{2}\right)$ of the three sampling sections at base flow.

Benthic macroinvertebrate sampling - Between the $18^{\text {th }}$ and the $26^{\text {th }}$ of March 2006, three benthic macroinvertebrate samples were collected within each brook trout sampling section (up, mid, and low) of each stream. Samples were collected from the deepest point 
of a representative riffle using a kick net $(500 \mu \mathrm{m}$ mesh) and agitating the substrate directly in front of the net (area approximately $.25 \mathrm{~m}^{2}$ ) for 30 seconds. Samples were preserved in the field with $90 \%$ ethanol and transported back to the laboratory for analysis. Benthic samples were divided into petri dishes and macroinvertebrates were separated from organic matter by hand under a dissecting scope at 40x. Macroinvertebrates were counted and identified to Family (Merit and Cummins 1996). Before the computation of various macroinvertebrate metrics, rare families (occurrence < 3) were removed from the data set (Cao and Larsen 2001) in attempt to reduce variability in the data set. Taxonomic richness, EPT richness, and abundance were calculated for each sample and averaged to obtain mean richness and abundance values for each stream. In preparation for dry-mass measurements, crayfish (Cambarus) were removed from samples. Crayfish are commonly not included in biomass measurements due to the possibility of adding large amounts of variance to the data set (Wallace et al. 1995). Samples were dried at $80^{\circ} \mathrm{C}$ for 24 hours, cooled in a desiccator and then weighed with an electronic balance to the nearest $0.0001 \mathrm{~g}$. Once again, samples were averaged to obtain mean dry-mass measures for each stream.

Physical habitat measures - Habitat was surveyed at summer base flow from a designated study reach within each stream following a modified version of Hankin and Reeves (1998). Study reaches generally began at the mouth of each stream or at a substantial barrier to fish and ended $500 \mathrm{~m}$ above the uppermost brook trout sampling section or at a substantial branch. Habitat units (pool, riffle, run) were identified visually and wetted width and water depth were measured at three transects within each habitat unit. Wetted width was estimated to the nearest $0.1 \mathrm{~m}$ and three depths were taken at each transect with a $2 \mathrm{~m}$ graduated staff. Habitat area was calculated for each habitat unit then summed by type to obtain total area of each habitat type within each stream. As the length of study reaches varied, summed area for each habitat type was divided by reach length to obtain percent area of each habitat type within each stream.

Arc GIS software version 8.3 (Environmental Systems Research Institute 2003) was used to estimate mean stream elevation (m), gradient, and watershed area $\left(\mathrm{km}^{2}\right)$. Mean elevation and gradient were estimated from study reach boundaries and basin area 
was calculated from the point where habitat surveys were initiated using coordinates derived from a global positioning system.

Stream $\mathrm{pH}$ and alkalinity were measured once each season over a 2 day period from a $250 \mathrm{ml}$ water sample taken at the downstream boundary of each study reach. Each polyethylene bottle was filled and emptied three times before the final water sample was taken. The lid to each bottle was secured under the surface of the water to eliminate air pockets. Samples were placed on ice and transported to WVDNR laboratories located in Elkins, West Virginia within 24 hours for analysis. Stream $\mathrm{pH}$ was measured with a Hanna (model 50-pH209) bench-top electronic pH meter. A $100 \mathrm{ml}$ water sample was then titrated to $\mathrm{pH} 4.5$ with $0.02 \mathrm{~N} \mathrm{H}_{2} \mathrm{SO}_{4}$ to measure alkalinity $(\mathrm{mg} \mathrm{CaCO}$ ) (USEPA 1979). Before generating a seasonal average for each stream, $\mathrm{pH}$ was converted to hydrogen ion concentration, averaged across seasons, then log transformed back to $\mathrm{pH}$ units. Alkalinity was averaged across seasons to obtain mean alkalinity for each stream.

Statistical analysis -- All statistical analyses were completed using the SAS 8.0 statistical software package (SAS Institute 1999). Pearson's correlation coefficients (r) were calculated for each possible pairwise comparison of water quality and physical and biological stream variables. Variables with correlations of $r \geq|0.85|$ were considered redundant and either the causal variable or the variable with the greatest variance was retained. This procedure is an important precursor to multivariate analysis of variance (MANOVA) and stepwise multivariate linear regression (SMLR). Data redundancy within post hoc MANOVA procedures reduces the likelihood of finding significant differences in post hoc tests as the alpha at which significance is determined declines with each variable tested. Furthermore, data redundancy or multicolinearity in SMLR can inflate model confidence intervals and even invert signs of regression coefficients (Myers 1990). Identifying redundant variables early in analysis will minimize these statistical problems.

Differences in macroinvertebrate metrics, water quality, and brook trout growth rates among geologic types were investigated using MANOVA. Significance of this test was set at alpha $=0.05$. As a follow up test, repeated measures of ANOVA were conducted to determine which specific variables differed significantly. Significance for 
these tests was set at a Bonferroni corrected alpha of $0.05 / \mathrm{n}$, where $\mathrm{n}$ is equal to the number of ANOVA tests performed. Each ANOVA test was then followed up by a post hoc Tukey test to determine which geologic types differed in respect to each variable being tested. Significance of these tests was set at an alpha of 0.05 .

Stepwise multiple linear regressions were used to determine the relative influence of water quality and physical and biological variables on brook trout growth rates within each cohort. Unfortunately, sample size $(n=25)$ limited the number of regressors that could be included in each model. Conservative texts suggest ten times as many samples as variables (Tabachnick and Fidell 1989). However this guideline is often grossly ignored (Scarnecchia and Bergersen 1987, Eggleton and Morgan 2000). To further reduce the set of variables included within each model, growth estimates were regressed against water quality, physical, and biological variables to assess their relevance. Variables with significant correlations $(p<0.1)$ to growth estimates were considered statistically important. Inclusion into SMLR analysis was based on both statistical and ecological relevance, however geology was included in each model as it is a variable of interest. This methodology reduces the chances of reporting erroneous findings based solely on statistical interpretation, but may increase the chances of researcher bias. No more than four variables were included within each model.

\section{Results}

A total of 1,598 fish encompassing ages 0 through 4 were captured from 25 headwater sites. Populations tended to be dominated by age 0 and 1 year olds and mean size at age varied by stream (Table 2). As age 3 and 4 brook trout were not found across all sites growth estimates within these cohorts could not be calculated for some streams. When age 3 and 4 fish were collected they were generally few in number resulting in variable mean size at age statistics. For these reasons, analysis was confined to cohorts 0 through 2. Water quality (Table 3), physical (Table 4), and biological characteristics (Table 5) of streams varied by site.

Pearsons correlation coefficients identified 4 pairs of variables exhibiting significant correlations $(r \geq|0.85|)$ (Table 6$)$. With the exception of percent pool habitat, all variables with the greatest variance were retained for future analysis. Percent pool 
habitat was retained in lieu of percent riffle habitat as pool habitat is likely more relevant to brook trout growth (Rosenfeld and Boss 2001). It is not surprising that $\mathrm{pH}$ and alkalinity were found to be correlated as they are often described as surrogate measures (Waters et al. 1990). While not found to be significantly correlated within this research, stream wetted width and gradient have been found to be a function of watershed area (Platts 1979, Lanka et al. 1987). For this reason, wetted width and gradient were removed from analysis in lieu of watershed area.

Results of MANOVA analysis reveal significant differences between water quality, macroinvertebrate metrics, and brook trout growth rates across geologic types (Wilks' Lambda $\mathrm{f}=2.59, \mathrm{p}=0.002$ ). Post Hoc sequential ANOVA tests show significant differences in mean macroinvertebrate richness $(\mathrm{F}=7.33, \mathrm{p}<0.001)$ and mean macroinvertebrate density $(\mathrm{F}=6.55, \mathrm{p}=0.001)$ (Table 7). However, differences were not found in mean $\mathrm{pH}$ and cohort specific brook trout growth estimates among geologic types. Post hoc Tukey analysis of water quality, macroinvertebrate metrics, and brook trout growth rates indicate Hampshire and Chemung geologies tended to contain macroinvertebrate communities that were more taxonomically rich and dense compared to Pottsville sites (Table 8). Additionally, $\mathrm{pH}$ was generally greater within Hampshire sites compared to Pottsville sites. While not significant, this trend suggests that the weathering properties of each geologic type influences stream $\mathrm{pH}$ as Pottsville geologic types typically provide less buffering capacity compared to Hampshire geologies (Welsh and Perry 1997).

Previous research has indicated significant positive correlations between $\mathrm{pH}$ and benthic macroinvertebrate density and richness (Kimmel et al. 1996, Mulholland et al. 1992). Within this research, Tukey tests suggest the presence of similar relationships as Hampshire sites tended to exhibit denser and more taxonomically diverse macroinvertebrate communities. Simple linear regression techniques were then used to test for relationships. Analysis revealed significant $(\mathrm{p}<0.05)$ correlations between mean $\mathrm{pH}$ and mean macroinvertebrate density $(\mathrm{F}=7.34, \mathrm{p}=0.013)$ and mean richness $(\mathrm{F}=$ $4.38, \mathrm{p}=0.047)$.

Simple linear regressions of cohort specific growth estimates and water quality and physical and biological stream variables show several significant correlations (Table 
9). All independent variables which were found to be significantly $(\mathrm{p}<0.1)$ correlated to growth rate estimates were included in SMLR analysis. Additionally, brook trout density and macroinvertebrate density were included in the age 1growth model as they may be ecologically important (Allen 1981, Utz and Hartman 2006). Significant models describing brook trout growth rates as a function of water quality and physical and biological stream characteristics (Table 10) indicate that among cohorts, $\mathrm{pH}$, elevation, macroinvertebrate density, and brook trout density are influencing brook trout growth rates within these systems.

\section{Discussion}

Stepwise multilinear regression analysis revealed $\mathrm{pH}$ to significantly influence growth within the age 0 and 1 cohorts. This result supports previous work that has found similar correlations between $\mathrm{pH}$ and salmonid growth (Beyerle and Cooper 1960, McFadden and Cooper 1962, Eggleton and Morgan 2000). In natural studies Beyerle and Cooper (1960), McFadden and Cooper (1962), and Eggleton and Morgan (2000) found brown and rainbow trout growth rates to be correlated to water quality measures. However, mechanisms behind these linkages were not identified. In this research, significant positive correlations between $\mathrm{pH}$ and macroinvertebrate biomass and richness may inpart explain this relationship as macroinvertebrates are an important food source for lotic salmonids (Allan 1981). Brook trout residing within streams of greater $\mathrm{pH}$ may benefit energetically from greater forage abundance possible resulting in increased growth.

Alternatively, at low $\mathrm{pH}$ growth may be inhibited by the mobilization of toxic metals (Mount et al. 1989). In laboratory studies, brook trout growth was reduced when fish were exposed to acidic conditions. Growth reductions were attributed to reduced consumption potentially as a result of stress from the mobilization of aluminum at low $\mathrm{pH}$ (Mount et al 1989).

The inclusion of $\mathrm{pH}$ into stepwise models and trends in mean $\mathrm{pH}$ among geologic types also suggest that geology may be indirectly influencing growth within these systems. While no significant differences in $\mathrm{pH}$ among geologic types were found within this research, the influence of geology on the $\mathrm{pH}$ of running waters has been previously documented (Johnson et al 1981, Sharpe et al 1987, Herlihy et al. 1993, Welsh and Perry 
1997). Streams flowing over geologic types which weather favorably (Hampshire) generally result in waters of greater $\mathrm{pH}$ compared to streams flowing over geologies resistant to weathering (Pottsville) (Welsh and Perry 1997). Trends in $\mathrm{pH}$ among geologic types within this research support this finding. Brook trout growth within well buffered systems may then be greater as a result of favorable $\mathrm{pH}$ and taxonomically richer and denser benthic macroinvertebrate communities. However, within streams of poorer water quality and benthic macroinvertebrate communities, brook trout growth may be subsidized by the consumption of terrestrial invertebrates (Utz and Hartman 2007). As terrestrial invertebrates may not be under the direct influence of stream geology, consumption of energy from terrestrial sources may act to weaken relationships between geology and brook trout growth.

The failure of the inclusion of geologic type into stepwise models may have been due to variability in $\mathrm{pH}$ among geologic types as a result of sampling frequency and the water quality prerequisites of study streams. As stream $\mathrm{pH}$ has been shown to vary substantially throughout the year (McClurg 2004), seasonal sampling likely resulted in the inclusion of substantial variation into the data set. Furthermore, the range of $\mathrm{pH}$ exhibited within streams included within this study was truncated due to the necessity of containing naturally reproducing brook trout populations. Successful recruitment may not occur below a $\mathrm{pH}$ of 4.5 , therefore limiting the possible range of $\mathrm{pH}$ within study streams (Cleveland et al. 1986). High variance within a limited $\mathrm{pH}$ range likely inhibited inclusion into stepwise models.

Similarly, high variance in $\mathrm{pH}$ among geologic types may be a function of inaccurate geologic classifications. The inclusion of multiple geologic types within the basin of a stream may influence water quality and thus the ecology of that system. This phenomenon may be best exemplified by Brushy Run. Brushy run lies predominately within the generally poorly buffered Mauch Chunk geology. However, small amounts of limestone have been previously reported to be associated with this geologic type and may dramatically influence the $\mathrm{pH}$ of surface waters (Dincola 1982). Evidence of greater $\mathrm{pH}$ relative to previously reported values for this geologic type and the presence of abundant and diverse macroinvertebrate populations suggest that limestone is present within this basin. This disparity highlights the importance of accurate geologic classifications as 
only a small quantity of limestone may dramatically alter the water quality characteristics and potentially the aquatic communities of a stream.

Within cohorts 1 and 2 the inclusion of brook trout density to linear models suggests that competitive interactions may influence adult growth rates. Lotic salmonids have been shown to establish size based dominance hierarchies in response to limited food or space (Fausch 1984, Elliot 1990). Dominant individuals will restrict access to resources which may result in reduced growth of subdominant individuals (Nakano 1995). This research is in support of evidence that lotic salmonids may experience density dependent growth (Jenkins 1999, Vollestad et al. 2002, Utz and Hartman 2006).

Within the age 0 cohort density was not found to influence growth. Within this cohort small body size $(<90 \mathrm{~mm})$ and the reduced cost of swimming associated with small body size may have enabled age 0 fish to avoid density dependent growth (Rosenfeld and Boss 2001). In the presence of a size based dominance hierarchy, smaller individuals may be relegated to sub optimal riffle areas or nonfocal positions within pools (Hughes and Reynolds 1994, Nakano 1995). Within riffles, greater water velocity will incur greater swimming costs and within pools, competition will restrict access to resources potentially limiting growth (Rosenfeld and Boss 2001, Nakano 1995). However, sufficiently small $(<90 \mathrm{~mm})$ individuals may be able to grow within riffle habitat as they have lower swimming costs and absolute energy requirements (Rosenfeld and Boss 2001). The ability to grow in isolation from dominance hierarchies within riffle habitats may release age 0 individuals from density dependent growth. However, stream elevation may act to limit growth within this cohort through variation in water temperature and metabolic rates (Elliot 1994, Sloat et al. 2005).

While stepwise models indicated significant relationships between growth rates and water quality and physical and biological variables the coefficients of regressor terms were not consistent among models. This is best exemplified within the growth models for cohorts 0 and 1 . Mean $\mathrm{pH}$ positively influenced age 0 growth but negatively influenced age 1 growth. This discrepancy may indicate that independent variables are linearly related in some capacity despite best efforts to eliminate multicolinearity (Myers 1990). Within a data set including water quality, and physical and biological habitat variables it may be nearly impossible to eliminate multicorrelation as these variables are 
all likely interrelated (Hynes 1975). However, the finding of significant reggressors within growth models may suggest that this effect is not severe. In extreme cases, multicolinearity can inflate confidence intervals and prevent significant findings (Myers 1990). Efforts to reduce highly linearly related variables before analysis may reduce the effect of multicorrelation. However, eliminating it completely within a data set such as this may not be possible.

In conclusion, geology, through its influence on stream $\mathrm{pH}$ and benthic macroinvertebrate community composition likely sets the upper limit on growth within these systems as benthic macroinvertebrates are an important food source for lotic salmonids. However, this relationship may be weakened depending on the degree to which brook trout feed on terrestrial invertebrates. Actual growth rates are likely determined through such secondary mechanisms as competition and elevation. However other factors not measured within this study also may influence growth such as habitat complexity (Power 1980, Beschta and Platts 1986).

Managers responsible for the conservation of brook trout within areas that receive high levels of acid precipitation such as the mid-Appalachian region need to consider the geologic origin of streams when evaluating brook trout populations. Brook trout inhabiting streams lying within poorly buffered geologies may experience reduced growth as a result of reduced $\mathrm{pH}$ and impaired macroinvertebrate communities. Within these systems, growth may then be more dependent upon secondary mechanism such as competition, habitat characteristics, or the consumption of terrestrial invertebrates. As a result, brook trout growth within these environments may be more sensitive to alterations in the afore mentioned factors. Future management decisions should consider the sensitivity of brook trout populations within poorly buffered geologic types as populations may be at increased risk of degradation.

Future work - As water quality may greatly influence the structure and health of lotic communities, future research should focus on gaining a better understanding of the relative influence that each geologic type has on stream water quality. This may be accomplished by studying streams of mixed geologic origin. Quantifying the percent of each geologic type within a watershed may identify critical thresholds of particular 
geologic types required to maintain favorable water quality and thus healthy aquatic communities. Furthermore, if robust, these thresholds could be used as predictors of both water quality and community structure within a particular stream without the need for direct sampling, saving ample time and effort. However, one potential problem to this approach is the need to account for hydrology. Stream $\mathrm{pH}$ is a result of the weathering properties of substrates over which running waters flow. The inclusion of a specific geologic type within a watershed in no way assures that its weathering properties are imparted to the stream lying within its boundaries. A watershed may contain three geologic types, however, the stream of interest may only come into contact with one. This effect may be most noticeable within a watershed containing limestone, as only a small amount of limestone within the hydrologic pathway, may dramatically alter the water quality of a given stream. Streams lying within uniform geologies would negate the influence of alternate geologic types however are likely rare in nature. Alternatively, by increasing sample size and the geologic diversity of study streams, the effect of hydrology may be minimized. Furthermore, it may be advantageous to isolate watersheds containing even small amounts of limestone to discern if, or the degree to which water quality is being influenced. Until hydrology can be controlled, the influence of geology on aquatic communities may be difficult to discern. In this instance, direct measures of $\mathrm{pH}$ may provide more accurate data to managers attempting to discern the health of aquatic communities within these systems. 


\section{Reference List}

Allan, J.D. 1981. Determinants of diet of brook trout (Salvelinus fontinalis) in a mountain stream. Canadian Journal of Fisheries and Aquatic Sciences. 38:184-192.

Anderson, G.W., S. R. Mckinley, and M. Colavecchia. 1997. The use of clove oil as an anesthetic for rainbow trout and its effects on swimming performance. Transactions of the American Fisheries Society. 17:301-307.

Baker, L.A., P. R. Kaufmann, A. T. Herlihy, and J. M. Eilers. 1990. Current status of surface water acid-base chemistry, NAPAP SOS/T Report 9. in: National Acid Preciptiation Assessment Program, State of Science and Technology, Volume II, Washington, D.C.

Beschta, R.L. and W. S. Platts. 1986. Morphological features in small streams: significance and function. Water Resources Bulletin. 22:369-379.

Beyerle, G.B. and E. L. Cooper. 1960. Growth of brown trout in selected Pennsylvania streams. Transactions of the American Fisheries Society. 89:255-262.

Burton, T.M., R. M. Stanford, and J. W. Allan. 1985. Acidification effects on stream biota and organic matter processing. Canadian Journal of Fisheries and Aquatic Resources. 42:669-675.

Busaker, G.P., I. R. Adelman, and E. M. Goolish. 1990. Growth. Pages 363-382 in C.B. Schrek and P.B. Moyle, editors. Methods for fish biology. American Fisheries Society, Bethesda, Maryland.

Cannan, C.E. and P. D. Armitage. 1999. The influence of catchment geology on the longitudinal distribution of macroinvertebrate assemblages in a groundwater dominated river. Hydrological Processes. 13:355-369.

Cao, Y. and D. P. Larsen. 2001. Rare species in multivariate analysis for bioassessment: some considerations. Journal of North American Benthological Society. 20:144153.

Clayton, J.L., E. S. Dannaway, R. Menendez, H. W. Rauch, J. J. Renton, S. M. Sherlock, and P. E. Zurbuch. 1998. Application of limestone to restore fish communities in acidified streams. North American Journal of Fisheries Management. 18:347-360.

Cleveland, L., E. E. Little, S. J. Hamilton, D. R. Buckler, and J. B. Hunn. 1986. Interactive toxicity of aluminum and acidity to early life stages of brook trout. Transactions of the American Fisheries Society. 15:610-620.

Curry, A.R., P. M. Powles, J. M. Gunn, and V. A. Liimatainen. 1991. Emergence chronology of brook charr, Salvelinus fontinalis, alevins in an acidic stream. 
Environmental Biology of Fishes. 31:25-31.

Devries, D.R. and R. V. Frie. 1996. Determination of age and growth. Pages 483 -508 in B.R. Murphy and D.W. Willis, editors. Fisheries techniques, $2^{\text {nd }}$ edition. American Fisheries Society, Bethesda Maryland.

Dincola, R.S. 1982. Geologic controls on the sensitivity of headwater streams to acid precipitation in Laurel Highlands of Pennsylvania. Masters Thesis, Pennsylvania State University, University Park Pennsylvania.

Eggleton, M. and E. Morgan. 2000. Rainbow trout (Oncorhynchus mykiss) production dynamics and relations with abiotic factors in two Southern Appalachian mountain streams. Journal of Freshwater Ecology. 15:251-268.

Elliot, J.M. 1990. Mechanisms responsible for population regulation in young migratory trout, Salmo trutta. III. the role of territorial behaviour. The Journal of Animal Ecology. 59:803-818.

Elliot, J.M. 1994. Quantitative ecology and the brown trout. Oxford University Press, New York, NY.

Fausch, K.D. 1984. Profitable stream positions for salmonids: relating specific growth rate to net energy gain. Canadian Journal of Zoology. 62:441-451.

Hankin, D.G. and G. H. Reeves. 1988. Estimating total fish abundance and total habitat area in small streams based on visual estimation methods. Canadian Journal of Fisheries and Aquatic Sciences. 45:834-844.

Herlihy, A.T., P. R. Kaufmann, M. R. Church, P. J. Wigington, J. R. Webb, and M. J. Sale. 1993. The effects of acidic deposition on streams in the Appalachian mountain and Piedmont region of the Mid-Atlantic United States. Water Resources Research. 29:2687-2703.

Hining, K.J., J. L. West, M. A. Kulp, and A. D. Neubauer. 2000. Validation of scales and otoliths for estimating age of rainbow trout from southern Appalachian streams. North American Journal of Fisheries Management. 20:978-985.

Hughes, N.F. and J. B. Reynolds. 1994. Why do Arctic grayling (Thymallus arcticus) get bigger as you go upstream? Canadian Journal of Fisheries and Aquatic Sciences. 51:2154-2163.

Hunt, R.L. 1973. Production and angler harvest of wild brook trout in Lawrence Creek, Wisconsin. Wisconsin Conservation Department Technical Bulletin. 35:1-52.

Hynes, H.B.N. 1975. The stream and its valley. Internationale Vereinigung für theoretische und angewandte Limnologie Verhandlungen. 19:1-15. 
Jenkins, T.M., S. Diehl, K. W. Kratz, and S. C. Cooper. 1999. Effects of population density on individual growth of brown trout in streams. Ecology. 80:941-956.

Johnson, N.M., C. T. Driscoll, J. S. Eaton, G. E. Likens, and W. H. McDowell. 1981. Acid rain, dissolved aluminum and chemical weathering at the Hubbard Brook Experimental Forest, New Hampshire. Geochimica et Cosmochimica Acta. 45:1421-1437.

Kimmel, W.G., E. L. Cooper, and C. C. Wagner. 1996. Macroinvertebrates and fish populations of four streams receiving high rates of hydrogen and sulfate ion deposition . Journal of Freshwater Ecology. 11:493-511.

Lanka, R.P. and W. A. Hubert. 1987. Relations of geomorphology to stream habitat and trout standing stock in small Rocky Mountain streams. Transactions of the American Fisheries Society. 116:21-28.

McClurg, S.E. 2004. Stream ecosystem response to mitigative limestone treatment in acid impaired, Central Appalachian streams. Masters Thesis, West Virginia University, Morgantown.

McFadden, J.T. and E. L. Cooper. 1962. An ecological comparison of six populations of brown trout (Salmo trutta). Transactions of the American Fisheries Society. 91:53-62.

Meegan, S.K., S. A. Perry, and W. B. Perry. 1996. Detrital processing in streams exposed to acidic precipitation in the Central Appalachian mountains. Hydrobiologia. 339:101-110.

Merritt, R.W. and K. W. Cummins. 1996. An introduction to the aquatic insects of North America. 3rd ed. Kendall and Hunt, Dubuque, Iowa.

Mount, D.R., C. G. Ingersoll, D. D. Gulley, J. D. Fernandez, T. W. LaPoint, and H. L. Bergman. 1989. Effect of long-term exposure to acid, aluminum, and low calcium on adult brook trout (Salvelinus fontinalis) survival, growth, fecundity, and progeny survival. Canadian Journal of Fisheries and Aquatic Sciences. 45:16231632.

Mulholland, P.J., C. T. Driscoll, J. W. Elwood, M. P. Osgood, A. V. Palumbo, A. D. Rosemond, M. E. Smith, and C. Schofield. 1992. Relationships between stream acidity and bacteria, macroinvertebrates, and fish: a comparison of north temperate and south temperate mountain streams, USA. Hydrobiologia. 239:7-24.

Myers, R.H. 1990. Classical and modern regression with applications. 2nd edition. Duxbury Press, Belmont, California. 
Nakano, S. 1995. Individual differences in resource use, growth, and emigration under the influence of a dominance hierarchy in fluvial red-spotted masu salmon in a natural habitat. Journal of Animal Ecology. 64:75-84.

Platts, W.S. 1979. Relationships among stream order, fish populations, and aquatic geomorphology in an Idaho river drainage. Fisheries. 4:5-9.

Power, G. 1980. Charrs; salmonid fishes of the genius Salvelinus. The Hauge, The Netherlands.141-201.

Riley, S.C. and K. D. Fausch. 1992. Underestimation of trout population size by maximum-likelihood removal estimates in small streams. North American Journal of Fisheries Management. 12:768-776.

Rosenfeld, J.S. and S. Boss. 2001. Fitness consequences of habitat use for juvenile cutthroat trout: energetic costs and benefits in pools and riffles . Canadian Journal of Fisheries and Aquatic Sciences. 58: 585-593.

SAS Institute. 2003. SAS 9.1 (computer software). SAS Institute Inc., Cary, North Carolina.

Scarnecchia, D.L. and E. P. Bergersen. 1987. Trout production and standing crop in Colorado's small streams, as related to environmental features. North American Journal of Fisheries Management. 7:315-330.

Sharpe, W.E., V. G. Leibfried, W. G. Kimmel, and D. R. DeWalle. 1987. The relationship of water quality and fish occurrence to soils and geology in an area of high hydrogen and sulfate ion deposition. Water Resources Bulletin. 23:37-46.

Sloat, M.R., B. B. Shepard, and R. G. White. 2005. Influence of stream temperature on the spatial distribution of westslope cutthroat trout growth potential within the Madison River basin, Montana. North American Journal of Fisheries Management. 25:225-237.

Stolarski, J.T. 2007. Age and growth of Appalachian brook trout in relation to habitat features and life history characteristics. Masters Thesis, West Virginia University, Morgantown.

Tabachnick, B.G. and L. S. Fidell. 1989. Using multivariate statistics. Harper and Row, New York.

United States Environmental Protection Agency. 1979. Methods for chemical analysis of water and wastes. 600/4-79-020. Washington, DC. U.S. Environmental Protection Agency. 
Utz, R.M. and K. J. Hartman. 2007. Identification of critical prey items to Appalachian brook trout (Salvelinus fontinalis) with emphasis on terrestrial organisms. Hydrobiologia. 575:259-270.

Utz, R.M. and K. J. Hartman. 2006. Temporal and spatial variation in the energy intake of a brook trout (Salvelinus fontinalis) population in an Appalachian watershed. Canadian Journal of Fisheries and Aquatic Sciences. 63:2675-2686.

Vannote, R.L., W. G. Minshall, K. W. Cummins, J. R. Sedell, and C. E. Cushing. 1980. The river continuum concept. Canadian Journal of Fisheries and Aquatic Sciences. 37:130-137.

VØllestad, L.A., E. M. Olsen, and T. Forseth. 2002. Growth-rate variation in brown trout in small neighboring streams: evidence of density dependence? Journal of Fish Biology. 61:1513-1527.

Wallace, B.J., J. R. Webster, and J. L. Meyer. 1995. Influence of log additions on physical and biological characteristics of a mountain stream. Canadian Journal of Fisheries and Aquatic Sciences. 52:2120-2137.

Waters, T.F.D.M.T.K.C.C. 1990. Annual production and production: Biomass ratios for three species of stream trout in Lake Superior tributaries. Transactions of the American Fisheries Society. 119:470-474.

Welsh, S.A. and S. A. Perry. 1997. Acidification and fish occurrence in the upper Cheat River drainage, West Virginia. Journal of the American Water Resources Association. 33:423-429.

West Virginia DNR. 2001. Middle Fork River limestone treatment of acid mine drainage. Final Report.39p.

White, G.C., D. R. Anderson, K. P. Burnham, and D. L. Otis. 1982. Capture-recapture and removal methods for sampling closed populations. Los Alamos National Laboratory, Los Alamos, New Mexico. LA-8787-NERP. 
Table 1: County, location, geology, Stahler stream order, and the number of fish species present for each research stream organized by geologic type. Locations labeled MNF refer to sites located within the Monongahela National Forest and MWERF to sites located within the MeadWestvaco Experimental Research Forest.

\begin{tabular}{|c|c|c|c|c|c|}
\hline Geology & Stream & County & Location & $\begin{array}{c}\text { Strahler } \\
\text { order }\end{array}$ & $\begin{array}{c}\text { Fish species } \\
\text { present }\end{array}$ \\
\hline \multirow[t]{5}{*}{ Chemung } & "Block Run & Pocahontas & MNF & 1 & 2 \\
\hline & Club House & Pocahontas & MNF & 1 & 8 \\
\hline & Elleber Run & Pocahontas & MNF & 1 & 2 \\
\hline & Lick Run & Pocahontas & MNF & 1 & 5 \\
\hline & Poca & Pocahontas & MNF & 1 & 2 \\
\hline \multirow[t]{5}{*}{ Hampshire } & Big Run & Pendleton & MNF & 1 & 4 \\
\hline & Elklick & Tucker & MNF & 2 & 5 \\
\hline & Little Low & Pendleton & MNF & 1 & 2 \\
\hline & Seneca Creek & Pendleton & MNF & 1 & 4 \\
\hline & Whites Run & Pendleton & MNF & 2 & 7 \\
\hline \multirow[t]{5}{*}{ Mauch Chunk } & Brushy Run & Pendleton & MNF & 2 & 6 \\
\hline & Crooked Fork & Pocahontas & MNF & 2 & 7 \\
\hline & Long Run (Seneca) & Pendleton & MNF & 2 & 3 \\
\hline & Red Run & Tucker & MNF & 2 & 2 \\
\hline & Roaring Creek & Pendleton & MNF & 1 & 3 \\
\hline \multirow[t]{5}{*}{ Pottsville-limed } & Birch Fork & Randolph & MWERF & 1 & 2 \\
\hline & Long Run (MWERF) & Randolph & MWERF & 2 & 5 \\
\hline & Panther & Randolph & MWERF & 1 & 2 \\
\hline & Rocky Run & Randolph & MWERF & 2 & 7 \\
\hline & Schoolcraft & Randolph & MWERF & 2 & 3 \\
\hline \multirow[t]{5}{*}{ Pottsville-unlimed } & Light Run & Randolph & MWERF & 1 & 4 \\
\hline & Little Branch & Pocahontas & MNF & 1 & 5 \\
\hline & North Fork Panther & Randolph & MWERF & 1 & 2 \\
\hline & Sand/Red Run & Pocahontas & MNF & 1 & 8 \\
\hline & Sugar Drain & Randolph & MWERF & 1 & 2 \\
\hline
\end{tabular}


Table 2: Mean, number of observations, and standard deviation of brook trout lengths $(\mathrm{mm})$ across cohorts $0-4$ within each stream organized by geology.

\begin{tabular}{|c|c|c|c|c|c|c|c|c|c|c|c|c|c|c|c|c|}
\hline \multirow[b]{2}{*}{ Geology } & \multirow[b]{2}{*}{ Stream } & \multicolumn{3}{|c|}{ Age 0} & \multicolumn{3}{|c|}{ Age 1} & \multicolumn{3}{|c|}{ Age 2} & \multicolumn{3}{|c|}{ Age 3} & \multicolumn{3}{|c|}{ Age 4} \\
\hline & & Length & $\mathrm{N}$ & Stdev & Length & $\mathrm{N}$ & Stdev & Length & $\mathrm{N}$ & Stdev & Length & $\mathrm{N}$ & Stdev & Length & $\mathrm{N}$ & Stdev \\
\hline \multirow[t]{5}{*}{ Chemung } & Block Run & 59.9 & 60.0 & 5.9 & 113.8 & 71.0 & 13.5 & 161.9 & 27.0 & 10.1 & 210.0 & "6.0 & 26.8 & . & . & . \\
\hline & Club House & 56.5 & 28.0 & 5.0 & 106.2 & 67.0 & 16.7 & 162.1 & 8.0 & 21.8 & . & . & . & . & . & . \\
\hline & Elleber Run & 59.4 & 34.0 & 6.1 & 117.7 & 95.0 & 14.0 & 162.5 & 43.0 & 14.3 & 280.0 & 6.0 & 31.6 & . & . & . \\
\hline & Lick Run & 50.0 & 2.0 & 0.0 & 120.7 & 13.0 & 18.4 & 159.8 & 6.0 & 11.6 & 200.0 & 1.0 & . & . & . & . \\
\hline & Poca & 57.7 & 9.0 & 8.6 & 137.2 & 66.0 & 17.3 & 175.1 & 9.0 & 7.3 & $\cdot$ & $\cdot$ & . & . & . & . \\
\hline \multirow[t]{5}{*}{ Hampshie } & Big Run & 48.6 & 57.0 & 6.4 & 97.6 & 49.0 & 12.7 & 137.7 & 33.0 & 14.6 & 192.5 & 11.0 & 21.0 & 224.0 & 1.0 & \\
\hline & Elklick & 70.5 & 38.0 & 5.1 & 129.5 & 24.0 & 10.3 & 182.7 & 19.0 & 16.2 & 227.5 & 2.0 & 7.8 & . & . & . \\
\hline & Little Low & 59.5 & 26.0 & 8.1 & 114.5 & 155.0 & 11.6 & 162.8 & 2.0 & 20.0 & 240.0 & 1.0 & & . & . & . \\
\hline & Seneca Creek & 56.5 & 19.0 & 3.7 & 104.3 & 59.0 & 12.2 & 143.7 & 31.0 & 15.1 & 201.8 & 5.0 & 22.9 & . & . & . \\
\hline & Whites Run & 64.4 & 130.0 & 8.5 & 119.0 & 88.0 & 12.1 & 181.8 & 58.0 & 26.2 & 250.3 & 7.0 & 21.0 & 343.3 & 3.0 & 20.2 \\
\hline \multirow[t]{5}{*}{ Mauch Chunk } & Brushy Run & 71.9 & 235.0 & 7.9 & 147.1 & 122.0 & 19.3 & 251.0 & 2.0 & 22.6 & . & . & . & 294.0 & 1.0 & . \\
\hline & Crooked Fork & 68.3 & 3.0 & 6.4 & 128.3 & 50.0 & 13.5 & 167.0 & 3.0 & 3.6 & . & . & . & . & . & . \\
\hline & Long Run (Seneca) & 71.4 & 86.0 & 11.0 & 150.1 & 71.0 & 22.7 & 211.9 & 11.0 & 14.3 & 238.0 & 2.0 & 9.9 & . & . & . \\
\hline & Red Run & 52.3 & 12.0 & 5.6 & 122.4 & 51.0 & 13.5 & 177.9 & 44.0 & 15.5 & 211.5 & 6.0 & 13.3 & . & . & . \\
\hline & Roaring Creek & 64.8 & 60.0 & 5.6 & 125.5 & 99.0 & 12.1 & 184.3 & 39.0 & 15.0 & 215.0 & 4.0 & 22.1 & . & . & . \\
\hline \multirow[t]{5}{*}{ Pottsville-limed } & Birch Fork & 59.8 & 23.0 & 4.4 & 113.5 & 19.0 & 7.4 & 157.4 & 19.0 & 14.8 & 185.7 & 3.0 & 7.5 & . & . & . \\
\hline & Long Run (MWERF) & 70.0 & 5.0 & 7.1 & 127.3 & 17.0 & 14.7 & 197.8 & 8.0 & 17.6 & . & . & . & . & . & . \\
\hline & Panther & 66.9 & 30.0 & 5.7 & 122.8 & 12.0 & 12.5 & 174.0 & 14.0 & 13.5 & 273.0 & 1.0 & . & . & . & . \\
\hline & Rocky Run & 56.9 & 14.0 & 4.5 & 126.0 & 20.0 & 14.1 & 167.1 & 18.0 & 19.5 & 196.7 & 3.0 & 12.0 & . & . & . \\
\hline & Schoolcraft & 66.0 & 3.0 & 3.6 & 124.4 & 33.0 & 12.7 & 166.9 & 24.0 & 17.5 & . & . & . & . & . & . \\
\hline \multirow[t]{5}{*}{ Pottsville-unlimed } & Light Run & 62.7 & 7.0 & 4.2 & 110.7 & 31.0 & 11.6 & 164.7 & 6.0 & 18.4 & 193.5 & 6.0 & 20.0 & . & . & . \\
\hline & Little Branch & 64.0 & 17.0 & 4.0 & 106.8 & 69.0 & 13.5 & 155.0 & 6.0 & 19.3 & . & . & . & . & . & . \\
\hline & North Fork Panther & 56.5 & 2.0 & 2.1 & 127.0 & 9.0 & 12.2 & 159.4 & 12.0 & 12.8 & 198.0 & 1.0 & . & . & . & . \\
\hline & Sand/Red Run & 55.6 & 10.0 & 6.0 & 111.0 & 61.0 & 13.4 & 152.0 & 5.0 & 8.2 & 210.0 & 1.0 & . & . & . & . \\
\hline & Sugar Drain & 62.8 & 24.0 & 5.3 & 114.8 & 30.0 & 13.7 & 173.9 & 7.0 & 13.1 & . & 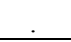 & . & . & . & . \\
\hline
\end{tabular}


Table 3: Mean $\mathrm{pH}$ and mean alkalinity with standard deviations for each study stream organized by geology.

\begin{tabular}{|c|c|c|c|c|c|c|}
\hline Geology & Stream & $\mathrm{N}$ & Mean $\mathrm{pH}$ & Stdev & $\begin{array}{l}\text { Mean Alkalinity } \\
\left(\mathrm{mg} \mathrm{CaCO}_{3}\right)\end{array}$ & Stdev \\
\hline \multirow{5}{*}{ Chemung } & "Block Run & 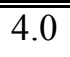 & 5.5 & 5.4 & 3.0 & 0.7 \\
\hline & Club House & 4.0 & 5.5 & 5.4 & 2.0 & 0.4 \\
\hline & Elleber Run & 4.0 & 5.8 & 5.6 & 3.4 & 0.6 \\
\hline & Lick Run & 4.0 & 5.9 & 5.7 & 4.7 & 1.7 \\
\hline & Poca & 4.0 & 5.5 & 5.4 & 2.4 & 0.5 \\
\hline \multirow[t]{5}{*}{ Hampshire } & Big Run & 4.0 & 5.8 & 5.7 & 4.6 & 1.3 \\
\hline & Elklick & 4.0 & 6.4 & 6.7 & 17.4 & 8.2 \\
\hline & Little Low & 4.0 & 6.0 & 5.9 & 5.4 & 2.2 \\
\hline & Seneca Creek & 4.0 & 5.7 & 5.5 & 6.4 & 2.6 \\
\hline & Whites Run & 4.0 & 6.7 & 6.7 & 22.3 & 11.0 \\
\hline \multirow[t]{5}{*}{ Mauch Chunk } & Brushy Run & 4.0 & 6.2 & 6.4 & 13.9 & 9.9 \\
\hline & Crooked Fork & 4.0 & 6.1 & 6.1 & 9.0 & 2.2 \\
\hline & Long Run (Seneca) & 4.0 & 6.2 & 6.4 & 3.9 & 1.0 \\
\hline & Red Run & 4.0 & 5.4 & 6.8 & 7.3 & 12.0 \\
\hline & Roaring Creek & 4.0 & 6.2 & 6.2 & 8.9 & 4.4 \\
\hline \multirow[t]{5}{*}{ Pottsville-limed } & Birch Fork & 4.0 & 6.2 & 6.2 & 8.5 & 3.3 \\
\hline & Long Run (MWERF) & 4.0 & 5.7 & 5.6 & 11.0 & 5.0 \\
\hline & Panther & 4.0 & 6.0 & 6.4 & 11.4 & 9.3 \\
\hline & Rocky Run & 4.0 & 5.2 & 5.0 & 1.5 & 0.6 \\
\hline & Schoolcraft & 4.0 & 5.8 & 6.4 & 8.3 & 6.3 \\
\hline \multirow[t]{5}{*}{ Pottsville-unlimed } & Light Run & 4.0 & 5.5 & 5.5 & 2.6 & 0.9 \\
\hline & Little Branch & 4.0 & 6.0 & 6.0 & 8.6 & 1.8 \\
\hline & North Fork Panther & 4.0 & 5.0 & 4.9 & 1.0 & 0.8 \\
\hline & Sand/Red Run & 4.0 & 5.3 & 5.0 & 1.8 & 0.6 \\
\hline & Sugar Drain & 4.0 & 6.1 & 6.0 & 7.9 & 1.9 \\
\hline
\end{tabular}


Table 4: Physical characteristics measured within each study stream organized by stream geology.

\begin{tabular}{|c|c|c|c|c|c|c|c|}
\hline Geology & Stream & $\begin{array}{c}\text { Mean elevation } \\
(\mathrm{m})\end{array}$ & Gradient & $\begin{array}{c}\text { Wet Width } \\
(\mathrm{m})\end{array}$ & $\begin{array}{l}\text { Subwatershed } \\
\text { area }\left(\mathrm{km}^{2}\right) \\
\end{array}$ & $\begin{array}{c}\text { Percent pool } \\
\text { habitat }\end{array}$ & $\begin{array}{c}\text { Percent riffle } \\
\text { habitat }\end{array}$ \\
\hline \multirow{5}{*}{ Chemung } & Block Run & 101030 & $\begin{array}{l}0.05 \\
\end{array}$ & 3 & 7.50 & $\begin{array}{l}0.12 \\
\end{array}$ & 0.86 \\
\hline & Club House & 950 & 0.04 & 2.9 & 8.22 & 0.17 & 0.81 \\
\hline & Elleber Run & 1147 & 0.05 & 3.2 & 5.99 & 0.05 & 0.94 \\
\hline & Lick Run & 997 & 0.05 & 2.1 & 2.57 & 0.09 & 0.89 \\
\hline & Poca & 1068 & 0.09 & 2.2 & 2.59 & 0.13 & 0.85 \\
\hline \multirow[t]{5}{*}{ Hampshire } & Big Run & 1155 & 0.04 & 2.5 & 3.83 & 0.40 & 0.53 \\
\hline & Elklick & 603 & 0.03 & 4.3 & 13.82 & 0.23 & 0.77 \\
\hline & Little Low & 973 & 0.06 & 2.8 & 5.37 & 0.12 & 0.88 \\
\hline & Seneca Creek & 1138 & 0.02 & 3.0 & 4.24 & 0.52 & 0.47 \\
\hline & Whites Run & 733 & 0.06 & 4.0 & 12.66 & 0.13 & 0.86 \\
\hline \multirow[t]{5}{*}{ Mauch Chunk } & Brushy Run & 716 & 0.06 & 3.4 & 18.82 & 0.14 & 0.84 \\
\hline & Crooked Fork & 1012 & 0.04 & 3.8 & 13.58 & 0.12 & 0.83 \\
\hline & Long Run (Seneca) & 701 & 0.03 & 4.0 & 13.55 & 0.21 & 0.76 \\
\hline & Red Run & 955 & 0.04 & 5.2 & 20.94 & 0.12 & 0.82 \\
\hline & Roaring Creek & 766 & 0.08 & 2.8 & 6.18 & 0.21 & 0.76 \\
\hline \multirow[t]{5}{*}{ Pottsville-limed } & Birch Fork & 872 & 0.03 & 2.5 & 5.78 & 0.24 & 0.72 \\
\hline & Long Run (MWERF) & 757 & 0.05 & 2.6 & 11.05 & 0.20 & 0.73 \\
\hline & Panther & 761 & 0.06 & 2.8 & 5.53 & 0.11 & 0.89 \\
\hline & Rocky Run & 821 & 0.04 & 3.8 & 9.15 & 0.15 & 0.84 \\
\hline & Schoolcraft & 742 & 0.03 & 3.1 & 8.34 & 0.26 & 0.74 \\
\hline \multirow[t]{5}{*}{ Pottsville-unlimed } & Light Run & 757 & 0.04 & 2.1 & 6.23 & 0.24 & 0.65 \\
\hline & Little Branch & 1073 & 0.07 & 1.7 & 2.00 & 0.13 & 0.83 \\
\hline & North Fork Panther & 770 & 0.05 & 2.1 & 3.59 & 0.16 & 0.83 \\
\hline & Sand/Red Run & 1065 & 0.05 & 3.2 & 4.02 & 0.13 & 0.86 \\
\hline & Sugar Drain & 872 & 0.08 & 2.2 & 1.78 & 0.16 & 0.82 \\
\hline
\end{tabular}


Table 5: Biological characteristics measured within each study stream organized by stream geology.

\begin{tabular}{|c|c|c|c|c|c|c|}
\hline Geology & Stream & $\begin{array}{l}\text { Brook trout } \\
\text { density }\left(\mathrm{m}^{2}\right)\end{array}$ & $\begin{array}{c}\text { Mean macroinvertebrate } \\
\text { density }\left(0.25 \mathrm{~m}^{2}\right)\end{array}$ & $\begin{array}{c}\text { Mean macroinvertebrate } \\
\text { richness }\end{array}$ & $\begin{array}{l}\text { Mean EPT } \\
\text { richness }\end{array}$ & $\begin{array}{c}\text { Mean macroinvertebrate } \\
\text { drymass }\left(\mathrm{g} / 0.25 \mathrm{~m}^{2}\right)\end{array}$ \\
\hline \multirow{5}{*}{ Chemung } & $\begin{array}{l}\text { Block Run } \\
\end{array}$ & 0.16 & 458.3 & (18.3 & 1011.0 & ( 0.27 \\
\hline & Club House & 0.11 & 453.3 & 23.0 & 11.3 & 0.19 \\
\hline & Elleber Run & 0.19 & 700.7 & 17.7 & 11.7 & 0.46 \\
\hline & Lick Run & 0.03 & 686.7 & 22.0 & 13.3 & 0.23 \\
\hline & Poca & 0.13 & 1154.0 & 22.3 & 13.0 & 0.51 \\
\hline \multirow[t]{5}{*}{ Hampshire } & Big Run & 0.20 & 380.0 & 20.0 & 11.7 & 0.12 \\
\hline & Elklick & 0.06 & 517.3 & 23.0 & 12.0 & 0.29 \\
\hline & Little Low & 0.29 & 1315.0 & 23.3 & 14.3 & 0.73 \\
\hline & Seneca Creek & 0.13 & 652.3 & 23.3 & 12.7 & 0.29 \\
\hline & Whites Run & 0.23 & 1072.0 & 21.7 & 12.7 & 0.60 \\
\hline \multirow[t]{5}{*}{ Mauch Chunk } & Brushy Run & 0.36 & 1894.3 & 20.3 & 13.3 & 0.41 \\
\hline & Crooked Fork & 0.02 & 311.3 & 17.7 & 12.0 & 0.13 \\
\hline & Long Run (Seneca) & 0.15 & 626.3 & 18.7 & 13.3 & 0.28 \\
\hline & Red Run & 0.07 & 60.0 & 10.7 & 7.7 & 0.03 \\
\hline & Roaring Creek & 0.24 & 428.3 & 16.3 & 12.0 & 0.18 \\
\hline \multirow[t]{5}{*}{ Pottsville-limed } & Birch Fork & 0.09 & 96.3 & 14.0 & 9.3 & 0.05 \\
\hline & Long Run (MWERF) & 0.03 & 92.7 & 15.0 & 9.3 & 0.03 \\
\hline & Panther & 0.07 & 159.0 & 17.3 & 9.7 & 0.03 \\
\hline & Rocky Run & 0.03 & 55.0 & 10.0 & 6.3 & 0.09 \\
\hline & Schoolcraft & 0.06 & 130.3 & 15.3 & 10.0 & 0.05 \\
\hline \multirow[t]{5}{*}{ Pottsville-unlimed } & Light Run & 0.05 & 158.7 & 18.3 & 12.0 & 0.05 \\
\hline & Little Branch & 0.18 & 499.0 & 20.7 & 12.0 & 0.21 \\
\hline & North Fork Panther & 0.02 & 91.7 & 14.7 & 8.0 & 0.02 \\
\hline & Sand/Red Run & 0.08 & 227.7 & 16.0 & 10.3 & 0.18 \\
\hline & Sugar Drain & 0.09 & 290.3 & 17.3 & 11.7 & 0.07 \\
\hline
\end{tabular}


Table 6: Pairs of correlated variables, Pearsons correlation coefficients, and the variable which was retained for regression analysis.

\begin{tabular}{lcc}
\hline Correlated variables & $\mathrm{r}$ & Variable retained \\
\hline \hline Mean $\mathrm{pH}$ and mean alkalinity & 0.86 & $\mathrm{Mean} \mathrm{pH}$ \\
Percent Pool habitat and percent riffle habitat & -0.97 & Percent pool habitat \\
Mean macroinvertebrate density and mean macroinvertebrate drymass & 0.85 & Mean macroinvertebrate density \\
Mean macroinvertebrate richness and mean EPT richness & 0.86 & Mean macroinvertebrate richness \\
\hline
\end{tabular}


Table 7: Sequential ANOVA results testing for differences in water quality, macroinvertebrate metrics, and brook trout growth rates among geologic types. Significance for these tests was set at a Bonferonni corrected alpha $=0.008$.

Variable F value

\begin{tabular}{lcc}
\hline \hline Mean $\mathrm{pH}$ & 1.77 & 0.175 \\
Mean macroinvertebrate density & 6.55 & 0.001 \\
Mean macroinvertebrate richness & 7.33 & $<0.001$ \\
Age 0 growth rate & 1.79 & 0.171 \\
Age 1 growth rate & 1.54 & 0.229 \\
Age 2 growth rate & 0.42 & 0.795 \\
\hline
\end{tabular}


Table 8: Results of post hoc Tukey tests testing for differences in $\mathrm{pH}$, macroinvertebrate richness and density, and brook trout growth rates by geologic types. Brook trout growth rates are expressed in units of instantaneous growth $(\mathrm{G})$ per year with the exception of the age 0 cohort where growth is expressed as instantaneous growth $(\mathrm{G})$ per 4 months. Significance of each test was set at alpha $=0.05$.

\begin{tabular}{|c|c|c|c|c|c|c|c|}
\hline Geology & $\mathrm{N}$ & Mean $\mathrm{pH}$ & $\begin{array}{l}\text { Mean macroinvertebrate } \\
\text { richness }\left(\operatorname{taxa} / 0.25 \mathrm{~m}^{2}\right)\end{array}$ & $\begin{array}{l}\text { Mean macroinvertebrate } \\
\text { density (number } / 0.25 \mathrm{~m}^{2} \text { ) }\end{array}$ & $\begin{array}{l}\text { Age } 0 \\
\text { growth }\end{array}$ & $\begin{array}{l}\text { Age } 1 \\
\text { growth }\end{array}$ & $\begin{array}{l}\text { Age } 2 \\
\text { growth }\end{array}$ \\
\hline Hampshire & 5 & $6.29^{\mathrm{A}}$ & $22.26^{\mathrm{A}}$ & $705.79^{\mathrm{A}}$ & $5.01^{\mathrm{A}}$ & $0.64^{\mathrm{A}}$ & $0.35^{\mathrm{A}}$ \\
\hline Chemung & 5 & $5.68^{\mathrm{A}}$ & $20.66^{\mathrm{A}, \mathrm{B}}$ & $645.05^{\mathrm{A}}$ & $4.83^{\mathrm{A}}$ & $0.74^{\mathrm{A}}$ & $0.32^{\mathrm{A}}$ \\
\hline Potsville-limed & 5 & $5.87^{\mathrm{A}}$ & $17.40^{\mathrm{A}, \mathrm{B}, \mathrm{C}}$ & $99.43^{\mathrm{B}}$ & $5.24^{\mathrm{A}}$ & $0.65^{\mathrm{A}}$ & $0.33^{\mathrm{A}}$ \\
\hline Mauch Chunk & 5 & $6.09^{\mathrm{A}}$ & $16.73^{\mathrm{B}, \mathrm{C}}$ & $391.26^{\mathrm{A}}$ & $5.36^{\mathrm{A}}$ & $0.72^{\mathrm{A}}$ & $0.38^{\mathrm{A}}$ \\
\hline Potsville-unlimed & 5 & $5.78^{\mathrm{A}}$ & $14.33^{\mathrm{C}}$ & $214.74^{\mathrm{A}, \mathrm{B}}$ & $5.06^{\mathrm{A}}$ & $0.63^{\mathrm{A}}$ & $0.34^{\mathrm{A}}$ \\
\hline
\end{tabular}

Note: Within a column, means with the same letter are not significantly different. 
Table 9: Results of simple linear regression testing for correlations between cohort specific brook trout growth rates and water quality, physical, and biological characteristics of 25 study streams.

\begin{tabular}{|c|c|c|c|c|c|c|}
\hline \multirow[b]{2}{*}{ Variable } & \multicolumn{2}{|c|}{ Age 0} & \multicolumn{2}{|c|}{ Age 1} & \multicolumn{2}{|c|}{ Age 2} \\
\hline & F value & $\mathrm{p}$ & F value & $\mathrm{p}$ & F value & $\mathrm{p}$ \\
\hline Mean $\mathrm{pH}$ & 13.42 & $0.001^{*}$ & 6.24 & $0.021^{*}$ & 3.89 & $0.060^{*}$ \\
\hline Mean elevation & 18.57 & $0.001^{*}$ & 0.42 & 0.525 & 2.61 & 0.119 \\
\hline Percent pool habitat & 0.19 & 0.667 & 1.51 & 0.232 & 0.00 & 0.981 \\
\hline Mean brook trout density & 0.23 & 0.638 & 0.57 & $0.459^{*}$ & 8.02 & $0.009^{*}$ \\
\hline Mean macroinvertebrate density & 0.25 & 0.622 & 0.00 & $0.994^{*}$ & 1.29 & 0.267 \\
\hline Mean macroinvertebrate richness & 0.01 & 0.910 & 0.71 & 0.408 & 0.40 & 0.530 \\
\hline Watershed area & 6.18 & $0.020^{*}$ & 0.02 & 0.879 & 3.57 & $0.071^{*}$ \\
\hline
\end{tabular}

Note: * designates variables which were included into SMLR analysis. 
Table 10: Stepwise multiple linear regression models depicting cohort specific brook trout rates as a function of water quality, and physical and biological stream conditions.

\begin{tabular}{|c|c|c|c|c|}
\hline Cohort & Model & $\mathrm{R}^{2}$ & F value & $\mathrm{p}$ \\
\hline 0 & $\mathrm{G}=0.394(\mathrm{pH})-1.150$ (elevation) +10.611 & 0.59 & 15.86 & $<0.001$ \\
\hline 1 & $\mathrm{G}=.001$ (Mean macroinvertebrate density) $-0.124(\mathrm{pH})-0.501$ (brook trout density) +1.393 & 0.37 & 4.26 & 0.017 \\
\hline 2 & $\mathrm{G}=0.302$ (brook trout density) -0.145 (elevation) +1.240 & 0.41 & 7.78 & 0.002 \\
\hline
\end{tabular}


Figure 1: Map showing the location of study stream watersheds. Streams not located within the Monongahela National Forest are located within the MeadWestvaco Experimental Research Forest.

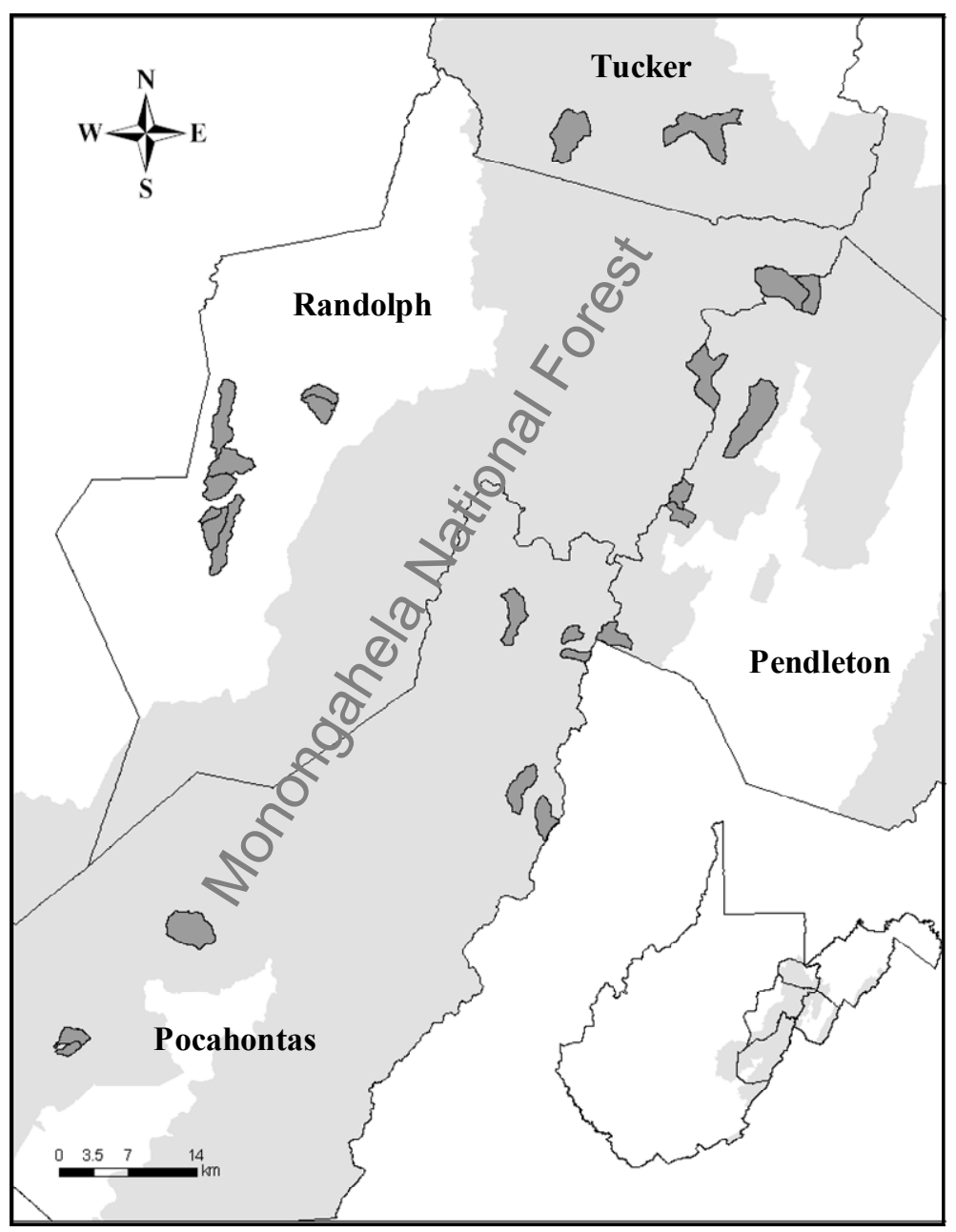


Chapter 4: Growth and condition of fluvial and resident individuals within partially migratory populations of brook trout.

\begin{abstract}
Evidence exists that within partially migratory salmonid populations, growth and condition of migratory individuals may be different than that of resident fish. These advantages are most often described within salmonid populations migrating between stream and ocean or lake environments. However, little evidence exists as to whether similar advantages are exhibited by salmonids migrating strictly within stream networks. We measured the growth and condition of fluvial and resident brook trout (Salvelinus fontinalis) within four Appalachian stream networks located in north central West Virginia. Populations were sampled during the summer due to the likelihood that fluvial and resident individuals become spatially segregated during this time. As these two lifehistory forms are morphologically similar, spatial segregation is crucial for the isolation and accurate measurement of each form. Brook trout residing within mainstem habitats during the summer were considered fluvial as spawning within these habitats does not occur. Resident fish were defined by the occupation of headwater habitats during the same period. Individuals were separated into age classes via scale analysis and differences in length, weight, and condition were investigated using T-tests. In most cases, age 1 and 2 fluvial brook trout held significant length, weight, and condition advantages over resident fish. Growth advantages became only marginal within age 3 and 4 cohorts and may be a result of angling mortality removing larger and faster growing individuals. Growth and condition advantages found within younger (age 1 and 2) fluvial individuals are likely a result of increased energy consumption within downstream positions. However, differences in fluvial maturation schedules may also play a role.
\end{abstract}

\title{
Introduction
}

Headwater stream dwelling salmonids have shown flexibility in expression of life history form (Power 1980, Kennedy et al. 2003). The term partial migration describes the phenomenon of a population which contains both migratory and resident individuals. Migration may arise within a population in response to spatial segregation of critical 
feeding, refuge, and reproductive habitats (Northcote 1997). Individuals exhibiting these types of movements within a stream-river network are termed fluvial. However, partially migratory populations are not limited to movement simply within stream-river networks, as anadromous and lacustrine fluvial populations are common (Jonsson and Jonsson 1993, Northcote 1997). In an attempt to maximize lifetime fitness, fluvial fish move amongst critical habitats in completion of annual life cycles (Power 1980). Resident individuals on the other hand remain sedentary and fulfill annual lifecycles within local environments.

Within partially migratory anadromous and lacustrine fluvial salmonid populations, migratory individuals have been shown to be larger at age than individuals of the general population (Craig 1978, Naslund et al. 1993, Morita and Takashima 1998). Growth advantages in these instances are generally attributed to the productive advantages and presence of larger prey organisms within ocean and lake environments (Keeley and Grant 2001). Within populations of stream-dwelling salmonids which exhibit mobility, those that moved have been found to be of greater size, but reduced condition at age relative to the general population (Gowan and Fausch 1995, Hilderbrand and Kershner 2004, Mogen and Kaeding 2005). Within these studies, weirs are utilized to capture and thus identify mobile individuals. Movement within streams may arise due to spatial separation of critical habitats (fluvial individuals), but also in response to inferior competitive ability (Jenkins 1969, Nakano 1995) or the search for more energetically profitable positions (Gowan and Fausch 1995). The latter individuals move, but do so in response to competitive or energetic deficiencies and may not be fluvial. As weirs are unable to separate fluvial fish from other mobile individuals, observed trends in growth and condition may not reflect a fluvial life-history.

Within Appalachia, evidence suggests that partially migratory populations of brook trout (Salvelinus fontinalis) may be present (Petty et al. 2005). These individuals reside within mainstem habitats during the summer and migrate up tributaries in the fall to spawn (Power 1980, Northcote 1997). Currently it is uncertain if fluvial fish benefit from increased growth at age compared to their resident counterparts as has been shown in other partially migratory populations (Craig 1978, Naslund et al. 1993, Morita and Takashima 1998). Our objectives were to determine if fluvial Appalachian brook trout 
experience length, weight or condition advantages at age in comparison to resident fish. We hypothesize $\left(h_{0}\right)$ there will be no difference between cohort specific growth and condition of resident and fluvial individuals.

\section{Methods}

Site description - This study was conducted within headwater tributaries and mainstem habitats of four West Virginia stream networks (Table 1). Sites were chosen on the basis of accessibility, however each contained naturally reproducing populations of brook trout and was devoid of barriers to fish movement such as dams or hanging culverts. Additionally, mainstem sites were selected to ensure that brook trout residing within them were in-fact migratory. Sites were chosen with strong currents and large substrates which negated the creation of fine gravel beds and local spawning. Individuals residing within these habitats during the summer are thus required to travel to adjacent habitats such as the head waters of tributaries in order to fulfill annual reproductive cycles. As migration is required, these individuals are considered fluvial for the purposes of this research. Similarly, individuals residing within headwater habitats during the summer are considered resident. These fish, by neglecting to take advantage of potentially more profitable down stream positions are likely sedentary.

Watershed land cover was dominated by secondary growth mixed deciduous hard wood forest. Watersheds were not actively logged with the exception of the Rocky Run stream network which is located within the MeadWestvaco Experimental Research Forest and is actively managed for wood fiber. Additionally, the West Virginia Division of Natural Resources (WVDNR) and the West Virginia Division of Environmental Protection have added limestone sand to the riparian areas of Birch Fork and Upper Rocky Run located within the Rocky Run stream network (WVDNR 2001). The addition of limestone sand is a common practice to remediate the effects of acid precipitation and acid mine drainage in this region. The procedure has shown to increase stream $\mathrm{pH}$, restore fish communities, and increase invertebrate abundance (Clayton et al. 1998). Light Run and Sugar Drain, also located within the Rocky Run stream network were not treated with limestone sand. These sites however retained the ability to support naturally 
reproducing brook trout populations and thus fulfilled necessary criteria and were included within this study.

Fish diversity varied across sites but was typical of Appalachian streams with diversity increasing with stream size. Headwater tributary fauna was typically dominated by brook trout and mottled sculpin (Cottus bairdii). Other fish sampled include white sucker (Catostomus commersoni), fantail darter (Etheostoma flabellare), northern hogsucker (Hypentelium nigricans), rainbow trout (Oncorhynchus mykiss), longnose dace (Rhinichthys cataractae), western blacknose dace (Rhinichthys obtusis), brown trout (Salmo trutta), creek chub (Semotilus atromaculatus).

Fish Sampling -Brook trout were sampled during July of 2006 from three representative $100 \mathrm{~m}$ sections (up, mid, and low) within each tributary. Three sampling sections were utilized in order to obtain density estimates. Estimates of headwater density are desirable as lotic salmonids may experience density dependant growth during the summer (Utz and Hartman 2006). As density may influence growth, it was measured so that its influence could be discerned. Brook trout were sampled during the summer because of the likelihood that fluvial and resident individuals were spatially segregated during this time (Power 1980, Petty et al. 2005). Furthermore, brook trout growth is near zero during the summer (Utz 2005). Reduced growth was desired to reduce variation in growth over time as all sites could not be sampled simultaneously. Experimental sections were bounded at both upstream and downstream ends with block nets to meet the assumption of a closed population. Fish were sampled via a pulsed DC backpack electrofishing unit and a standard three pass technique. All individuals were immobilized in a $120 \mathrm{mg} \cdot \mathrm{L}^{-1}$ solution of clove oil and ethanol (Anderson et al. 1997), weighed to the nearest gram using a spring scale, measured to the nearest $\mathrm{mm}$ total length, and sampled for scales (DeVries and Frie 1996). Scale samples were placed in individually labeled scale envelopes for later examination. Individuals were allowed to recover fully within an instream holding bin before being released close to the point of capture.

Mainstem sites were sampled differently. Capture probabilities of backpack electrofishing units have been found to decrease with stream wetted width (Thompson and Rahel 1996). As population estimates within mainstem habitats using this capture 
methodology would be unreliable, a single pass technique within unbounded sections was utilized. Mainstem sections were sampled until roughly 50 individuals were captured or until reasonable effort failed to increase sample sizes. Fish were processed by previously described methods. In the laboratory, brook trout scales $(n=20-30)$ were wet mounted on glass slides and viewed under a microscope at 45X. Annuli were identified and counted following DeVries and Frie (1996).

Statistical analysis -- All statistical analyses were completed using the SAS 8.3 statistical software package (SAS Institute 1999). Relative condition $\left(\mathrm{K}_{n}\right)$ was calculated for individuals within each stream as:

$$
\mathrm{K}_{\mathrm{n}}=\left(\mathrm{W} / \mathrm{W}^{\prime}\right)
$$

Where $\mathrm{W}$ is the weight of an individual in grams and $\mathrm{W}^{\prime}$ is the length-specific mean weight of a fish in that population (Anderson and Newman 1996). Within headwater sites, length, weight, and condition data were lumped by respective stream network. Cohort specific differences in length, weight, and relative condition between headwater and mainstem habitats were investigated using T-tests at an alpha of 0.05 . Headwater population estimates for each experimental section were computed using the depletion process of Zippin in the program CAPTURE (White et al. 1992). If less than 30 fish were captured, then the actual number of fish caught was substituted for an estimate (Riley and Fausch 1992). Section population estimates were averaged to obtain a mean population estimate for each stream. Fish density was then calculated as the mean population estimate divided by the mean wetted area $\left(\mathrm{m}^{2}\right)$ of the three experimental sites, at base flow. The calculation of density estimates within mainstem habitats was not possible due to the use of one backpack electrofishing unit and evidence of low capture efficiency under these conditions (Thompson and Rahel 1996). To determine the influence of density on headwater fish growth, mean length at age was regressed against mean density estimates of each stream. Regressions were considered significant at an alpha of 0.05 . 


\section{Results}

A total of 201 fluvial and 1,209 resident brook trout encompassing ages 0 through age 4 were sampled across four stream networks (Table 2). In most cases, fluvial brook trout held length and weight advantages over resident individuals across age classes (Table 3). However, not all relationships were significant. Significant length, weight, and condition advantages tended to be held by fluvial individuals within age 1 and 2 cohorts. Trends in condition across cohorts were generally not consistent and are likely a function of small sample size and weak length-weight relationships. Fluvial growth and condition advantages tended to become marginal among age 2 and 3 fish within the Rocky Run stream network and among age 3 and 4 fish in the other stream networks. The convergence of fluvial and resident length estimates within older fish may indicate the presence of substantial fishing pressure. Age 0 mainstem individuals only experienced length and weight advantages within the Seneca Creek stream network. However, sample size of mainstem individuals was low, especially within the age 0,3 and 4 cohorts (Table 2) likely limiting the statistical power of analysis within these cohorts.

Simple linear regressions of mean headwater densities and mean growth estimates across cohorts 0 through 2 indicate no detectable relationship between brook trout growth and density across all headwater sites (Figure 1). Regression analysis was not completed within cohorts 3 and 4 due to small sample size (Table 2). Among headwater sites within each stream network, relationships between brook trout growth and brook trout density are equally as vague. Within the North Fork and Seneca Creek stream networks, growth and density relationships are difficult to interpret as each network contains only two data points. Furthermore, with only one headwater site within the Laurel Fork stream network, growth and density relationships can only be interpreted in the presence of alternate sites.

\section{Discussion}

Within the Appalachian stream networks included in this study, growth (length and weight) of fluvial individuals tended to be greater than that of resident fish. These results are consistent with research involving anadromous (Craig 1978, Morita and 
Takashima 1998) and lacustrine fluvial populations of char (Naslund et al. 1993). Within the latter studies, growth advantages are attributed to the presence of more energetically profitable forage and the general productive advantages within larger water (Naslund et al. 1993, Keeley and Grant 2001). This may also be the case within Appalachian stream networks. Utz and Hartman (2006) noted that brook trout occupying larger, downstream positions, benefited from increased energy consumption relative to individuals located upstream. Although this could not be attributed to increases in food abundance, stream productivity and benthic macroinvertebrate density and biomass likely increase downstream (Vannote et al. 1980, Bopp 2002) potentially resulting in increased growth.

Increased energy consumption may also be facilitated by the ingestion of prey with greater energetic value. While downstream shifts in macroinvertebrate communities may play a role (Minshall et al.1982), substantial energy supplements are likely provided by the ingestion of forage fish. In downstream areas, Utz and Hartman (2006) noted greater incidents of piscivory in relation to headwater areas within Appalachian brook trout populations. As fish typically provide more energy than invertebrate prey, shifts to piscivory may result in increased growth (Jonsson et al. 1999, Keeley and Grant 2001). Furthermore, size at age advantages within downstream locations may allow fluvial individuals to overcome gape limitations in less time and switch to a piscivorous feeding strategy earlier in life.

Increased growth of fluvial individuals may also be a result of differences in fish density between mainstem and headwater sites. Lotic salmonids have been shown to establish size based dominance hierarchies in response to limited food or space, restricting resource allotment (Fausch 1984, Elliot 1990). Within Appalachia, summer food limitation may promote dominance hierarchies and thus limit growth (Cada et al 1987). In these instances, reduced density may enable increased energy acquisition and growth, due to decreases in territory defense and associated energy allocation to this task (Nakano 1995). While mainstem densities were not measured in this study, evidence suggests that densities may be low (Thorne 2004) potentially allowing for increased growth. Within headwater sites, growth and density were not found to be correlated. This is unexpected as previous work has documented density relationships during this time (Utz and Hartman 2006). The lack of finding may be related to the use of mean size 
at age estimates instead of seasonal measures of growth. The majority of brook trout growth occurs during spring when food is abundant (Cada et al. 1987, Utz 2005). Under these conditions, territory size may shrink, allowing a greater number of individuals access to resources (Grant et al. 1998). However, as food becomes sparse, density dependent relationships may form (Utz and Hartman 2006). Mean size at age may then be poor at detecting density relationships as it may largely be determined by spring growth under density independent feeding conditions. Furthermore, at the time of sampling dominance hierarchies may already have been in place and resulted in the emigration of inferior competitors, therefore altering density estimates. While not evidenced in this research, it is likely that fish within headwater sites experience density dependent mechanisms during parts of the year (Jenkins 1999, Utz and Hartman 2006). At these times, reduced density may result in greater growth potential.

Alternatively, differences in fluvial maturation schedules may have also contributed to growth advantages (Jonsson and Jonsson 1993). The onset of maturity usually occurs near asymptotic body size which is largely regulated by local food supply and individual ration (Forseth et al 1994). Unlike being sedentary, mobility allows access to food items of adjacent or more distant habitats enabling fluvial individuals to maintain growth trajectories and avoid growth stagnation. As asymptotic body size is not reached, maturation may be delayed (Jonsson and Jonsson 1993). Immature fluvial individuals obtain greater body size in relation to their resident counterpart during this additional time as a juvenile. Energy normally devoted to gamete production is channeled to somatic growth resulting in greater fluvial body size and possibly condition (Wooton 1998). This phenomenon is most often observed with partially migratory anadromous and lacustrine populations moving into more productive ocean and lake environments (Jonsson et al. 1989, Jonsson et al. 1990). Within Appalachian systems however it is uncertain as to whether downstream consumption advantages are sufficient to allow individuals to avoid growth stagnation and thus maturity.

Evidence of low mainstem densities in relation to headwater sites suggests that the occupation of downstream positions, while energetically profitable, may also result in greater mortality (Northcote 1997). Increased mortality may be a result of the greater likelihood of temperature extremes and predation within mainstem habitats or it may be 
related to the energetic requirements of migration (Jonsson and Jonsson 1993). Predation may result from piscivory, as this feeding strategy may be more frequent in downstream sites (Utz 2005), or may be a result of angling. Within Appalachia, angling may be a substantial source of mortality which can potentially alter the structure of populations (Webster 2004). While not measured within this study, anglers have been frequently observed within study streams (Jason Stolarski, personal observation). Evidence of similar fluvial and resident growth within older cohorts (age $>2$ ) suggests that angling mortality may be responsible for the convergence in growth rates in older fish.

By removing the largest and fastest growing individuals from a population, angling acts to depress mean size at age estimates (Anderson and Nehring 1984). The onset of cohort growth estimate reductions will be a function of the size at which anglers harvest trout. Within Appalachian, Webster (2004) found that anglers on average kept native brook trout that were $180 \mathrm{~mm}$ long. The results of this study confer with Webster (2004) as fluvial and resident growth estimates tended to converge within individuals of approximately $200 \mathrm{~mm}$ in length. These results suggest that angling may be depressing the size structure of older individuals within Appalachian populations.

The finding of greater size at age within fluvial populations of Appalachian brook trout highlights the importance of mainstem habitats within stream networks. Individuals occupying these sites likely consume more energy and thus have greater growth potential. Individuals of greater size at age may experience increases in fecundity (Roff 1984). Larger, more fecund fluvial individuals will likely increase headwater spawning effort. Fluvial spawning effort is of particular importance after periods of drought or flood which may be common within Appalachian systems. These events can alter the structure of headwater populations and may reduce resident spawning effort in subsequent years (Carline and McCullough 2003, Hakala and Hartman 2004). By supplementing spawning effort in these instances, fluvial brook trout may contribute to the persistence of populations. Population persistence is of increased concern due to recent research documenting reductions in brook trout range and abundance (Marschall and Crowder 1996).

The potential importance of fluvial brook trout to the persistence of populations highlights the need for conservation of this life-history form. The importance of tributary 
as well as mainstem habitats should be considered in future management decisions.

While tributary streams represent important spawning habitats, mainstem areas likely provide better feeding conditions. However, angling and barriers to movement such as acid mine drainage or hanging culverts may prohibit the utilization of these habitats resulting in reduced growth potential. 


\section{Reference List}

Anderson, G.W., S. R. Mckinley, and M. Colavecchia. 1997. The use of clove oil as an anesthetic for rainbow trout and its effects on swimming performance. Transactions of the American Fisheries Society. 17:301-307.

Anderson, R.M. and R. B. Nehing. 1984. Effects of a catch-and-release regulation on a wild trout population in Colorado and its acceptance by anglers. North American Journal of Fisheries Management. 4:257-265.

Anderson, R.O. and R. M. Neumann. 1996. Length, weight, and associated structural indices. Pages 447-482 in B.R. Murphy and D.W. Willis, editors. Fisheries Techniques, 2nd edition. American Fisheries Society, Bethesda, Maryland.

Bopp, J.A. 2002. Combined effects of water chemistry, canopy cover, and stream size on benthic macroinvertebrates along a Central Appalachian stream continuum. Masters Thesis, West Virginia University, Morgantown.

Cada, G.F., J. M. Loar, and D. K. Cox. 1987. Food and feeding preferences of rainbow and brown trout in southern Appalachian streams. American Midland Naturalist. 117:374-385.

Carline, R.F. and B. J. McCullough. 2003. Effects of floods on brook trout populations in the Monongahela National Forest, West Virginia. Transactions of the American Fisheries Society. 132:1014-1020.

Clayton, J.L., E. S. Dannaway, R. Menendez, H. W. Rauch, J. J. Renton, S. M. Sherlock, and P. E. Zurbuch. 1998. Application of limestone to restore fish communities in acidified streams. North American Journal of Fisheries Management. 18:347-360.

Craig, P.C. 1978. Movements of stream-resident and anadromous Arctic char (Salvelinus alpinus) in a perennial spring on the Canning River, Alaska. Journal of the Fisheries Research Board of Canada. 35:48-52.

Devries, D.R. and R. V. Frie. 1996. Determination of age and growth. Pages 483 -508 in B.R. Murphy and D.W. Willis, editors. Fisheries techniques, $2^{\text {nd }}$ edition. American Fisheries Society, Bethesda Maryland.

Elliot, J.M. 1990. Mechanisms responsible for population regulation in young migratory trout, Salmo trutta. III. the role of territorial behaviour. The Journal of Animal Ecology. 59:803-818.

Fausch, K.D. 1984. Profitable stream positions for salmonids: relating specific growth rate to net energy gain. Canadian Journal of Zoology. 62:441-451.

Forseth, T., O. Ugedal, and B. Jonsson. 1994. The energy budget, niche shift, 
reproduction and growth in a population of Arctic charr, Salvelinus alpinus. Journal of Animal Ecology. 63:116-126.

Gowan, C. and K. D. Fausch. 1995. Mobile brook trout in two high elevation Colorado streams: re-evaluating the concept of restricted movement. Canadian Journal of Fisheries and Aquatic Sciences. 53:1370-1381.

Grant, J.W.A., S. O. Steingrimsson, E. R. Keeley, and R. A. Cunjak. 1998. Implications of territory size for the measurement and prediction of salmonid abundance in streams. Canadian Journal of Fisheres and Aquatic Sciences. 55(Suppl. 1):181190.

Hakala, J.P. and K. J. Hartman. 2004. Drought effect on stream morphology and brook trout (Salvelinus fontinalis) populations in forested headwater streams. Hydrobiologia. 515:202-213.

Hilderbrand, R.H. and J. L. Kershner. 2004. Are there differences in growth and condition between mobile and resident cutthroat trout? Transactions of the American Fisheries Society. 133:1042-1046.

Jenkins, T.M. 1969. Social structure, position choice and micro-distribution of two trout species (Salmo trutta and Salmo gairdneri) resident in mountain streams. Animal Behavior Monographs. 2:56-123.

Jenkins, T.M., S. Diehl, K. W. Kratz, and S. C. Cooper. 1999. Effects of population density on individual growth of brown trout in streams. Ecology. 80:941-956.

Jonsson, B. and N. Jonsson. 1993. Partial migration: niche shift versus sexual maturation in fishes. Reviews in Fish Biology and Fisheries. 3:348-365.

Jonsson, B., N. Jonsson, and J. Ruud-Hansen. 1989. Downstream displacement and life history variables of Arctic charr (Salvelinus alpinus) in a Norwegian river. Physiological Ecology Japan, Special Volume. 1: 93-105.

Johnston, T. A. and R. A. Cunjak. 1999. Dry mass-length relationships for benthic insects: a review with new data from Catamaran Brook, New Brunswick, Canada. Freshwater Biology 41: 653-674.

Jonsson, N., B. Jonsson, and L. P. Hansen. 1990. Partial segregation in the timing of migration of Atlantic salmon of different ages . Animal Behavior. 40:313-321.

Keeley, E.R. and J. Grant. 2001. Prey size of salmonid fishes in streams, lakes, and oceans. Canadian Journal of Fisheries and Aquatic Sciences. 58:1122-1132.

Kennedy, B.M., D. P. Peterson, and K. D. Fausch. 2003. Different life histories of brook trout populations invading mid-elevation and high-elevation cutthroat trout streams in Colorado. Western North American Naturalist. 63:215-223. 
Marschall, E.A. and L. B. Crowder. 1996. Assessing population responses to multiple anthropogenic effects: a case study with brook trout. Ecological Applications. 6:152-167.

Minshall, W.G., R. C. Petersen, and C. F. Nimz. 1985. Species richness in streams of different size from the same drainage basin. The American Naturalist. 125: 16-38

Mogen, J.T. and L. R. Kaeding. 2005. Identification and characterization of migratory and non-migratory bull trout populations in the St. Mary River drainage, Montana. Transactions of the American Fisheries Society. 134:841-852.

Morita, K. and Y. Takashima. 1998. Effect of female size on fecundity and egg size in white-spotted charr: comparison between sea-run and resident forms. Journal of Fish Biology. 53:1140-1142.

Nakano, S. 1995. Individual differences in resource use, growth, and emigration under the influence of a dominance hierarchy in fluvial red-spotted masu salmon in a natural habitat. Journal of Animal Ecology. 64:75-84.

Naslund, I., G. Milbrink, O. Eriksson, and S. Holmgren. 1993. Importance of habitat productivity differences, competition, and predation for the migratory behavior of Arctic char. Oikos. 66:38-546.

Northcote, T.G. 1997. Potamodromy in salmonidae--living and moving in the fast lane. North American Journal of Fisheries Management. 17:1029-1045.

Petty, T.J., P. J. Lamothe, and P. M. Mazik. 2005. Spatial and seasonal dynamics of brook trout populations inhabiting a Central Appalachian Watershed. Transactions of the American Fisheries Society. 134:572-587.

Power, G. 1980. Charrs; salmonid fishes of the genius Salvelinus. The Hauge, The Netherlands.141-201.

Riley, S.C. and K. D. Fausch. 1992. Underestimation of trout population size by maximum-likelihood removal estimates in small streams. North American Journal of Fisheries Management. 12:768-776.

Roff, D.A. 1984. The evolution of life history parameters in teleosts. Canadian Journal of Fisheries and Aquatic Sciences. 41:989-1000.

Thompson, P.D. and F. J. Rahel. 1996. Evaluation of depletion-removal electrofishing of brook trout in small rocky mountain streams. North American Journal of Fisheries Management. 16: 332-339.

Thorne, D. 2004. Spatial and seasonal variation in brook trout diet, growth, and 
consumption in a complex Appalachian watershed. Masters thesis, West Virginia University, Morgantown.

Utz, R.M. 2005. Temporal trends in consumption, growth, and successful feeding traits of a central Appalachian brook trout population at the watershed scale. Masters Thesis, West Virginia University, Morgantown.

Utz, R.M. and K. J. Hartman. 2006. Temporal and spatial variation in the energy intake of a brook trout (Salvelinus fontinalis) population in an Appalachian watershed. Canadian Journal of Fisheries and Aquatic Sciences. 63:2675-2686.

Vannote, R.L., W. G. Minshall, K. W. Cummins, J. R. Sedell, and C. E. Cushing. 1980. The river continuum concept. Canadian Journal of Fisheries and Aquatic Sciences. 37:130-137.

Webster, J.J. 2004. Reasons for overwinter declines in age-1+ brook trout populations (Salvelinus fontinalis) in Appalachian headwater streams. Masters Thesis, Morgantown.82pp.

West Virginia DNR. 2001. Middle Fork River limestone treatment of acid mine drainage. Final Report.39p.

White, G.C., D. R. Anderson, K. P. Burnham, and D. L. Otis. 1982. Capture-recapture and removal methods for sampling closed populations. Los Alamos National Laboratory, Los Alamos, New Mexico. LA-8787-NERP.

Wooton, R.J. 1998. Ecology of teleost fishes. Kluwer Academic Publishers, Dordrecht, The Netherlands. 
Table 1: Stream order, county, basin area, and the number of fish species observed for headwater and mainstem sites within each stream network. Numbers in parenthesis by each stream network are 10 digit hydrologic unit codes.

\begin{tabular}{|c|c|c|c|c|c|c|}
\hline Stream Network & Stream & Description & $\begin{array}{c}\text { Strahler } \\
\text { Order } \\
\end{array}$ & County & $\begin{array}{c}\text { Basin Area } \\
\left(\mathrm{km}^{2}\right) \\
\end{array}$ & $\begin{array}{c}\text { Observed } \\
\text { fish species }\end{array}$ \\
\hline \multirow[t]{3}{*}{ North Fork (0505000301) } & North Fork & Mainstem & 3 & Pocahontas & 28.84 & 6 \\
\hline & Block Run & Tributary & 1 & Pocahontas & 7.49 & 2 \\
\hline & Elleber Run & Tributary & 1 & Pocahontas & 5.99 & 2 \\
\hline \multirow[t]{5}{*}{ Rocky Run (0502000102) } & Lower Rocky Run & Mainstem & 3 & Randolph & 27.79 & 5 \\
\hline & Birch Fork & Tributary & 1 & Randolph & 5.77 & 2 \\
\hline & Light Run & Tributary & 1 & Randolph & 6.22 & 3 \\
\hline & Sugar Drain & Tributary & 1 & Randolph & 1.78 & 1 \\
\hline & Upper Rocky Run & Tributary & 1 & Randolph & 9.15 & 4 \\
\hline \multirow[t]{3}{*}{ Seneca Creek (0207000101) } & Lower Seneca Creek & Mainstem & 3 & Pendleton & 61.66 & 10 \\
\hline & Whites Run & Tributary & 2 & Pendleton & 12.66 & 7 \\
\hline & Upper Seneca Creek & Tributary & 1 & Pendleton & 4.23 & 4 \\
\hline \multirow[t]{2}{*}{ Laurel Fork (0207000101) } & Laurel Fork & Mainstem & 3 & Pendleton & 83.82 & 8 \\
\hline & Little Low Place & Tributary & 1 & Pendleton & 5.37 & 1 \\
\hline
\end{tabular}


Table 2: Cohort specific sample size of mainstem and tributary sites within each stream network.

\begin{tabular}{lccccccc}
\hline Stream Network & Site & Age 0 & Age 1 & Age 2 & Age 3 & Age 4 & Total \\
\hline \hline North Fork & Mainstem & 7 & 29 & 15 & 5 & 0 & 56 \\
& Tributary & 93 & 167 & 70 & 12 & 0 & 342 \\
& & & & & & & \\
\multirow{3}{*}{ Rocky Run } & Mainstem & 3 & 20 & 8 & 5 & 0 & 36 \\
& Tributary & 68 & 101 & 49 & 12 & 0 & 230 \\
& & & & & & & \\
Seneca Creek & Mainstem & 11 & 29 & 15 & 3 & 3 & 61 \\
& Tributary & 149 & 147 & 89 & 12 & 3 & 400 \\
& & & & & & & \\
Laurel Fork & Mainstem & 2 & 37 & 9 & 0 & 0 & 48 \\
& Tributary & 24 & 157 & 56 & 0 & 0 & 237 \\
\hline
\end{tabular}


Table 3: T-test results testing for differences in mean length, weight, and condition between mainstem and tributary sites within each stream network.

\begin{tabular}{|c|c|c|c|c|c|c|c|c|c|c|c|}
\hline \multirow[b]{2}{*}{ Site } & \multicolumn{5}{|c|}{ Mean } & \multirow{2}{*}{$\begin{array}{c}\text { Mean } \\
\text { Weight }\end{array}$} & \multicolumn{5}{|c|}{ Mean } \\
\hline & Age & Section & Length & $\mathrm{t}$ value & $\mathrm{p}$ & & $\mathrm{t}$ value & $\mathrm{p}$ value & condition & t value & $\mathrm{p}$ \\
\hline \multirow[t]{8}{*}{ North Fk. } & 0 & Mainstem & 61 & 0.34 & 0.733 & 3 & 1.62 & 0.109 & 1.78 & 2.39 & 0.019 \\
\hline & & Tributary & 60 & & & 2 & & & 1.47 & & \\
\hline & 1 & Mainstem & 128 & 3.93 & $<0.001$ & 21 & 3.18 & 0.002 & 1.42 & -0.42 & 0.579 \\
\hline & & Tributary & 116 & & & 16 & & & 1.44 & & \\
\hline & 2 & Mainstem & 209 & 10.55 & $<0.001$ & 97 & 9.96 & $<0.001$ & 1.61 & 3.9 & $<0.001$ \\
\hline & & Tributary & 162 & & & 42 & & & 1.45 & & \\
\hline & 3 & Mainstem & 242 & -0.15 & 0.884 & 149 & -0.01 & 0.995 & 1.63 & 2.69 & 0.017 \\
\hline & & Tributary & 245 & & & 149 & & & 1.45 & & \\
\hline \multirow[t]{8}{*}{ Rocky Run } & 0 & Mainstem & 63 & 0.12 & 0.901 & 3 & -0.16 & 0.871 & 1.05 & -0.22 & 0.826 \\
\hline & & Tributary & 62 & & & 3 & & & 1.08 & & \\
\hline & 1 & Mainstem & 129 & 3.65 & $<0.001$ & 20 & 3.41 & $<0.001$ & 0.965 & -0.49 & 0.628 \\
\hline & & Tributary & 115 & & & 15 & & & 0.98 & & \\
\hline & 2 & Mainstem & 164 & -0.08 & 0.939 & 42 & -0.67 & 0.508 & 0.981 & -2.93 & 0.005 \\
\hline & & Tributary & 164 & & & 45 & & & 1.1 & & \\
\hline & 3 & Mainstem & 198 & 0.71 & 0.488 & 75 & 0.51 & 0.617 & 1.01 & -0.96 & 0.352 \\
\hline & & Tributary & 192 & & & 70 & & & 1.28 & & \\
\hline \multirow[t]{10}{*}{ Seneca Creek } & 0 & Mainstem & 72 & 3.25 & 0.001 & 4 & 2.43 & 0.016 & 1.35 & 1.75 & 0.082 \\
\hline & & Tributary & 63 & & & 3 & & & 1.04 & & \\
\hline & 1 & Mainstem & 135 & 7.81 & $<0.001$ & 22 & 6.76 & $<0.001$ & 1.18 & 13.04 & $<0.001$ \\
\hline & & Tributary & 113 & & & 14 & & & 0.88 & & \\
\hline & 2 & Mainstem & 212 & 5.13 & $<0.001$ & 100 & 5.73 & $<0.001$ & 1.32 & 10.1 & $<0.001$ \\
\hline & & Tributary & 169 & & & 45 & & & 1.01 & & \\
\hline & 3 & Mainstem & 259 & 1.48 & 0.162 & 184 & 2.09 & 0.06 & 1.5 & 4.2 & 0.001 \\
\hline & & Tributary & 230 & & & 129 & & & 1.18 & & \\
\hline & 4 & Mainstem & 344 & 0.01 & 0.99 & 327 & 1.87 & 0.136 & 1.17 & 1.31 & 0.261 \\
\hline & & Tributary & 343 & & & 286 & & & 0.904 & & \\
\hline \multirow[t]{6}{*}{ Laurel Fork } & 0 & Mainstem & 65 & 0.85 & 0.402 & 4 & 1.82 & 0.082 & 1.55 & 0.59 & 0.563 \\
\hline & & Tributary & 60 & & & 3 & & & 1.18 & & \\
\hline & 1 & Mainstem & 138 & 9.84 & $<0.001$ & 26 & 9.93 & $<0.001$ & 1.15 & 14.91 & $<0.001$ \\
\hline & & Tributary & 114 & & & 15 & & & 0.914 & & \\
\hline & 2 & Mainstem & 181 & 4.96 & $<0.001$ & 82 & 4.77 & $<0.001$ & 1.3 & 2.35 & 0.022 \\
\hline & & Tributary & 158 & & & 46 & & & 1.1 & & \\
\hline
\end{tabular}



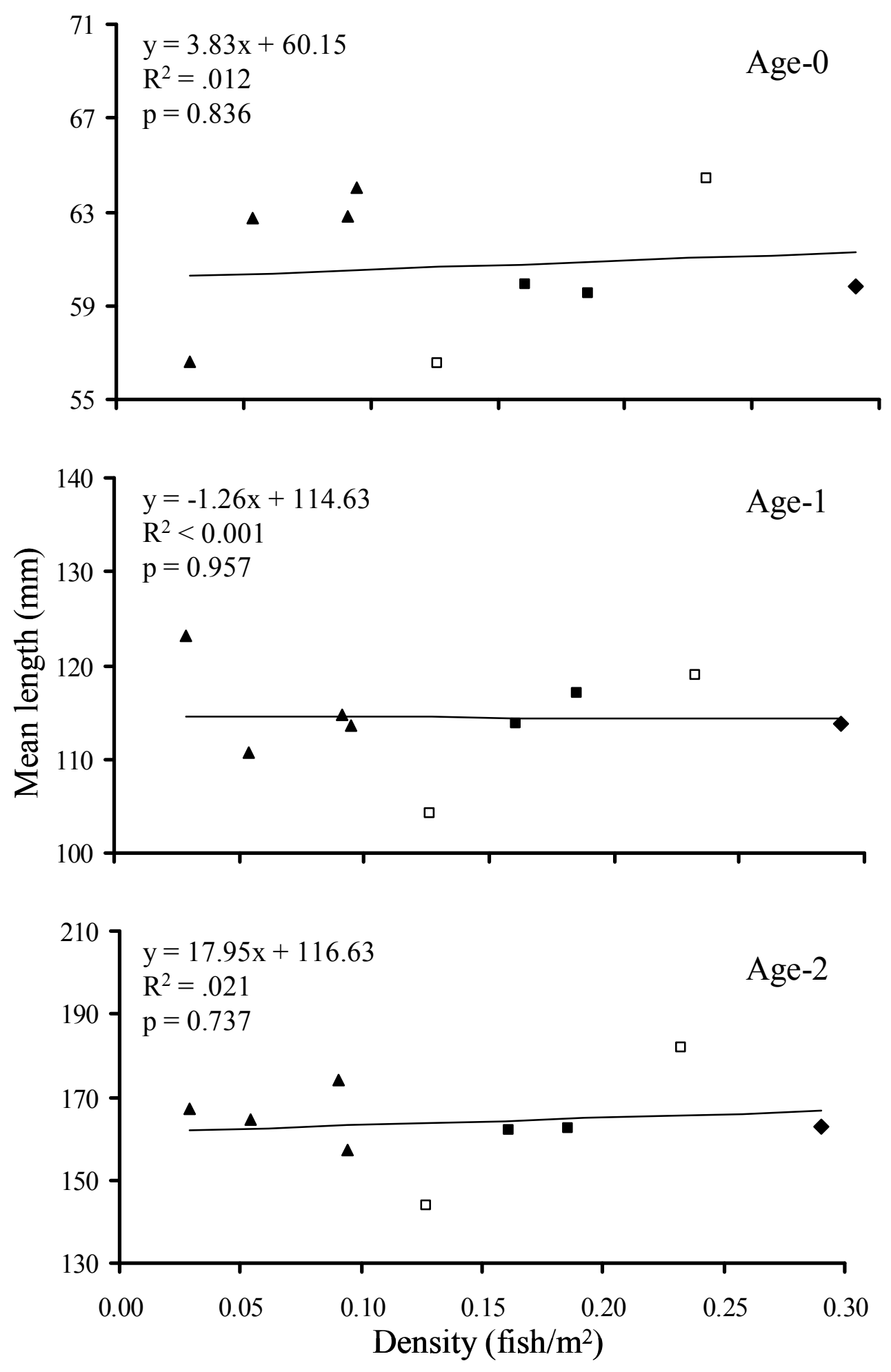

Figure 1: Mean length at age of brook trout as a function density within headwater tributaries: triangles, Rocky Run stream network tributaries: shaded squares, North Fork stream network tributaries: open squares, Seneca Creek stream network tributaries: diamond, Laurel fork stream network tributary. 


\section{Jason T. Stolarski Curriculum vitae}

349 Baldwin St.

Morgantown, WV 26505

jasonstolarski@hotmail.com

work/home 413-627-7015

\section{$\underline{\text { Education }}$}

West Virginia University (WVU), Morgantown, WV: M.S. in Fisheries Resources, graduation date: December 2007

- Master's Thesis: Age and growth of Appalachian brook trout in relation to life-history and habitat characteristics

Advisor: Dr. Kyle Hartman

Pertinent Coursework: Fish Ecology, GIS, Grants and Grantsmanship, Aquatic

Toxicology, Statistics (x2), Advanced Ichthyology, Limnology, Quantitative Ecology

Total Credits: 37 currently, 46 expected (semester system), current GPA 4.00

University of Massachusetts (UMASS), Amherst, MA: B.S. in Wildlife and Fisheries Conservation

Pertinent Coursework: Biology of Invertebrates, Human Dimensions, Ecology (x2), Fisheries Conservation, Fish Parasitism, Fish Ecology, Plant and Animal Sampling

Techniques, Fisheries Population Dynamics

Total Credits: 120 (semester system), final GPA 3.73

University of Alaska (UAF), Fairbanks, AK: Domestic exchange program (one semester)

Pertinent Coursework: Genetics, Wildlife Management

Total Credits: 14 (semester system) final GPA 3.80

\section{Professional Experience}

Graduate Research Assistant, WVU, Morgantown, WV July '05-Present

- Included personal research, research for collaborative long-term project, and assisting other graduate students with field work.

Duties Involved: Extensive backpack electrofishing, BVET habitat analysis, fish aging (scale, otolith, fin ray techniques) elastomer tagging, aquatic invertebrate sampling and identification, organizing and leading field crews, data entry and analysis

Work Load: Minimum $20 \mathrm{hrs} /$ week, usually $40+$. Salary of $\sim \$ 850 /$ month Supervisor: Dr. Kyle Hartman

Graduate Teaching Assistant, WVU, Morgantown, WV Aug '07-Dec '07

- Included overseeing four introductory biology labs. 
Duties Involved: Preparation of teaching material, lecturing, instruction and assistance with basic laboratory techniques (microscopy, bacteria culture), evaluation of student work

Work Load: Minimum 20hrs/week, usually $30+$. Salary of $\sim \$ 960 /$ month

Supervisor: Dr. Jane Caldwell

Fisheries Technician, United States Fish and Wildlife Service (USFWS), Fairbanks, AK May-Sep (2003 \& 2004).

- Crew member (2003), crew leader (2004) of a chum salmon escapement project on the Yukon River

Duties involved: Organizing and leading field crew (up to 8 members) during daily tagging sessions, establishment, maintenance, and removal of remote field camp, spaghetti tagging, boat operation and maintenance, weir construction and operation, conflict resolution

Work Load: 48hrs/week, usually $60+. ~ \sim \$ 10.50 / \mathrm{hr}$ (GS 6)

Supervisor: Chrissy Apodaca

Fisheries Technician, UMASS, Amherst, MA Jun '01-Sep '01

- Assisted a masters candidate researching the effects of large woody debris additions to headwater streams within the Quabbin Reservoir

Duties involved: Electroshocking, aquatic invertebrate sampling, debris dam creation, snorkel surveying, gastrolavage, habitat measurement

Work Load: 40hrs/week. \$8.00/hr

Supervisor: Jim Sotiropulolos

\section{Volunteer Experience}

Fisheries Technician, USFWS, King Salmon, AK Jun '02-Sep '02

- Crew member involved in estimating escapement of 5 western salmon species into Frosty Creek, Cold Bay, AK

Duties involved: Weir construction and maintenance, establishment, maintenance, and removal of remote field camp, floy tagging, post spawning egg retention surveys Supervisor: Kellie Whitton

\section{$\underline{\text { Skills and Qualifications }}$}

\section{Computer skills}

Familiar with the following software: SAS, MARK, CAPTURE, ArcGIS, Procite, Microsoft Excel, Word, and Powerpoint

\section{Written and oral communication}

Public research presentations, poster presentations, formal seminar presentations

\section{SCUBA Certified}

\section{Certified CPR and First Aid}




\section{Honors and Awards}

Best Student Poster - March 2007 Joint Technical Meeting of the Pennsylvania and West Virginia American Fisheries Society Chapters

Graduated Cum Laude - Umass May 2003

Roger J. Reed Memorial Scholarship - May 2002

- Awarded annually to a UMASS junior for academic excellence in the fisheries field

\section{$\underline{\text { Public Presentations }}$}

Stolarski, J.T. and K.J. Hartman. 2007. Age and growth of Appalachian brook trout in relation to life-history and habitat features. Masters Seminar. Morgantown, WV.

November 16, 2007

Stolarski, J.T. and K.J. Hartman. 2007. Annulus formation and aging verification in Appalachian brook trout. Poster. Joint Technical Meeting of the Pennsylvania and West Virginia AFS Chapters. Morgantown, WV. March 10, 2007

Stolarski, J.T. and K.J. Hartman. 2006. A comparison of three aging techniques for Appalachian brook trout. American Fisheries Society Student Colloquium. Auburn, AL. October 24, 2006

Stolarski, J.T. and K.J. Hartman. 2006. Annulus formation and aging verification in Appalachian brook trout. Poster. American Fisheries Society National Meeting. Lake Placid, NY. September 10, 2006

\section{$\underline{\text { References }}$}

Kyle Hartman, Ph.D. Professor of Fisheries West Virginia University Division of Forestry Morgantown, WV 26506 hartman@wvu.edu 304-293-2941 x2494
Stuart Welsh, Ph.D. Assistant Unit Leader USGS, COOP Unit, WVU 333 Percival Hall Morgantown, WV 26506 swelsh@wvu.edu 304-293-2941 x2419

Chrissy Apodaca

Ph.D. Candidate (Biological Sciences)

USGS, COOP Unit, AK

University of Alaska

Fairbanks, AK 99775

Chrissy.apodaca@uaf.edu

907-474-6052
Jane Caldwell, Ph.D. Professor of Biology West Virginia University 3324-A life Sciences Bldg Morgantown, WV 26506 Jane.caldwell@mail.wvu.edu 304-293-5201 x31459 